\title{
(4)
}

UNIVERSIDAD PERUANA DE CIENCIAS APLICADAS

\author{
FACULTAD DE NEGOCIOS \\ CARRERA DE MARKETING
}

\section{Análisis de las necesidades de información de identificación personal. Una investigación para ciudadanos mayores de edad que residen en Lima Metropolitana}

\author{
TESIS \\ Para optar el título profesional de: \\ Licenciado en Marketing
}

\section{AUTOR(ES)}

Radicy Paredes, Febo Alexander (0000-0002-9658-1422)

Urcia Harlet, Erika Milagros (0000-0001-6974-6749)

ASESOR

Berdejo Chávez, Pedro Rubén (0000-0002-3859-7346)

Lima, 07 de julio 2018 
Dedicatoria

Dedicamos esta tesis a nuestras familias, amigos y a nuestros seres queridos que sin dudarlo nos brindaron todo su apoyo, sin ellos no hubiera sido posible cumplir con creces esta tarea. No podemos dejar de mencionar por sobre a todo a nuestros padres que gracias a su consideración y cariño nos inculcaron los valores necesarios por los cuales logramos cumplir esta sacrificada tarea en esta etapa educativa de nuestra vida. 
Epígrafe

"El elemento más importante no es la tecnología sino las relaciones humanas" (Rheingold, Howard 2004).

¿Es posible analizar cuál es la información de identificación personal que los ciudadanos mayores de edad utilizan o solicitan con mayor frecuencia en la red o de forma presencial y además conocer si tienen insatisfacción al utilizar estos servicios o trámites que las distintas instituciones o empresas brindan? El bajo conocimiento sobre el uso de los servicios de información de identificación personal que se realizan a través internet y de manera presencial y que son ofrecidos por diversas instituciones a los ciudadanos de Lima Metropolitana fue lo que nos motivó a realizar un análisis sobre este tema, con el deseo de poder comentar y recomendar propuestas de mejora para una mejor gestión a las diferentes administraciones que trabajan en la atención y servicio al ciudadano. 


\section{Resumen}

Los ciudadanos mayores de edad necesitarán a lo largo de sus vidas, varios documentos de información de identificación personal que utilizarán para representar y demostrar su identidad única como una persona natural en la sociedad.

Este trabajo es un análisis de algunas de las necesidades de estos ciudadanos en la ciudad de Lima sobre 5 aspectos principales (legal, profesional, gubernamental, salud y financiero).

Para el desarrollo de este análisis, brindamos conceptos que ayudan a comprender el panorama de la realidad peruana en comparación con la realidad en otros países y regiones donde el nivel de interoperabilidad y el desarrollo del Gobierno Electrónico juegan un papel importante en el uso, compartición y protección de la información de identificación personal.

Este análisis también se respalda en el desarrollo de una investigación cualitativa para conocer la percepción y el conocimiento que los ciudadanos mayores de edad tienen sobre el gobierno y las entidades privadas a los que deben acudir para obtener documentos específicos de información de identificación personal y conocer el punto de vista de los especialistas que representan a algunas de las entidades que proporcionan estos documentos.

Palabras clave: Documentos de informacion de identificación personal, Gobierno Electrónico, interoperabilidad, ciudadano mayor de edad, entidad privada, Gobierno. 


\begin{abstract}
Adult citizens will need throughout their lives various documents of personally identifiable information that they will use to represent and demonstrate their unique identity as a natural person in the society. This paper is an analysis of some of the needs of these citizens in Lima City about five main aspects: legal, professional, governmental, health, and financial.

In order to the develop this analysis, we offer concepts that help to understand the Peruvian's reality in comparison with the reality in other countries and region's realities where the level of interoperability and the development of Electronic Government play an important role for using, sharing and protecting personally identifiable information.

This analysis is also based on qualitative research methods to identify the perception and the knowledge that adult citizens have about the government and private agencies where they have to go to obtain specific documents of personally identifiable information and to know the point of view of the specialists who represent some of the agencies that provide such documents.

Adult citizen, Estate, Personally Identifiable Information documents, Government, Private companies.
\end{abstract}

Keywords: Personally identifiable information, electronic government, interoperability, adult citizens, private agencies, government. 
Tabla de Contenido

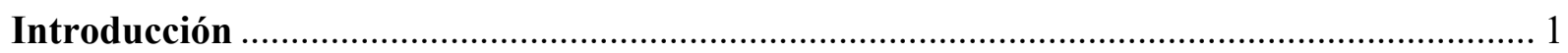

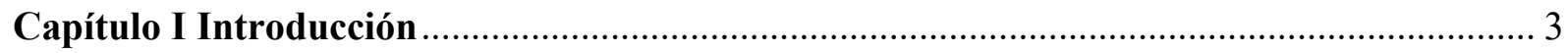

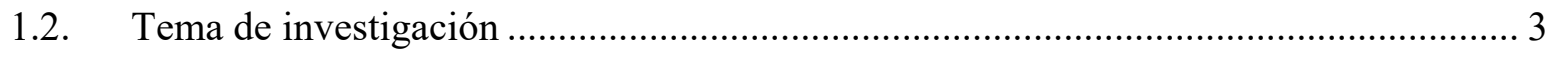

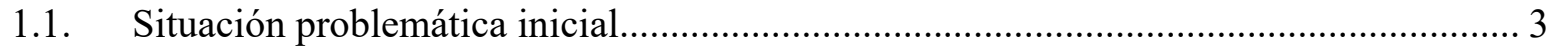

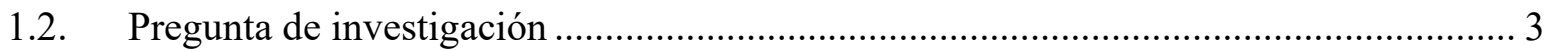

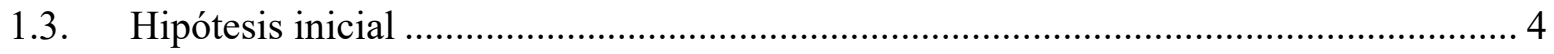

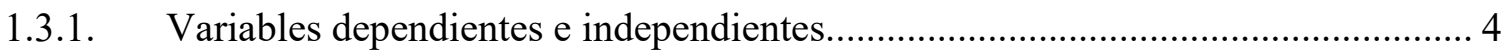

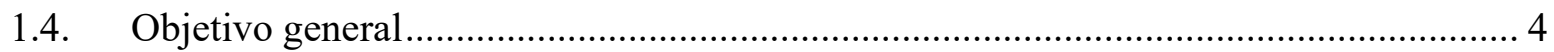

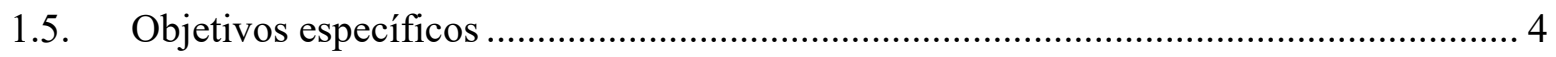

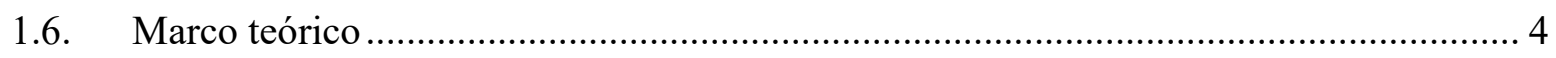

1.6.1. Identificación Personal del Ciudadano. ........................................................... 4

1.6.2. Información de identificación personal. ........................................................... 7

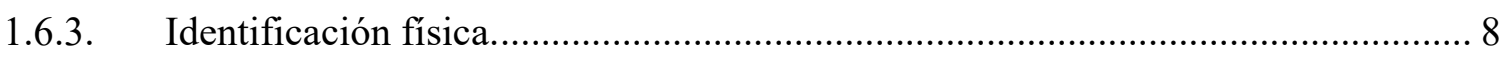

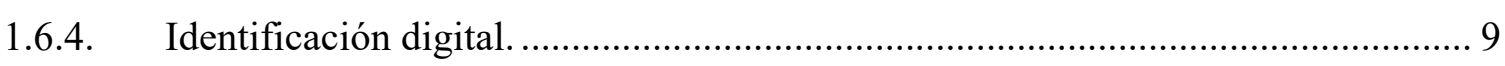

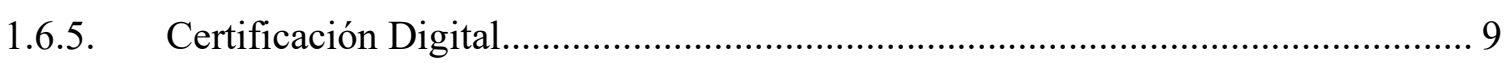

1.6.5.1. Beneficios de utilizar un certificado digital................................................ 11

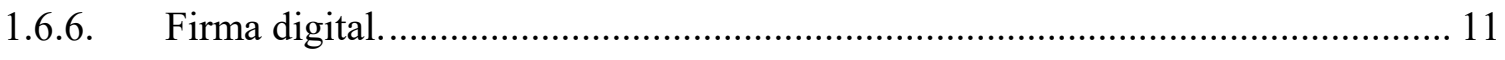

1.6.7. Documento Nacional de Identificación electrónico - DNIe.................................. 11

1.6.8. Identidad digital según el uso en el ciberespacio.............................................. 12

1.6.8.1. Objetivos logrados al tener una identidad digital. ......................................... 13

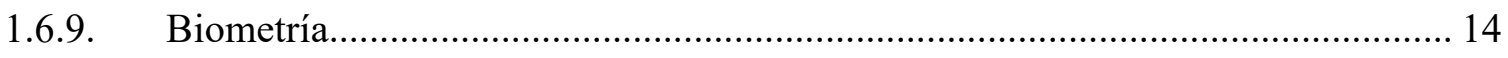

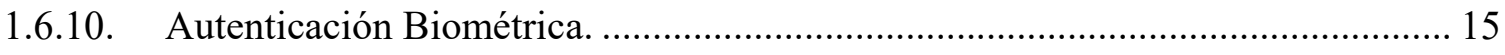

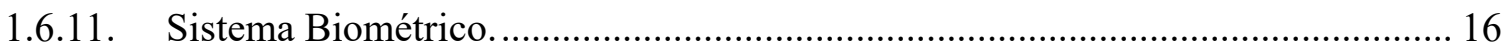

1.6.12. Últimos avances en los servicios de información de Identificación Digital

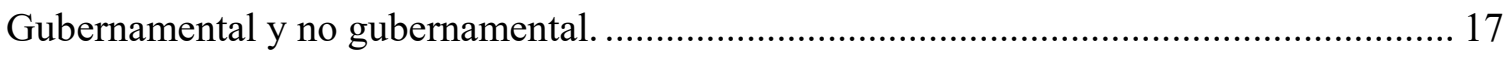

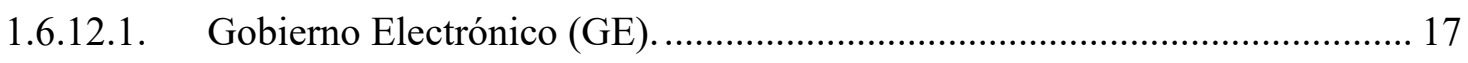

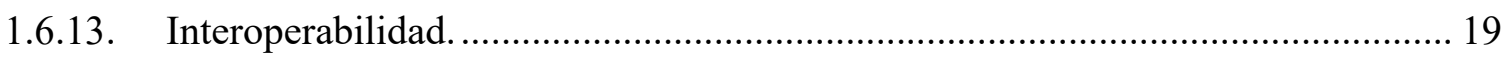

1.6.14. Los servicios de información de identificación digital y el nivel de Interoperabilidad

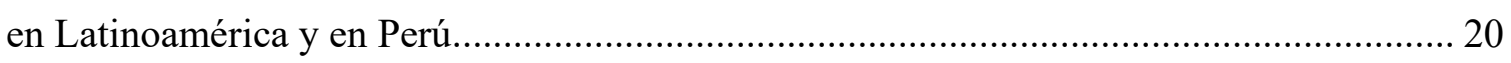




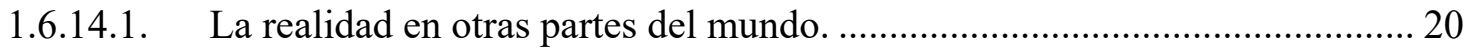

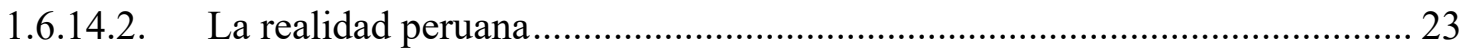

1.6.14.3. Instituciones relacionadas a la información de identificación personal en Perú. 26

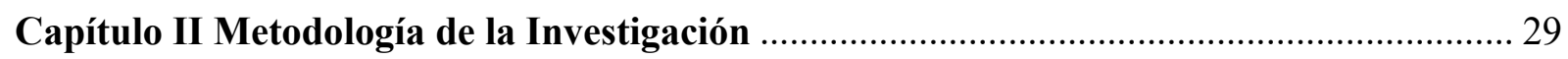

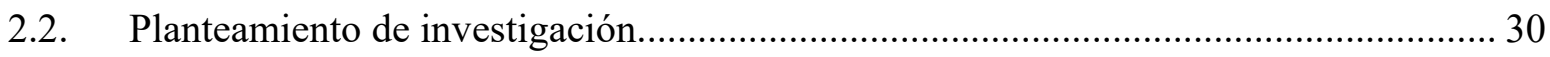

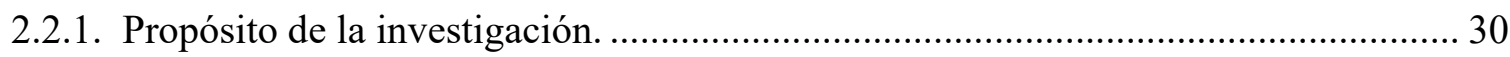

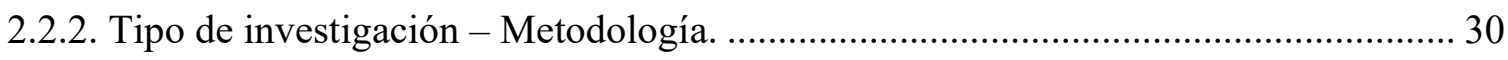

2.2.2.1 Técnica. Entrevistas a profundidad con expertos y focus group. ....................... 31

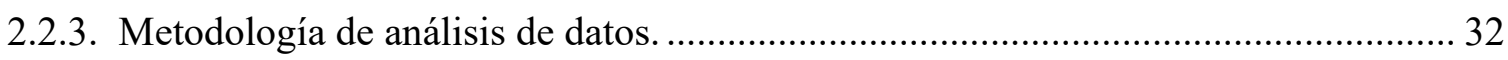

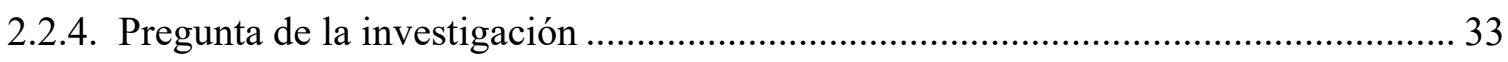

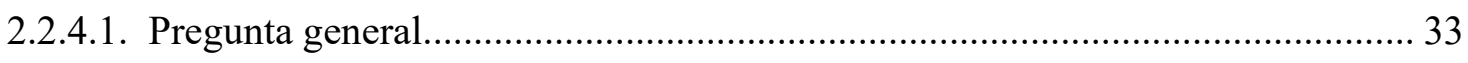

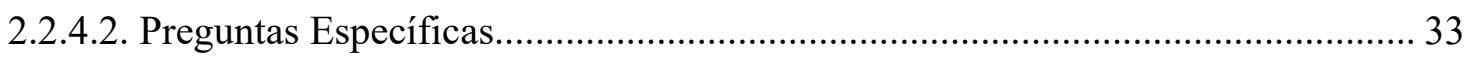

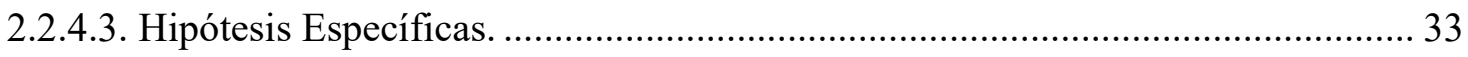

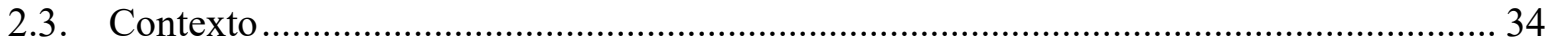

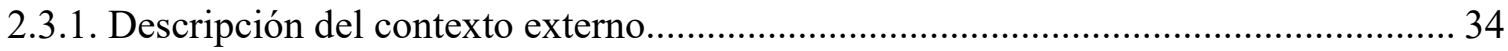

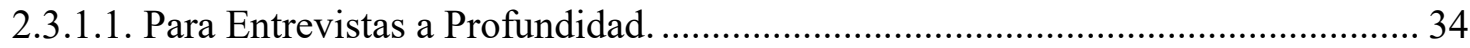

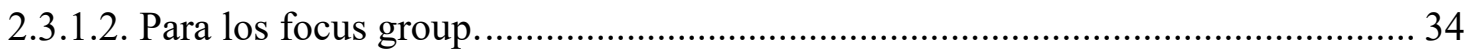

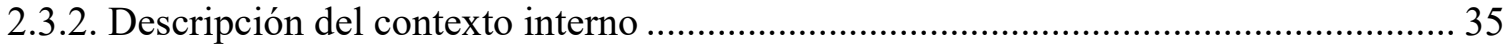

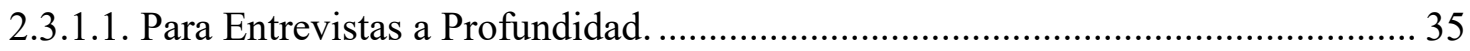

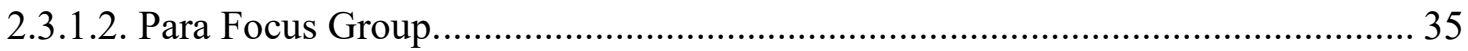

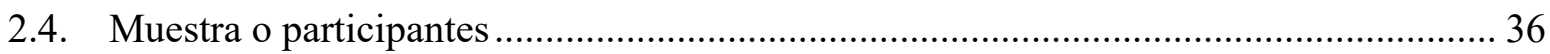

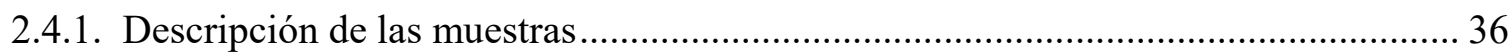

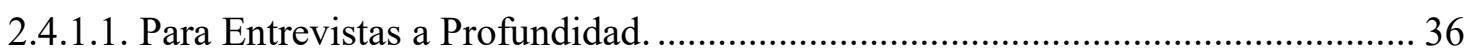

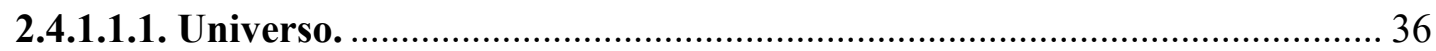

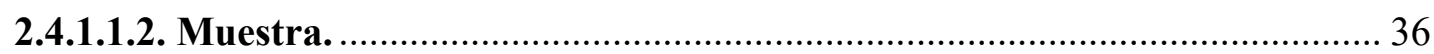

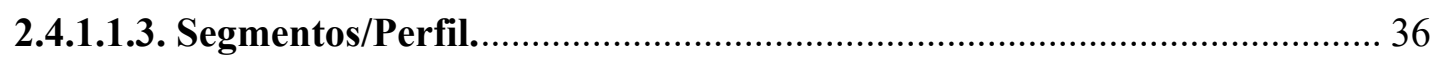

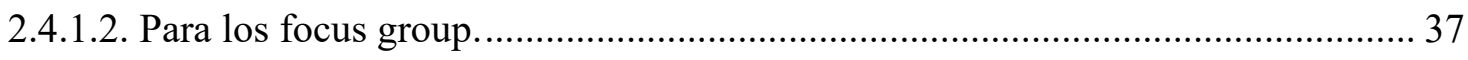

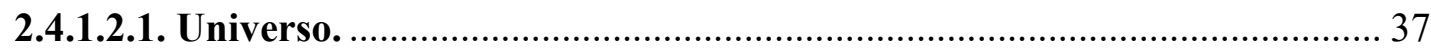

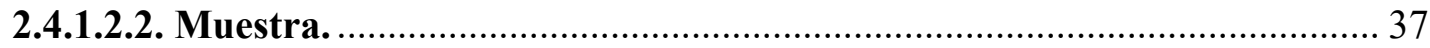

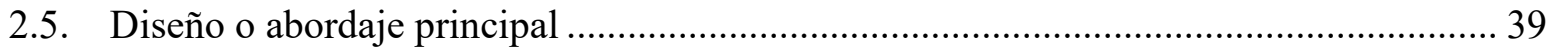


2.5.1. Identificación de la estructura de la entrevista a profundidad y focus group .............. 39

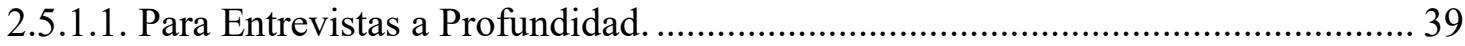

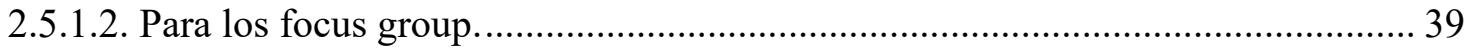

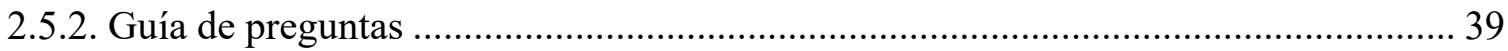

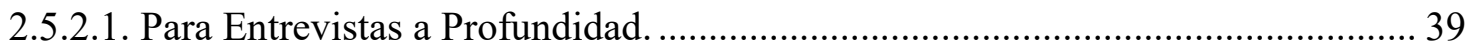

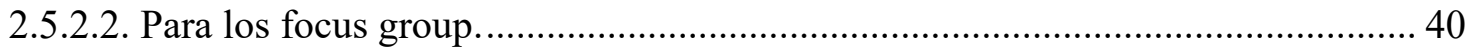

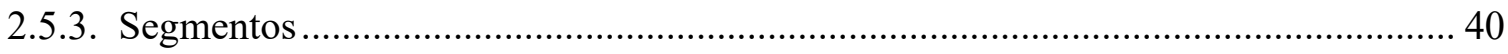

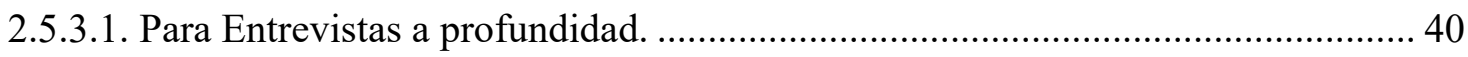

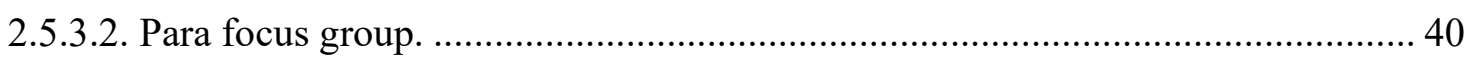

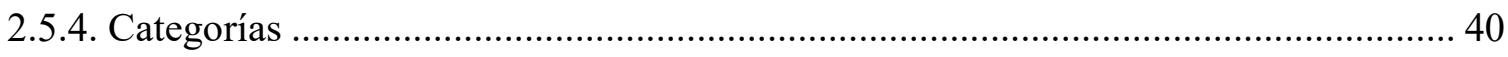

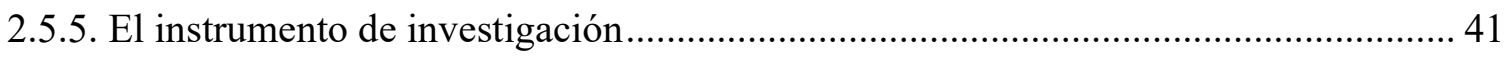

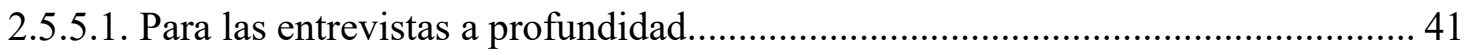

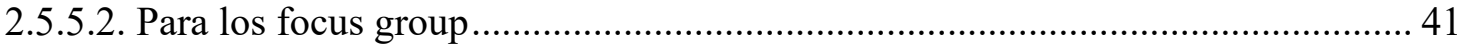

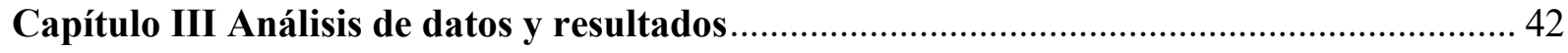

3.1. Procedimiento: Procesamiento de la información .......................................................... 42

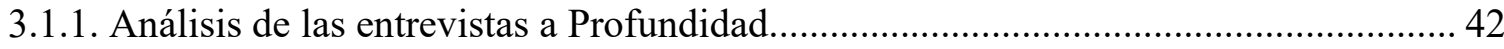

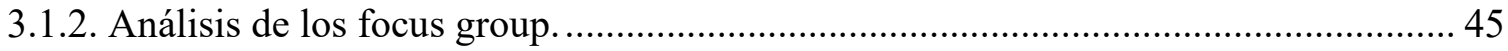

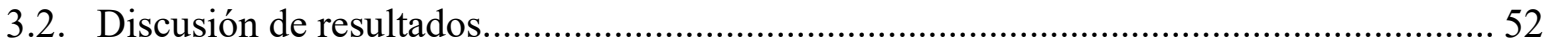

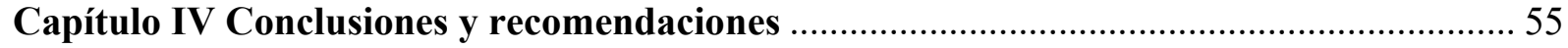

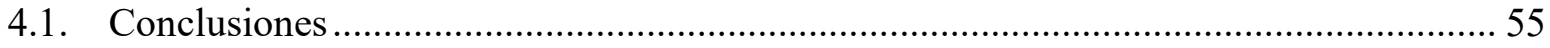

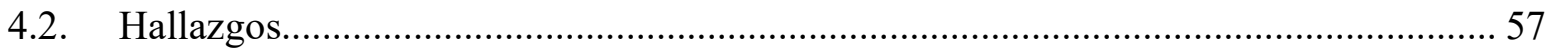

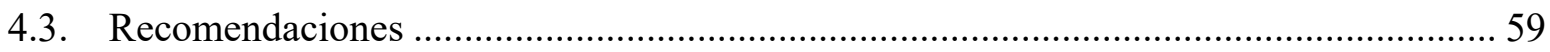

\section{Índice de Tablas}

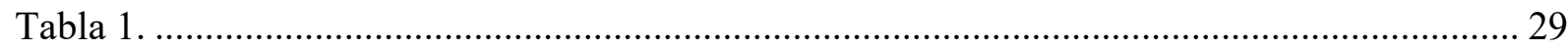

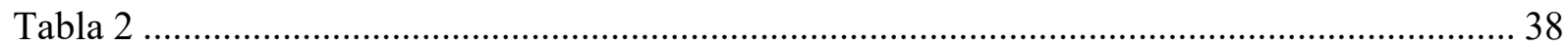




\section{Introducción}

En nuestro país, todo ciudadano al cumplir los 18 años es considerado un ciudadano con la mayoría de edad que está apto para realizar diversos tipos de trámites de información de identificación personal por cuenta propia. Para empezar, deberá realizar por ley el trámite para obtener el Documento Nacional de Identidad del ciudadano mayor (DNI), y a medida que se desenvuelva en la sociedad, los documentos de información de identificación personal que requieran de instituciones gubernamentales o privadas irán en aumento, y en algunos casos, irán obteniendo más complejidad a lo largo de su vida.

Ante esta situación, se espera que las instituciones del Estado y privadas cumplan con brindar las facilidades y comunicar por medio de todos los disponibles y por diferentes canales como acceder a estos servicios.

En ese contexto, cada vez que un ciudadano realiza consultas, búsquedas y trámites, puede encontrar aspectos que le dificulte, o facilite el acceso a un determinado servicio de información de identificación personal. Este trabajo de investigación pretende averiguar si el ciudadano mayor de edad conoce o no cuáles son las instituciones que brindan los servicios, cuáles son algunos de estos servicios básicos, así como conocer la satisfacción sobre estos procesos por parte del ciudadano mayor de edad y cuáles son algunos de eso fines.

Para ello, hemos considerado analizar los puntos de vista de profesionales expertos que trabajan en puestos estratégicos de diferentes áreas en instituciones del gobierno y algunas empresas privadas quiénes están más familiarizados con la solicitud o entrega de algunos documentos de información de identificación personal. Estos especialistas han brindado una visión desde el punto de vista de quienes ofrecen los servicios a los ciudadanos mayores de edad.

Con el fin de brindar una idea más clara sobre cuáles son los trámites o servicios que un ciudadano mayor de edad realiza con mayor frecuencia, investigaremos las necesidades o situaciones por las cuales un ciudadano mayor de edad suele realizar algunos de estos trámites o solicitudes de servicios, indagaremos cuáles son las barreras que impiden o las vías que permiten realizarlos; y también analizaremos si factores como la edad, el nivel cultural o la situaciones socioeconómicas 
son las que marcan las diferencias sobre el conocimiento que tienen los ciudadanos de estos trámites y de las instituciones que las brinda.

Para esta investigación se realizaron entrevistas a profundidad y focus group a ciudadanos de diferentes edades a fin de evaluar los distintos conceptos, ideas y conocimiento de estas personas hacia los sistemas de información de identificación personal; así también, para conocer la percepción sobre el servicio que brindan las empresas privadas y del Estado e identificar la problemática que se presenta en cada situación expuesta por los entrevistados. Finalmente, expondremos propuestas de soluciones que podrían ser tomadas en cuenta por parte de quien desee utilizar este documento para una propuesta de mejora de gestión. 


\section{Capítulo I}

\section{Introducción}

\subsection{Tema de investigación}

El tema de la presente investigación es el siguiente: Análisis de las necesidades de información de identificación personal. Una investigación sobre ciudadanos mayores de edad que residen en Lima Metropolitana.

\subsection{Situación problemática inicial}

Los ciudadanos tienen a lo largo de su vida distintas necesidades de información de identificación personal desde que cumplen la mayoría de edad (a partir de los 18 años), y que solicitarán en diferentes circunstancias. Para la obtención de documentos de información de identificación personal, el ciudadano mayor de edad puede recurrir a diversas páginas de organismos gubernamentales o privados, donde deberá buscar la información necesaria para realizar dicho trámite, ya sea en forma presencial o virtual.

En muchos casos las páginas web de dichos organismos son desconocidas, no muestran la información necesaria o los contenidos de estas son muy difíciles de entender, por lo que el ciudadano tiene que recurrir a diversas búsquedas, y en algunos casos parte del trámite deberá realizarse también de manera presencial, lo cual le puede tomar más tiempo del debido, convirtiéndose el proceso extenso y burocrático.

\subsection{Pregunta de investigación}

¿Cuán satisfecho está el ciudadano mayor de edad con los servicios que ofrecen las instituciones que gestionan documentos y servicios de información de identificación personal en Lima Metropolitana? 


\subsection{Hipótesis inicial}

La falta de integración de sistemas entre entidades relacionadas a la gestión de la información de identificación personal, así como la falta de conocimiento de la población sobre estas instituciones, son la causa de insatisfacción del ciudadano mayor de edad que requieren estos documentos y servicios.

\subsubsection{Variables dependientes e independientes.}

- Interoperabilidad / Integración de las instituciones.

- Falta de conocimiento de los ciudadanos sobre las instituciones que brindan servicio de información de identificación personal.

\subsection{Objetivo general}

Identificar las necesidades de información de identificación personal, su uso y la importancia de la accesibilidad al ciudadano mayor de edad.

\subsection{Objetivos específicos}

- Conocer el propósito de la obtención de la información de identificación personal.

- Conocer qué tanto conoce el ciudadano mayor de edad sobre los organismos gubernamentales y privados que ofrecen los servicios $\mathrm{y}$ documentos de información de identificación personal.

- Conocer el nivel de interoperabilidad de los organismos estatales y privados que brindan servicios de información de identificación personal al ciudadano mayor de edad.

\subsection{Marco teórico}

\subsubsection{Identificación Personal del Ciudadano.}

En el mundo, la identidad se define según la Real Academia Española como el "conjunto de rasgos propios de un individuo o de una colectividad que los caracterizan frente a los demás" (Real Academia Española, 2001, $22^{\circ}$ ed.). 
En la época colonial, la Iglesia se encargaba de registrar a las personas basándose en el Derecho Canónico. La Ley $\mathrm{N}^{\circ} 10$ del Libro VII, Título XXII de la Novísima Recopilación de 1680, dispone la formación de los estados mensuales de los recién nacidos, de las personas que se casaban y morían, inscribiéndolos en los Registros Parroquiales.

El 21 de marzo de 1749, el Consejo Real español es enviado con la misión de inscribir a todos los prelados del reino, incluyendo a las colonias de ultramar. Asimismo, debían encargarse de custodiar y velar de la seguridad de los libros de bautismos, casamientos y entierros.

En el Perú, en 1821 se estableció un nuevo régimen político, el cual generó un conjunto de modificaciones en el sistema jurídico hispano-indiano para que se adaptase a la nueva realidad política del país. El proceso para establecer un sistema jurídico codificado fue un proceso lento y recién en el año 1852 se creó el primer Código Civil Peruano junto con los Registros de Estado Civil, siendo los Gobernadores de distrito los encomendados para esta gestión. En el año 1856 se establecieron las municipalidades, las cuales encargarían de administrar y llevar el control de los libros de Registro del Estado Civil, supervisado por la Corte Suprema de Justicia de la República.

La primera ley del notariado en el Perú fue la Ley $\mathrm{N}^{\circ} 1510$ del 15 de diciembre de 1911. En su artículo $44^{\circ}$ se establecía la preeminencia de la llamada fe de conocimiento sobre la fe de identificación:

La introducción debe expresarse: $6^{\circ} \mathrm{La} \mathrm{Fe}$ de conocimiento de los otorgantes, de los testigos, de los intérpretes [...]; $7^{\circ}$ La comprobación de identidad de la persona por dos testigos, vecinos y conocidos, si el notario no tiene conocimiento anterior de alguno de los interesados. (Ley $\mathrm{N}^{\circ} 1510,1911$, art. 44).

Es decir, se suponía, en el Perú de los años diez - con una población de aproximadamente seis millones de habitantes, mayoritariamente rural, y sin 
documentos nacionales de identidad - que el notario, en primer lugar, debía conocer previamente a los comparecientes. Por eso, en los usos notariales de la época se agregaba la frase:

“Ante mí se presentó don Agapito Gonzáles, vecino de esta ciudad [...] a quien conozco".

El hecho de que el notario no conociera a la persona era una excepción a la regla, en cuyo caso debía identificarla. Como los documentos nacionales de identidad tenían un uso muy limitado, la única manera que tenía el notario de identificar a una persona que no conocía era a través de testigos que manifestarían conocerlo y que corroborarían su identidad.

El acto de sufragar siempre estuvo vinculado a la identificación de las personas, es por tal razón que cuando se dictó la normativa registral, se hizo con la exclusiva finalidad de organizar procesos electorales y considerando al ciudadano solo como una unidad de registro. Por tal motivo, se creó el título del documento de sufragio que era llamado la Libreta Electoral, la cual tenía por finalidad identificar a quien iba a sufragar. Con el tiempo, la emisión manual de este documento generó un alto grado de inseguridad jurídica.

De acuerdo al párrafo 1 visible de la página web RENIEC, ¿quiénes somos? (reniec.gob.pe), se crea el Registro Nacional de Identificación y Estado Civil (RENIEC) con el fin de identificar a las personas naturales, otorgar el documento de identidad y registrar la inscripción de hechos vitales y las modificaciones de los estados civiles de los ciudadanos [Consulta: 10 demayo de 2018]

$\mathrm{Al}$ respecto, a Constitución Política del Perú refiere, en el inciso 1 del artículo $2^{\circ}$ que:

"Toda persona tiene derecho: A la vida, a su identidad, a su integridad moral, psíquica y física y a su libre desarrollo y bienestar. El concebido 
es sujeto de derecho en todo cuanto le favorece". (1993, art. 2, inciso $1)$.

En otras palabras, estos derechos constituyen un conjunto de rasgos propios a cada individuo, los que proyectan al mundo exterior, permitiéndole ser reconocido como persona y un ser humano individual.

De acuerdo a lo mencionado, Nuñes (2016) afirma que "Estos atributos permiten individualizar a la persona en la sociedad de la información. Es necesario en un entorno digital que cada cual sea "uno mismo" y no "otro" (p. 13).

\subsubsection{Información de identificación personal.}

Como definición general de la información de identificación personal, Rouse, Margaret (2014) refiere que:

"La información de identificación personal (PII) es cualquier dato que podría identificar potencialmente a un individuo específico".

La información de identificación personal (Personally Identifiable Information, PII) es toda información que puede diferenciar una persona de otra. Esta información puede ser considerada como sensible o no sensible.

La PII no sensible es la información que se transmite de forma no cifrada, y es información que puede ser encontrada de manera fácil como, por ejemplo, en registros públicos, guías telefónicas, directorio de empresas o redes sociales.

Por otro lado, la PII sensible es aquella información que se transmite de manera encriptada, o como según define la Real Academia Española, señala la acción de "Transcribir con una clave" (REA, 2001, 22 ed.) y es información que, de ser revelada, podría ocasionar algún daño a la persona que pertenece esa información. De esta manera, se considera PII sensible, por ejemplo, a la información biométrica, médica o financiera. 


\subsubsection{Identificación física.}

A nivel mundial, la identidad brinda al ciudadano el derecho de tener acceso a servicios como salud, educación, alimentación, seguridad, deportes, entre otros. Así, desde su nacimiento, una persona tiene derecho a un documento de identidad; siendo que, al obtener la mayoría de edad, este documento permitirá al ciudadano, efectuar múltiples trámites como acciones civiles, comerciales, administrativas, judiciales, y otras en general.

En términos de nomenclatura, a nivel mundial, a el documento de identidad adopta diferentes denominaciones tales como Cédula de Identidad (CI), Cédula de Ciudadanía (CC), Tarjeta de Identidad (TI), Registro Civil (RC), Cédula de Extranjería (CE), Carné de Identidad (CI), Documento Nacional de Identidad (DNI), Documento Único de Identidad (DUI), identificación oficial o simplemente identificación (ID), entre otras.

En la mayoría de los países este documento es obligatorio, aunque existen otros donde la población es tan amplia, como el caso de la India, donde no es posible documentar a todos los ciudadanos, creando así problemas para validar su identificación al momento de solicitar algún subsidio o un beneficio del gobierno.

En nuestro país, el documento que nos identifica es el Documento Nacional de Identificación (DNI), y es emitido por el Registro Nacional de Identificación y Estado Civil (RENIEC), entidad del Estado encargada de la identificación de todos los peruanos.

Dentro del DNI se consignan datos personales tales como nombres, apellidos, estado civil, así como el Código Único de Identificación (CUI), con el mismo número que el del DNI; mediante dicho documento, las personas serán identificadas tanto por organismos gubernamentales como no gubernamentales, desde que nace hasta el día de su muerte. Además, en el DNI también se incluyen datos como la fecha de nacimiento, si es donador de órganos, la fecha en que se 
emitió el documento junto con su vencimiento, el grupo de votación, información del código de ubigeo donde nació, así como el código OACI (Código que es definido por la Organización de Aviación Civil Internacional y es el mismo que puede encontrar en los pasaportes).

Por último, otro dato valioso incluido en el DNI es la dirección de la persona. En el caso de los menores de edad, este dato debe ser declarado por la madre, el padre o tutor y solo puede ser actualizada por el declarante. En el caso del DNI de una persona adulta, es recomendable actualizar el lugar de residencia periódicamente por motivos de mudanza dentro o fuera del país.

\subsubsection{Identificación digital.}

Al respecto, podemos definir a nivel general que:

La identidad digital y el uso de los medios de identificación permiten verificar que soy la persona que digo ser en internet, en forma indubitable. La identidad digital debe ser garantizada por cada país, pero debe permitir que la persona natural sea identificada tanto en el ámbito público como en el ámbito privado. (Nuñez, 2016, p. 3).

Lo que también debemos saber es que, en nuestro país, existen disposiciones legales con el fin de garantizar el uso y consecuencias de la identidad digital. Estas disposiciones legales son las mencionadas en el Reglamento de la Ley de Firmas y Certificados Digitales aprobado con el Decreto Supremo Nº 052-2008PCM respecto al certificado digital.

\subsubsection{Certificación Digital.}

El certificado digital es un documento no analógico, la cual contiene información sobre una persona natural o jurídica; es emitido por una entidad autorizada que vincula un par de claves (una pública y una privada) con una persona y asegura así su identidad digital. A través del uso de este certificado digital, una persona puede usar su identidad en entornos virtuales y firmar documentos de manera 
digital con el mismo valor legal que una firma manuscrita realizada en un documento en papel o similares.

La tecnología de certificación digital ya se emplea en Asia, Oceanía, Europa y América, con consecuencias positivas en el bienestar de los ciudadanos, en la economía de las empresas y en empresas, en la gestión y eficiencia de las entidades públicas.

El certificado digital está asociado a un software que permite firmar de manera digital toda clase de documentos electrónicos, dotándole a la firma cien por ciento de autenticidad, inalterabilidad y carácter vinculante.

En el Perú, la ley de Firmas y Certificados Digitales promulgada en el año 2000, declara la regulación del uso de la firma digital. Específicamente, dicha ley indica que:

"La presente Ley tiene por objeto regular la utilización de la firma electrónica otorgándole la misma validez que una firma manuscrita u otra análoga que conlleve manifestación de voluntad”. (2000, art. 1).

El Dr. Jorge Yrivarren (2012), jefe actual del RENIEC, señala que en la sociedad existen 4 procesos importantes en los que la sociedad participa, los cuales son:

"El comercio electrónico, los negocios electrónicos, el aprendizaje electrónico y el Gobierno Electrónico”. (Andina, 2013).

Con el fin de que todos tengan la oportunidad de un libre acceso a la información disponible en el ciberespacio, el certificado digital está integrado en el Documento Nacional de Identificación electrónico (DNIe) y cifrada en un dispositivo, el cual RENIEC también emite, en caso de que el ciudadano lo solicite. 


\subsubsection{Beneficios de utilizar un certificado digital.}

Algunos de los principales beneficios que trae consigo el uso del certificado digital es la reducción de tiempo de los procedimientos administrativos, pues el tiempo consumido en las notificaciones se reduce de días a segundos.

Disminuye o elimina los costos de movilidad de las personas, evitando así las horas de trabajo extra de las personas saliendo de sus casas y/o trabajos para trasladarse a las distintas entidades gubernamentales o privadas para realizar trámites.

\subsubsection{Firma digital.}

Una firma digital cumple con todas las funciones de la firma manuscrita, es decir identifica a la persona que firma, vincula el documento con la persona que lo firma y preserva la integridad del documento firmado.

La Ley de Firmas y Certificados Digitales y su Reglamento regula la utilización de la firma digital otorgándole a la misma validez y eficacia jurídica que la firma manuscrita, estableciendo el régimen jurídico aplicable a los Prestadores de Servicios de Certificación Digital los mismos que cuentan con valor probatorio en los procesos judiciales y/o procedimientos administrativos.

\subsubsection{Documento Nacional de Identificación electrónico - DNIe.}

A nivel internacional, durante el año 2011, el gobierno de España emitió más de 25 millones de DNI electrónicos, colocándose en el primer lugar entre los países que otorgan este documento. Le seguía Marruecos con 20 millones, Arabia Saudí con 17.7 millones, Bélgica con 10.5 millones, Hong Kong con 7 millones, Alemania con 4.1 millones y los Emiratos Árabes Unidos con 3.8 millones. Por su parte, Guatemala ya había entregado más de 3.5 millones de tarjetas electrónicas de identificación a adultos, y en el 2014 ya tenía proyectado entregar más de 400 mil tarjetas electrónicas de identidad a menores de edad. 
Desde noviembre de 2010, en Alemania se emplea el documento de identidad electrónico o Elektronischer Personalausweis. Este documento contiene un chip que almacena información del ciudadano como su nombre, fecha de nacimiento, foto y huella digital. Entre otros usos, este documento puede ser usado para la autenticación "en línea" de la firma electrónica y en aplicaciones gubernamentales (e-government).

En el Perú, el DNI electrónico (DNIe) documento emitido por el Registro Nacional de Identificación y Estado Civil (RENIEC), acredita presencial y electrónicamente la identidad personal de su titular, permitiendo la firma digital de documentos electrónicos y el ejercicio del voto electrónico. (Fuente: artículo 45 del Reglamento de la Ley de Firmas y Certificados Digitales).

De esta manera, el DNIe contribuye en la implementación de políticas de Gobierno Electrónico, los cuales son utilizados por la sociedad, facilitando de esta manera el acceso eficiente y seguro a actividades dentro del ciberespacio.

\subsubsection{Identidad digital según el uso en el ciberespacio.}

Según la literatura y fuentes digitales especializadas, se vuelve pertinente prestar atención a la diferencia entre identificación digital e identidad digital para fines analíticos de la presente investigación.

Según Giones y Serrat (2010), los ciudadanos adultos tienen una amplia gama de actividades en el ciberespacio, desde entrar a una página web, utilizar una aplicación o revisar perfiles de otros o propios en su red social favorita desde cualquier dispositivo móvil, en cualquier lugar del mundo. El uso creciente del internet por los usuarios es incalculable. Desde las últimas décadas, la sociedad activa genera, gestiona y usa los datos disponibles en la red, siendo ello, lo que podríamos llamar una revolución tecnológica. En relación a los datos personales que existen en la red y la sobre exposición de los mismos, se presenta la posibilidad de crear varios perfiles que identifiquen a una persona y que puedan, o no, coincidir con los verdaderos datos que esta posee. 
Las distintas herramientas de las que se dispone y se puede utilizar en el ciberespacio, brinda a las personas la posibilidad de construir una identidad digital. Así, tenemos, por ejemplo, los blogs, microblogs, portales de noticias y sitios web; redes sociales, material multimedia como fotografías, videos $\mathrm{y}$, por último, el correo electrónico. Sin embargo, es probable que esta identidad sea distinta a la real, entre otras razones debido a que la gente desea mostrar lo mejor de sí mismo en la red, generando de esta manera una vulnerabilidad por sobreexposición de información que posiblemente convierta a cualquier ciudadano en blanco de aquellos que busquen usurpar la identidad de la víctima y usarla con fines fraudulentos. Existen delitos con respecto a falsas identidades, robo de identidad, plagios y fraudes. No obstante, para evitar el atentado de la privacidad y el posible riesgo de ser atacado por estas modalidades de fraude informático, el usuario debe educarse, aprender a defenderse de manera ética y legal frente a los delincuentes cibernéticos, o a quienes pretendan utilizar dichos datos personales para sus propios fines.

\subsubsection{Objetivos logrados al tener una identidad digital.}

Así, podemos afirmar que el fin de gestionar una identidad digital exitosa conlleva a los siguientes puntos:

Tener en cuenta que las actividades en el ciberespacio que el ciudadano desarrolla y de acuerdo con sus objetivos, conllevará a una cultura digital positiva con el tiempo.

Lograr visibilidad y una buena reputación es posible a través de la especialización y el uso de dicha especialización dentro de lugares donde el usuario pueda recibir buenas apreciaciones.

No compartir datos personales a la ligera, aunque de haber la necesidad de hacerlo, el usuario debe identificar un lugar seguro y certificado. 


\subsubsection{Biometría.}

La definición de la palabra biometría, de acuerdo con la Real Academia Española, se deriva de dos palabras; bio que significa vida y metría que tiene el significado de medida, concluimos que es el estudio que mide e identifica características de un ser humano $\left(2001,22^{\circ}\right.$ ed.).

A modo de rescatar la efectividad que trae consigo la importancia de la biometría en la solución de problemáticas sociales, mencionamos un caso histórico que sirvió como precedente en la resolución de casos criminalísticos. El año 1892, el antropólogo Juan Vucetich ${ }^{1}$ investigaba el cruel homicidio de dos niños por sendos cortes en la garganta. Este hecho constituyó para el investigador la oportunidad de poner en práctica sus teorías y estudios respecto a la unicidad de las impresiones dactilares humanas. Durante la diligencia, en un lugar de la escena del crimen, accesible sólo para el asesino, se encontró la impresión dactilar de sangre del pulgar derecho de una persona. En la investigación y con la ayuda de Vucetich a través de la aplicación de la biometría, para aquel entonces mecanismo innovador, se pudo descubrir que esta impresión dactilar pertenecía nada menos que a la madre de los niños, quien resultó ser la asesina. Así, Francisca Rojas, madre de los niños, se convirtió en la primera persona en el mundo en ser condenada a partir de la evidencia de sus huellas dactilares.

Ya en los años sesenta el FBI de EE. UU, la Police de Francia y la Policía Nacional de Japón, iniciaron simultáneamente procesos para desarrollar algoritmos que permitieran la creación de un sistema automatizado de identificación de impresiones dactilares, en el cual una computadora pudiese asistir (y de ser posible reemplazar) los procesos de clasificación, búsqueda y comparación de las cartillas de impresiones dactilares de delincuentes e

\footnotetext{
${ }^{1}$ Antropólogo argentino nacido en Croacia. Su nombre, Iván Vučetić, fue posteriormente castellanizado a Juan Vucetich.
} 
investigados que estaban en poder de la policía. Se preveía que con el tiempo y el incremento de la población se haría inviable la comparación manual.

En el Perú, en el año 1996, la Superintendencia Nacional de los Registros Públicos, SUNARP, con apoyo del Programa de las Naciones Unidas para el Desarrollo, (PNUD), procedió al escaneo en imagen digital de todos los tomos y fichas existentes en todos sus registros. Al momento de definir el proyecto, debía decidirse cuál sería la manera ideal y segura de identificar electrónicamente al registrador y se decidió que la identificación biométrica por impresión dactilar mediante un escáner sería la manera más segura de confirmar la identidad del registrador y de su voluntad indubitable de inscribir el título.

En términos conceptuales, Alfredo Ortiz (2010) sostiene que "La biometría es el estudio de métodos automáticos para el reconocimiento único de humanos basados en uno o más rasgos conductuales o físicos intrínsecos” (p.9).

Entre las características humanas que se miden y que la biometría rescata, tenemos al ADN, las huellas dactilares, la retina y el iris de los ojos, así como los patrones faciales o de la voz, y las medidas de las manos a efectos de autenticación de identidades. La tecnología biométrica contribuye entre otras cosas a la verificación de la identidad de los empleados y contribuye a la creación de entornos laborales más seguros como parte del proceso de recopilación de datos.

\subsubsection{Autenticación Biométrica.}

Por definición, la autentificación biométrica es un proceso técnico por el cual se determina la identidad de una persona midiendo y analizando sus características físicas, como, por ejemplo, patrones faciales o la geometría de la mano; además, también es posible estudiar el comportamiento, tal como la forma de caminar o cómo una persona realiza su firma.

La autenticación biométrica no es nueva. El uso de las características físicas o del comportamiento para reconocer, autenticar e identificar a las personas ha 
estado ocurriendo durante miles de años. En el siglo II A. C., el emperador chino Ts'in Shi ya autenticaba ciertos sellos con una huella dactilar; y, en el siglo XIX, el oficial de policía francés Bertillon había dado los primeros pasos hacia la identificación de los criminales por sus características anatómicas.

No pasó mucho tiempo antes de que el Metropolitan, el Departamento de Policía de Nueva York y la policía francesa comenzaran oficialmente a usar las huellas dactilares como un método de identificación.

Por su parte, el uso de la biometría está dando importantes pasos en el desarrollo de técnicas que son usadas cada vez más por las diferentes entidades financieras para identificar a las personas. Por ejemplo, las entidades financieras tienen las imágenes (huellas y rostros) guardadas del cliente, el cual le permite validar la identidad al momento de realizar alguna transacción mediante huella digital o una foto selfie. Estas acciones, ayudan a reducir en gran medida los riesgos de fraude electrónico. Con el tiempo, los procedimientos operativos de las entidades financieras para la autenticación de usuarios, emplearán cada vez más mecanismos biométricos para la identificación de sus clientes en los canales digitales, de la mano con los avances tecnológicos orientados para este fin.

\subsubsection{Sistema Biométrico.}

Al respecto del uso y mecanismo del sistema biométrico, Ortiz afirma que es el sistema que reconoce los patrones y características físicas o de comportamiento, logrando identificar al individuo comparándolos con una plantilla biométrica guardada o almacenada previamente en el sistema (2010, p.11).

Sobre su aplicación, Nuñez sostiene que "Dependiendo la aplicación, esta plantilla puede estar almacenada en una base de datos centralizada o en un dispositivo individual, como un token o una tarjeta inteligente" (2016, p.17). 


\subsubsection{2. Últimos avances en los servicios de información de Identificación Digital Gubernamental y no gubernamental.}

Para hablar de los últimos avances, primero definiremos algunos conceptos:

\subsubsection{Gobierno Electrónico (GE).}

Es posible identificar algunas definiciones con ciertas variantes otorgadas por diversos organismos internacionales. Por ejemplo, de acuerdo al párrafo 1 visible del portal de la Organización de los Estados Americanos (portal.oas.org), define al Gobierno Electrónico como: "la aplicación de las tecnologías de la información y la comunicación (TIC) al funcionamiento del sector público, con el objetivo de incrementar la eficiencia, la transparencia y la participación ciudadana" [Consulta: 14 de junio de 2018].

De otra variante de definición, la Comisión Económica para América y el Caribe (CEPAL) define al GE como "el uso de las tecnologías de la información y comunicación (TIC) para proveer servicios gubernamentales independientes del tiempo, distancia y complejidad organizacional" (2011, p.11).

En las definiciones mencionadas, la idea principal parece ser muy clara: mejorar el funcionamiento de las instituciones del gobierno para brindar un servicio más eficiente y acercarse más al ciudadano.

No obstante, no hay que confundir el término con el de Gobernabilidad Electrónica o e-Government. Éste último se refiere a la administración electrónica de los servicios que brinda el Estado al ciudadano y a la entrega de mejores servicios que le represente al ciudadano un mejor uso de su tiempo y poder tener un acceso más rápido y efectivo.

En resumidas cuentas, no se trata simplemente de "digitalizarlo todo", sino de evaluar cuáles son las necesidades del ciudadano para brindarle mejores 
servicios de una forma más accesible. Esto implica alcanzar mayores niveles de eficiencia en el quehacer gubernamental, mejorando procesos del gobierno, aumentando la calidad de los servicios públicos, incorporando más y mejor información en los procesos decisorios y facilitando la coordinación entre las diferentes instancias de gobierno.

Los beneficios que brinda el Gobierno Electrónico están dirigidos, entre otros ámbitos, hacia el Estado, el ciudadano, hacia las empresas. Hacia el Estado: fortalece la innovación y modernización al mejorar la comunicación internamente y entre instituciones, genera nuevos servicios, permite mejorar procesos de gestión internos.

Hacia el ciudadano: el Gobierno Electrónico permite ofrecer mejores servicios con reducción de tiempos y de costos y mejorar la participación ciudadana con un diálogo más horizontal e inmediato, fortaleciendo la gobernabilidad.

Hacia las empresas: permite establecer relaciones comerciales con mayor transparencia e inmediatez, al realizar trámites online.

Hoy en día algunas empresas no gubernamentales, tales como bancos, empresas de telecomunicaciones y notarías, utilizan por ejemplo la identificación decadactilar en coordinación con RENIEC para evitar suplantación de la identidad y fraudes.

Según un estudio publicado por EY, Los retos que traen las nuevas tecnologías en el sector financiero (2016), las entidades financieras enfocarán su inversión en tecnología biométrica para agilizar y asegurar los procedimientos operativos para autenticar a sus clientes y usuarios, esto dentro de sus canales presenciales y digitales.

En el Perú, la revista Semana Económica publicó un artículo Gobierno digital en el Perú: la identidad va primero en donde hace referencia de los avances en cuestión de tecnología digital que ya han sido implementadas en algunas 
entidades gubernamentales, en donde RENIEC tiene una ventaja en el desarrollo de aplicaciones por sobre las demás. Se espera que esta brecha se vaya cerrando $\mathrm{y}$ todas las entidades del Estado realicen estos desarrollos por el bienestar de los ciudadanos que buscan realizar trámites o consultas (Semana Económica, 2017).

En esta marcha, RENIEC ha iniciado un proceso de digitalización, la cual data desde año 1998, con el fin de tener todos los datos de los ciudadanos desde el antiguo registro electoral, logrando así, colocar dentro de un solo documento datos, certificados digitales e información biométrica. Lo siguiente que se propone esta institución es desarrollar la tecnología basada en biometría, tal como la huella dactilar, el rostro, la voz y el iris que servirá para crear patrones $\mathrm{y}$ tener una plena identificación de una persona.

\subsubsection{Interoperabilidad.}

La interoperabilidad, de acuerdo al primer parráfo visible del portal web de la PCM gobiernodigital.gob.pe, es "la habilidad de los sistemas TIC, y de los procesos de negocios que ellas soportan, de intercambiar datos y posibilitar compartir información y conocimiento" [Consulta: 14 de junio de 2018].

Por su parte, la Organización para la Cooperación y el Desarrollo Económicos (OCDE) define a la Interoperabilidad como:

La habilidad de las organizaciones gubernamentales de compartir e integrar información usando estándares comunes que se considera hoy en día crucial para el gobierno electrónico. La exitosa innovación en los servicios y la prestación multicanal de servicio dependen de las estrategias, políticas y arquitecturas que permiten la interoperación de datos, sistemas TIC, procesos de negocio y canales de distribución, de tal forma que los servicios estén adecuadamente integrados. (OCDE, 2005, p, 66). 
En ese caso, la Interoperabilidad entre entidades de la administración pública, consiste en que estas se interconecten, y compartan sus procesos de manera confiable y eficiente.

Esta interconexión entre entidades de la administración pública permitiría que los gobiernos controlen que las instituciones no paguen pensiones de jubilación a personas fallecidas, puedan detectar y evitar el uso fraudulento de los documentos de identidad, y puedan ofrecer al ciudadano acceso a la información verídica sobre su estado civil, propiedades, estado crediticio, multas, etc.

En el Perú, se ha creado a través del Decreto Supremo 083-2011-PCM, la Plataforma de Interoperabilidad del Estado (PIDE), que es administrada por la Oficina Nacional de Gobierno Electrónico (ONGEI) y que tiene como fin implementar servicios públicos por medios electrónicos y el intercambio electrónico de datos entre instituciones del Estado a través de internet, telefonía móvil y otros medios tecnológicos disponibles. En el año 2016, mediante el Decreto Legislativo 1246 se trató de impulsar su implementación, creando algunas medidas de simplificación administrativa, así como estableciendo plazos a las diferentes entidades del gobierno para la implementación progresiva en esta plataforma.

\subsubsection{Los servicios de información de identificación digital y el nivel de Interoperabilidad en Latinoamérica y en Perú.}

\subsubsection{La realidad en otras partes del mundo.}

La Comisión Europea elaboró un documento llamado Comprender las políticas de la Unión Europea: la Agenda Digital para Europa (2010) con motivo de impulsar la economía europea y aprovechar las ventajas sociales y económicas del mercado digital. Dentro de sus actividades, anualmente la Comisión Europea elabora una agenda. Por ejemplo, en el año 2014 la Comisión Europea estimaba que para el año 2020, habría 16 millones más de puestos de trabajo que tendrán en sus perfiles 
conocimientos de tecnologías de la información y comunicaciones. Además, esta agenda nos informa que la economía digital de la Unión Europea (UE) crece un $12 \%$ al año. Asimismo, por cada dos puestos de trabajo perdidos de manera presencial, la economía de internet genera cinco.

En el año 2017, Maciejewski, Fleuret y Gouardéres, realizaron una notable investigación sobre el mundo digital en el contexto europeo: Una Agenda Digital para Europa, 2-3. En dicho trabajo, los autores señalan algunos resultados alcanzados, por ejemplo:

Reducción a tarifas más bajas en comunicaciones electrónicas.

Mejor conexión a internet para todos con una amplia cobertura de banda ancha generalizada.

Mayor protección de los consumidores en los servicios de telecomunicaciones mediante la adopción de legislación sobre protección de la privacidad y de los datos, reforzada con el nuevo marco regulador sobre protección de datos. (Maciejewski et al., 2018, p.5).

Por su parte, de acuerdo a la tesis Ortega (2010), titulada Modelo de un proceso integrado para el registro de identificación de personas en Latinoamérica, se menciona que las realidades en los países de América Latina sobre el manejo de información de identificación son similares en tanto que se enfocan en el cumplimiento de cuatro funciones o responsabilidades de los poderes públicos que desempeña el Registro Civil y de Identificación, más específicamente la autora señala:

"La función de registro civil propiamente dicha, la función estadística, la función de identificación y la función electoral" (p.48). 
También menciona que, en la mayoría de estos países, los sistemas de registro civiles y de identificación tienen problemas estructurales, y que:

"Los registros de identificación se realizan a través de mecanismos lentos, obsoletos, que implican largos tiempos en la producción y entrega del Documento de Identidad" (p.58).

Si tomamos como ejemplo Europa, podemos encontrarnos con realidades donde a pesar de tener un mayor avance en el tema (a comparación de nosotros) también tienen (según sus ciudadanos) algunas deficiencias.

En España, por ejemplo, el DNI electrónico se estrenó en el año 2006 y es hasta el 2015 que se desarrolla una versión mejorada de éste enfocada en su sistema de seguridad, la versión 3.0. Los datos que contiene: información básica (nombres, apellidos, edad, sexo, estatus civil, dirección), con la adición del NIF (Número de Identificación Fiscal para personas físicas y jurídicas). De esta manera, el DNI 3.0 puede reemplazar en algunos casos, el uso de pasaporte para el ingreso a algunos países. El chip contiene, además, información como la plantilla biométrica de la impresión dactilar, fotografía digitalizada del ciudadano y la imagen digitalizada de la firma manuscrita. El chip electrónico no contiene información relativa a datos sanitarios, fiscales, judiciales, penales, infracciones de tráfico, etc. Otro aspecto de avance en interoperabilidad en este país es en el sector salud, ya que el Sistema Nacional de Salud ha implementado desde el 2006, la digitalización de Historias Clínicas que puedan ser compartidas por centros de salud para beneficio de los pacientes. Además, el sistema brinda a los usuarios recetas electrónicas, lo cual favorece a aquellos que padezcan enfermedades crónicas y no puedan desplazarse hasta su centro de salud.

Suecia es otro ejemplo de sistemas de interoperabilidad y gobierno electrónico más avanzados. Por ejemplo, el gobierno otorga a los ciudadanos un Número Personal de Identidad (personnummer) y una tarjeta de Identificación electrónica (e-ID), los cuales son asignados por la Agencia Sueca de Administración Tributaria. Este es un documento adicional al documento de identificación 
nacional y permite formas de identificación electrónica. A través del e-ID, los ciudadanos pueden acceder a su información personal, además de a la información de empresas que posee; finalmente, manejar actividades en bancos, autoridades y empresas.

En Latinoamérica, solo Argentina habría generalizado el uso del DNI digital y a mediados del año 2017 se habría establecido este documento como el único documento de identidad válido. La masificación del uso de este documento comprendió no sólo la adquisición de implementos tecnológicos, estandarización de materiales y de los procesos sino además la capacitación del recurso humano en TIC y la toma de más de 30 medidas de seguridad para lograr que sea completamente inviolable.

\subsubsection{La realidad peruana}

Dentro de sus funciones, el Estado peruano direcciona sus acciones en la búsqueda del crecimiento del mercado digital, razón por la cual elaboró La Agenda Digital Peruana 2.0 (2011), un documento de política elaborado con el concurso del sector privado y público, en la que además participaron algunas entidades representativas del sector civil y académico.

La Agenda Digital Peruana contiene la visión, estrategias específicas y objetivos necesarios para un desarrollo adecuado, implementación y promoción de la sociedad de la información en nuestro país con el fin de lograr la modernización del Estado.

Algunos de los objetivos y estrategias, rescatados de la agenda digital en relación a la investigación aquí presentada, ayuda a demostrar que el Estado busca generar soluciones a los problemas que la investigación ha señalado.

De esta manera, el Decreto Supremo 066-2011-PCM creó el Plan de Desarrollo de la Sociedad de la Información en el Perú, La Agenda 
Digital Peruana 2.0. En dicho Plan se exponen objetivos y estrategias clave. Precisamente, el documento señala en su objetivo 7 que el objetivo es "promover una Administración Pública de calidad orientada a la población" (2011, p.56). Este objetivo señala que existe una preocupación con respecto a que como país desea promover una administración pública de calidad. Sin embargo, al ser este un objetivo muy general observamos que se han creado algunas estrategias, de las cuales señalaremos tres que se ajustan a los objetivos de la investigación.

DS 066-2011-PCM este Decreto Supremo dice:

"Estrategia 1. Impulsar la Interoperabilidad entre las instituciones del Estado para la cooperación, el desarrollo, la integración y la prestación de más y mejores servicios para la sociedad.

Desde un punto tecnológico y en concordancia con las tendencias del Gobierno Electrónico, el país se encuentra en un estado donde la interoperabilidad en el Estado se hace imperiosa". (Plan de Desarrollo de la Sociedad de la Información en el Perú, La Agenda Digital Peruana 2.0, 2011, pg. 56)

Hemos considerado esta estrategia como un aspecto muy importante en nuestro análisis, y en concordancia con la agenda, este punto sustenta nuestra hipótesis.

DS 066-2011-PCM este Decreto Supremo dice:

"Estrategia 2. Proveer a la población, información, trámites y servicios públicos accesibles por todos los medios. 
Un principio fundamental del Gobierno Electrónico es la entrega de información, servicios y trámites a la sociedad utilizando los canales que las TIC pueden soportar". (Plan de Desarrollo de la Sociedad de la Información en el Perú, La Agenda Digital Peruana 2.0, 2011, p. 58).

En esta estrategia se evidencia que el Estado desea utilizar todos los canales que las TIC puedan soportar a fin de comunicar y proveer información, realizar trámites y crear servicios públicos accesibles en todo medio posible. Esta es la razón por la cual esta estrategia brindó la base para comprobar si la misma, se cumple o no.

DS 066-2011-PCM este Decreto Supremo dice:

"Estrategia 4. Implementar mecanismos para mejorar la seguridad de la Información.

En la actualidad existe el aumento de las amenazas cibernéticas sobre infraestructuras de TIC del ámbito público y privado, lo que hace necesario contar con una Estrategia Nacional de Ciberseguridad con el objetivo de minimizar los riesgos de sufrir algún tipo de incidente en las infraestructuras críticas, la disuasión del crimen cibernético, que se produce haciendo uso de las redes teleinformáticas, entre otros; pudiendo el impacto de estos incidentes causar ingentes pérdidas económicas y de imagen institucional". (Plan de Desarrollo de la Sociedad de la Información en el Perú, La Agenda Digital Peruana 2.0, 2011, p. 60).

Nuestro país está al tanto del aumento de la inseguridad ciudadana y en el mundo cibernético esa inseguridad es latente, es por tal motivo que, con el objetivo de minimizar esta situación, el Estado peruano y entidades privadas cuentan con estrategias de ciberseguridad. En 
referencia a ello y en relación con el análisis de la investigación, validaremos si los ciudadanos y los expertos afirman o contradicen esta estrategia planteada desde al año 2011 a la fecha.

En la actualidad, existe en el Perú un conjunto de organismos gubernamentales, los cuales se encuentran interconectados a través de la Plataforma de Interoperabilidad del Estado (PIDE), infraestructura tecnológica desarrollada por la Oficina Nacional de Gobierno Electrónico (ONGEI) a través del Decreto Supremo No 083-2011-PCM y que permite implementar servicios públicos en línea e intercambiar datos entre entidades del Estado. Sin embargo, vale aclarar que, si bien esta plataforma tiene como objetivo agilizar procesos entre entidades y hacerlas de forma virtual, encontramos una contradicción ya que, para solicitar el permiso de uso e implementación de este servicio, la solicitud debe hacerse de forma física, a través del envío de documentación por mesa de partes (E1 Peruano, 2017).

Tal como lo señala el texto el Libro blanco de interoperabilidad de gobierno electrónico para América Latina y el Caribe (2007), la interoperabilidad entre organismos del gobierno es una realidad en otras partes del mundo, y son precisamente organismos regionales como la CEPAL (Comisión Económica para América Latina y el Caribe) o el BID, que refuerzan la importancia de lograr esta interconexión entre organismos para así, brindar al ciudadano información relevante que le ayuden a resolver problemas concretos y además protejan su seguridad, todo ello a fin de lograr una mayor efectividad del Estado en materia de organización y servicio.

\subsubsection{Instituciones relacionadas a la información de identificación personal en Perú.}

Entre las instituciones más reconocidas para trámites de información de identificación tenemos: 
- RENIEC, Registro Nacional de Identificación y Estado Civil, organismo del Estado que se encarga de la identificación de los ciudadanos peruanos y de la emisión del DNI.

- SUNAT, Superintendencia Nacional de Administración Tributaria, institución que administra, fiscaliza y recauda tributos internos y ofrece servicios a los contribuyentes (persona natural o jurídica) con el fin de promover sus obligaciones tributarias.

- PNP, Policía Nacional del Perú, institución que entre sus funciones, expide certificados de antecedentes policiales al ciudadano mayor de edad.

- Superintendencia Nacional de Migraciones, organismo encargado del control migratorio y de la emisión de los documentos de viaje (pasaportes).

- ESSALUD, El Seguro Social de Salud, entidad responsable de la administración de la Seguridad Social en el Perú.

- Poder Judicial, que tiene entre sus obligaciones la facultad de emisión de antecedentes judiciales a los ciudadanos mayores de edad.

- MTC, Ministerio de transportes y comunicaciones, que entre sus funciones emite las licencias de conducir, entre otros.

- De acuerdo con la Ley del Procedimiento Administrativo General, artículo I del Título Preliminar de la Ley $N^{\circ} 27444$, refiere que el ámbito de aplicación de la Plataforma de Interoperabilidad del Estado Peruano comprende a las siguientes instituciones: 
$\checkmark$ El Poder Ejecutivo, incluyendo Ministerios y Organismos Públicos;

$\checkmark$ El Poder Legislativo;

$\checkmark$ El Poder Judicial;

$\checkmark$ Los Gobiernos Regionales;

$\checkmark$ Los Gobiernos Locales;

$\checkmark$ Los Organismos a los que la Constitución Política del Perú y las leyes confieren autonomía.

$\checkmark$ Las demás entidades y organismos, proyectos y programas del Estado, cuyas actividades se realizan en virtud de potestades administrativas y, por tanto, se consideran sujetas a las normas comunes de derecho público, salvo mandato expreso de ley que las refiera a otro régimen; $\mathrm{y}$

$\checkmark$ Las personas jurídicas bajo el régimen privado que prestan servicios públicos o ejercen función administrativa, en virtud de concesión, delegación o autorización del Estado, conforme a la normativa de la materia. (El Peruano, 2017). 


\section{Capítulo II}

\section{Metodología de la Investigación}

Tabla 1.

Matriz de consistencia

\begin{tabular}{|c|c|c|c|c|c|c|}
\hline Planteamiento del problema & Objetivos & Hipótesis & $\begin{array}{l}\text { Variablese } \\
\text { indicadores }\end{array}$ & Muestras & Diseño & Instrumento \\
\hline Pregunta general & Objetivo general & & & & & \\
\hline $\begin{array}{l}\text { ¿Cuán satisfecho está el ciudadano } \\
\text { mayor de edad con los servicios que } \\
\text { ofrecen las instituciones que } \\
\text { gestionan documentos y servicios de } \\
\text { información de identificación } \\
\text { personal en Lima Metropolitana? }\end{array}$ & $\begin{array}{l}\text { En este trabajo planteamos una } \\
\text { investigación sobre las necesidades } \\
\text { de información de identificación } \\
\text { personal, su uso y la importancia de } \\
\text { su accesibilidad al ciudadano mayor } \\
\text { de edad. }\end{array}$ & $\begin{array}{l}\text { La falta de integración de } \\
\text { sistemas entre entidades } \\
\text { relacionadas a la gestión de la } \\
\text { información de identificación } \\
\text { personal y la falta de } \\
\text { conocimiento de la población } \\
\text { de estas instituciones, son la } \\
\text { causa de insatisfacción del } \\
\text { ciudadano mayor de edad que } \\
\text { requieren estos documentos y } \\
\text { servicios. }\end{array}$ & $\begin{array}{l}\text { Interoperabilidad/ } \\
\text { Integración de las } \\
\text { instituciones. }\end{array}$ & $\begin{array}{l}\text { Para Entrevistas a } \\
\text { profundidad } \\
\text { S entrevistas a } \\
\text { especialistas en temas } \\
\text { de: } \\
\text { - Financiero } \\
\text { - Legal } \\
\text { - Salud } \\
\text { - Laboral } \\
\text { - Gubernamental }\end{array}$ & $\begin{array}{l}\text { Método } \\
\text { Entrevista a } \\
\text { profundidad } \\
\text { Nivel de } \\
\text { Investigáión } \\
\text { Cualitativa }\end{array}$ & $\begin{array}{l}\text { - Guia de } \\
\text { indagación }\end{array}$ \\
\hline Preguntas Especificas & Objetivos Especificos & Hipótesis Secundaria & $\begin{array}{l}\text { Variables e } \\
\text { indicadores }\end{array}$ & Muestras & Diseño & Instrumento \\
\hline $\begin{array}{l}\text { 1. ¿Qué servicios de información de } \\
\text { identificación personal son más } \\
\text { solicitados por un ciudadano mayor } \\
\text { de edad y con qué fines? }\end{array}$ & $\begin{array}{l}\text { 1. Conocer cúal es el fin de la } \\
\text { obtención de la información de } \\
\text { identificación personal. }\end{array}$ & $\begin{array}{l}\text { 1. El fin de la obtención de } \\
\text { estos trámites está ligadoa } \\
\text { una necesidad coyuntural. }\end{array}$ & \multirow{3}{*}{$\begin{array}{l}\text { Falta de } \\
\text { conocimiento de } \\
\text { los ciudadanos } \\
\text { sobre las } \\
\text { instituciones que } \\
\text { brindan servicio } \\
\text { de información de } \\
\text { identificación } \\
\text { personal. }\end{array}$} & $\begin{array}{l}\text { Para Focus Group: } \\
\text { realizada a } 36 \\
\text { ciudadanos hombres y } \\
\text { mujeres mayores de } \\
\text { edad }\end{array}$ & \multirow[t]{3}{*}{$\begin{array}{l}\text { Método } \\
\text { Focus Group } \\
\text { Nivel de } \\
\text { Investigación } \\
\text { Cualitativa }\end{array}$} & \multirow[t]{3}{*}{$\begin{array}{l}\text { - Cuestionario } \\
\text { filtro } \\
\text { - Guia de } \\
\text { indagación }\end{array}$} \\
\hline $\begin{array}{l}\text { 2. ¿E1 ciudadano mayor de edad } \\
\text { sabe donde acudir si tiene que } \\
\text { tramitar algún documento o servicio } \\
\text { de información de identificación } \\
\text { personal? }\end{array}$ & $\begin{array}{l}\text { 2. Conocer que tanto conoce el } \\
\text { ciudadano mayor de edad sobre los } \\
\text { organismos gubernamentales y } \\
\text { privados que ofrecen los serviciosy } \\
\text { documentos de información de } \\
\text { identificación personal. }\end{array}$ & $\begin{array}{l}\text { 2. El ciudadano mayor de } \\
\text { edad tiene una vaga idea de } \\
\text { cuáles son las instituciones } \\
\text { que ofrecen servicios y } \\
\text { documentos de información } \\
\text { de identificación personal. }\end{array}$ & & $\begin{array}{l}\text { - Grupo } 1 \text { N.S.E A,B,C1 } \\
\text { Edad } 18 \text { a } 29 \text { años } \\
\text { - Grupo } 2 \text { N.S.E A,B,C1 } \\
\text { Edad } 30 \text { a } 49 \text { años }\end{array}$ & & \\
\hline $\begin{array}{l}\text { 3. LLas entidades estatales y } \\
\text { privadas están interconectadas para } \\
\text { brindar una buena experiencia de } \\
\text { atención a los ciudadanos mayores } \\
\text { de edad de Lima Metropolitana en } \\
\text { cuanto a los servicios de } \\
\text { información de identificación } \\
\text { personal? }\end{array}$ & $\begin{array}{l}\text { 3. Conocer el nivel de } \\
\text { interoperabilidad de los organismos } \\
\text { estatales y privados que brindan } \\
\text { servicios de información de } \\
\text { identificación personal al ciudadano } \\
\text { mayor de edad. }\end{array}$ & $\begin{array}{l}\text { 3. El nivel de } \\
\text { interoperabilidad de una } \\
\text { organización con otraes } \\
\text { deficiente por lo cuál los } \\
\text { servicios de información de } \\
\text { identificación personal suelen } \\
\text { ser burocráticos e ineficientes }\end{array}$ & & $\begin{array}{l}\text { - Grupo } 3 \text { N.S.E A,B,C1 } \\
\text { Edad 50 a más años } \\
\text { - Grupo } 1 \text { N.S.E C2,D1 } \\
\text { Edad } 18 \text { a } 29 \text { años } \\
\text { - Grupo } 2 \text { N.S.E C2,D1 } \\
\text { Edad } 30 \text { a } 49 \text { años } \\
\text { - Grupo } 3 \text { N.S.E C2,D1 } \\
\text { Edad } 50 \text { a más años }\end{array}$ & & \\
\hline
\end{tabular}




\subsection{Planteamiento de investigación}

\subsubsection{Propósito de la investigación.}

La presente investigación tiene como principal objetivo analizar las necesidades de información de identificación personal del ciudadano mayor de edad en Lima Metropolitana, así como la importancia de la accesibilidad y eficiencia de los organismos que brindan estos documentos y servicios.

La investigación es relevante, puesto que contribuye con el análisis y con algunas recomendaciones clave que coadyuven a reducir los problemas, en la mayoría de los casos relacionados con el desconocimiento de las páginas web de organismos; además, con la poca exposición de información necesaria o la alta dificultad de los contenidos, los cuales son identificadas como muy difíciles de entender. Aunque dichos problemas se vienen resolviendo, se realizan a un ritmo lento y poco eficiente por parte de las entidades gubernamentales y privadas; y en algunos casos, los trámites se realizan de manera presencial, lo cual implica una inversión considerable de tiempo para el ciudadano mayor de edad, convirtiéndose en un proceso extenso y burocrático.

Pertinentemente, presentaremos los resultados de la investigación, dentro de la cual recomendaremos algunos planes de acción a fin de cambiar la percepción de los ciudadanos mayores de edad, principalmente en relación al servicio de información de identificación personal brindado por las instituciones gubernamentales y entidades privadas en Lima Metropolitana.

\subsubsection{Tipo de investigación - Metodología.}

Durante la investigación de tesis realizada por Chung García, Rupailla y Seminario (2017), por la cual buscaron identificar los factores claves para mejorar la calidad del servicio al cliente en las Municipalidades de Lima Metropolitana, aplicaron el método cualitativo debido a su pertinencia para la interpretación del entorno, el recojo de los detalles y experiencias de los ciudadanos, aportando así un punto de vista "natural" de los entrevistados. En 
ese mismo horizonte analítico y debido a las coincidencias con los objetivos de la presente tesis, abordaremos la investigación desde la metodología cualitativa y nos apoyaremos en la teoría fundamentada. La investigación es de carácter exploratorio y recoge así la descripción, comprensión e interpretación de percepciones producidas por experiencias de los participantes que aporten datos fidedignos y guíen una investigación veraz y cercana sobre la situación a investigar. Ello nos ha permitido verificar la factibilidad de nuestro estudio. Así, se trata de un estudio de carácter exploratorio, es decir, no necesariamente generalizable.

Este estudio cualitativo, tiene como objetivo analizar las necesidades de información de identificación personal para uso cotidiano o recurrente del ciudadano mayor de edad en Lima Metropolitana, y por tal razón es un estudio no estructurado y no estadístico.

Hemos elegido realizar una investigación exploratoria ya que el tema seleccionado ha sido poco investigado y hemos abordado nuevas perspectivas. Al haber elegido una investigación cualitativa utilizamos las siguientes técnicas:

\subsubsection{Técnica. Entrevistas a profundidad con expertos y focus group.}

A). Entrevistas a profundidad con expertos

Las entrevistas a profundidad con expertos son entrevistas semiestructuradas, nos permite conocer la situación actual y real de algunas organizaciones, el cómo afrontan la necesidad del ciudadano sobre información de identificación personal, así también la percepción que tienen los expertos sobre nuestro tema propuesto, información que nos será de mucho valor para la orientación de nuestra investigación.

Se ha seleccionado 5 diferentes rubros para la realización de estas entrevistas a profundidad, las cuales son:

- Gubernamental / Tecnológica 
- Salud

- Laboral

- Legal/ Jurídico (en general)

- Financiero

Estos rubros considerados son relevantes para nuestra investigación debido a que los ciudadanos mayores de edad han tenido que realizar al menos una vez algún trámite de documentos o servicios de información de identificación personal.

B). Focus Group

Hemos aplicado focus group semiestructurados, este método nos permitió recoger y analizar información importante sobre cuál es la necesidad de información de identificación personal por parte del ciudadano, así como las situaciones más comunes y frecuencia en la que puede requerir este tipo de esta información y además conocer la percepción y conocimiento que tiene el ciudadano sobre los servicios que ofrecen entidades gubernamentales y privadas en cuanto a brindar los documentos y servicios.

\subsubsection{Metodología de análisis de datos.}

Finalmente, se analizó conjuntamente la información de los focus group, entrevistas a profundidad, el marco teórico y para a partir de este análisis establecer una teoría fundamentada en datos que se materialice en un diagnóstico general, conclusiones (hipótesis explicativas), y recomendaciones (hipótesis de posibles soluciones).

Hemos abordado la investigación bajo el diseño de la teoría fundamentada (Hernandez, 2014) ya que es un sistema de investigación aprobado y que, a diferencia de otros diseños de investigación, nos ha permitido proponer una 
teoría general, mas no especifica, al respecto de las necesidades de información de identificación personal de los ciudadanos mayores de edad que residen en Lima Metropolitana.

\subsubsection{Pregunta de la investigación}

\subsubsection{Pregunta general.}

¿Cuán satisfecho está el ciudadano mayor de edad con los servicios que ofrecen las instituciones que gestionan documentos y servicios de información de identificación personal en Lima Metropolitana?

\subsubsection{Preguntas Específicas.}

1. ¿Qué servicios de información de identificación personal son más solicitados por un ciudadano mayor de edad y con qué fines?

2. ¿Sabe el ciudadano mayor de edad dónde acudir si tiene que tramitar algún documento o servicio de información de identificación personal?

3. ¿Las entidades estatales y privadas están interconectadas para brindar una buena experiencia de atención a los ciudadanos mayores de edad de Lima Metropolitana en cuanto a los servicios de información de identificación personal?

2.2.4.3. Hipótesis Específicas.

1. El fin de la obtención de estos trámites está ligado a una necesidad coyuntural.

2. El ciudadano mayor de edad tiene una vaga idea de cuáles son las instituciones que ofrecen servicios y documentos de información de identificación personal.

3. El nivel de interoperabilidad de una organización con otra es deficiente por lo cual los servicios de información de identificación personal suelen ser burocráticos e ineficientes. 


\subsection{Contexto}

\subsubsection{Descripción del contexto externo.}

Para nuestra investigación nos centramos en dos fases, la primera es la entrevista a profundidad a expertos y la segunda es un focus group.

\subsubsection{Para Entrevistas a Profundidad.}

Las entrevistas a profundidad con expertos fueron diseñadas para recoger información directa de especialistas de diferentes rubros de organismos gubernamentales (tecnológica, jurídico, salud) y de instituciones privadas (rubro financiero y laboral) que tengan contacto directo con el tema planteado en nuestra investigación.

Los ambientes donde se desarrollaron las entrevistas con expertos fueron en las oficinas de los entrevistados:

- Oficinas de RENIEC, Av. Bolivia 109, Cercado de Lima.

- Domicilio de la especialista en Banca: Avenida César Vallejo 1429, Lince.

- Oficinas del Ministerio de Salud, Av. Gral. Salaverry 801, Jesús María.

- Oficinas de 10Head Hunters, Pasaje. Aurora 321, Cercado de Lima.

\subsubsection{Para los focus group.}

Los focus group fueron programados con la finalidad de conocer la percepción que los ciudadanos tienen con respecto al servicio brindado por algunas instituciones donde pueden acudir para trámites de información de identificación personal, (como por ejemplo las oficinas 
de RENIEC) y descubrir nuevos hallazgos no considerados aún en la investigación.

Además, para dicha herramienta metodológica, se buscó un lugar de fácil acceso y con las condiciones para lograr un ambiente de confianza para poder realizar las preguntas y obtener sus opiniones. Se realizaron en dos locaciones:

- Domicilio ubicado en Jr. Salaverry 375 Magdalena, ambientes de comedor.

- Local de la Dirección de Hidrografía y Navegación, Av. Agustín Gamarra 483, Callao, ambientes de sala de reuniones del Departamento de Navegación.

\subsubsection{Descripción del contexto interno}

\subsubsection{Para Entrevistas a Profundidad.}

Las entrevistas a profundidad con las especialistas realizadas de manera presencial, se desarrollaron de manera fluida y cordial, en tanto que se realizaron en ambientes propios del entrevistado (domicilio y oficina), generando así confianza entre el entrevistador y entrevistado.

La entrevista telefónica se realizó también con fluidez gracias a la flexibilidad del entrevistado al cedernos la entrevista en altas horas de la noche, demostrando así su interés en colaborar a nuestra investigación.

\subsubsection{Para Focus Group.}

Para los 6 focus group, podemos afirmar que todos los que participaron en cada uno de estos, tuvieron oportunidad de expresar sus ideas y comentarlas libremente gracias al manejo de la mediadora que generó 
el ambiente adecuado, logrando de esta manera una relación de confianza entre los entrevistados y el entrevistador.

\subsection{Muestra o participantes}

\subsubsection{Descripción de las muestras}

\subsubsection{Para Entrevistas a Profundidad.}

La muestra para las entrevistas a profundidad con expertos está conformada de la siguiente manera:

\subsection{Universo.}

Especialistas de diversas áreas que tengan conocimiento del uso de la información de identificación personal que residen en Lima Metropolitana.

\subsection{Muestra.}

La metodología de muestreo de expertos fue el muestreo no probabilístico por juicio (Hernández, 2014), ya que esta muestra no representa estadísticamente el universo o población que se estudia, sino más bien, tomamos segmentos que nos permitieron entender el espectro del problema principal y el número de la muestra ha sido tomado de acuerdo a nuestra capacidad operativa y manejo de tiempos.

\subsection{Segmentos/Perfil.}

- Dimensión Legal/Jurídico: Un profesional en derecho (abogado) que haya laborado o tenga conocimiento en los aspectos legales sobre la compartición de la información de identificación personal de las personas naturales para empresas. 
- Dimensión Gubernamental y tecnológica: Un profesional especialista en el tema de información de identificación personal, que labore y que tenga conocimiento de lo que ofrece la entidad del Estado en cuanto a la situación actual de los sistemas de información que se brindan a los ciudadanos.

- Dimensión Financiera: Un especialista en el sector financiero que tenga conocimiento sobre las necesidades financieras de los ciudadanos y empresas en cuanto a sistemas de identificación.

- Dimensión Salud: Un especialista que pueda aportar información acerca del tipo de información útil para la gestión de las necesidades de salud de los ciudadanos.

- Dimensión Laboral: Un especialista que pueda aportar con información acerca del tipo de información útil para la gestión en procesos de inserción laboral.

\subsubsection{Para los focus group.}

La muestra para los focus group está conformada de la siguiente manera:

\subsection{Universo.}

Lo ciudadanos peruanos que residen en Lima Metropolitana.

\subsection{Muestra.}

Para el presente estudio se consideró una muestra no probabilística por cuotas. Fueron 36 ciudadanos agrupados en 6 focus group, y cada uno compuesto por 6 ciudadanos 
mayores de 18 años a quienes previamente se les entregó un cuestionario filtro.

La muestra elegida para el estudio se agrupó en segmentos A, B, C1, C2, D y también se consideró separarlos por la variable de edad.

Tabla 2

Ficha técnica de muestreo según edades

Segmentos: A, B, C1, C2, D

Por la variable de edad:

\section{N.S.E A, B, C1}

- Edades de 18 a 29 años

- Edades de 30 a 49 años

- Edades de 50 a más años

\section{N.S.E C2, D1}

- Edades de 18 a 29 años

- Edades de 30 a 49 años

- Edades de 50 a más años

Nota: Elaboración propia.

La muestra fue seleccionada de acuerdo con las fichas filtro y a la conveniencia de accesibilidad y proximidad geográfica de los investigadores, por lo tanto, no es una muestra probabilística. 


\subsection{Diseño o abordaje principal}

\subsubsection{Identificación de la estructura de la entrevista a profundidad y focus group}

\subsubsection{Para Entrevistas a Profundidad.}

La entrevista a profundidad se realizó a través de un cuestionario semiestructurado. Para estas entrevistas se usaron diferentes guías de indagación, dependiendo de la especialidad de la persona a la que se entrevistó. La estructura del cuestionario fue elaborada siguiendo la metodología de la tabla de conceptos y dimensiones diseñada por Roberto Hernández (2014). (Véase anexo $\mathrm{N}^{\circ} 1$ ).

\subsubsection{Para los focus group.}

Para la realización de estos se realizó un cuestionario semiestructurado. Las preguntas fueron las mismas para cada grupo, esto debido a que ninguno de los participantes tenía el conocimiento de los especialistas y lo que se debería de escuchar y rescatar era la información sobre las diferentes experiencias de cada grupo.

\subsubsection{Guía de preguntas}

\subsubsection{Para Entrevistas a Profundidad.}

La primera etapa del plan de estudio se centró en realizar las entrevistas a profundidad a expertos. Para ello se elaboró la guía de preguntas, obtenidas de los objetivos de investigación. (Véase Anexo $\mathrm{N}^{\circ} 1$ ).

Seguidamente a la conclusión de todas las entrevistas a los expertos, se revisaron y analizaron las respuestas y se definieron las Fichas de Informes para cada una de las entrevistas (Véase Anexo $\mathrm{N}^{\circ} 2$ al 6). 


\subsubsection{Para los focus group.}

La segunda etapa de la investigación se inició con la elaboración del cuestionario filtro o ficha de reclutamiento para los participantes del focus group. (Véase anexo $\mathrm{N}^{\circ} 7$ ).

Para los focus group se diseñó una guía de indagación orientada a responder nuestros principales objetivos, así como a identificar aquellos aspectos que respalden nuestra hipótesis. Las preguntas fueron obtenidas de los objetivos de investigación. (Véase Anexo $\mathrm{N}^{\circ} 8$ ); y finalmente, se generaron los Informes respectivos. (Véase Anexo $\mathrm{N}^{\circ} 9$ al 14).

Se seleccionó a los participantes coordinando un lugar accesible y cercano para ellos, así como un horario y día adecuado.

\subsubsection{Segmentos}

\subsubsection{Para Entrevistas a profundidad.}

La segmentación para las entrevistas se realizó en base a la especialidad y experiencia profesional, con el fin de abordar los temas propuestos.

\subsubsection{Para focus group.}

La segmentación en este caso, fue realizada separando características demográficas de edad y nivel socio económico, con el fin de analizar las necesidades de los ciudadanos en diferentes etapas de su vida y de acuerdo con su nivel social y económico.

\subsubsection{Categorías}

- Falta de conocimiento de los servicios de información:

$\checkmark$ Por edades

$\checkmark$ Por N.S.E. 
- Interoperabilidad de las instituciones pertenecientes a las áreas investigadas:

$\checkmark$ Entrevistas a profundidad a especialistas elegidos por segmentos

\subsubsection{El instrumento de investigación}

2.5.5.1. Para las entrevistas a profundidad

Guía de indagación por cada especialista.

\subsubsection{Para los focus group}

- Encuesta filtro de N.S.E para los participantes.

- Guía de indagación. 


\section{Capítulo III}

\section{Análisis de datos y resultados}

\subsection{Procedimiento: Procesamiento de la información}

\subsubsection{Análisis de las entrevistas a Profundidad}

Objetivo Nro. 1: Conocer cuál es el fin de la obtención de la información de identificación personal.

Desde el punto de vista de la banca, la especialista expresó que la información que solicitan al ciudadano (cliente), dependerá del fin comercial (ya sea que deseen préstamos, seguros, cuentas de ahorro, etc.). Lo relevante para la Banca es que esta información pueda ser verificada con ayuda de otras instituciones. Al respecto, la entrevistada afirmó que:

"Para evaluaciones, si califica o no a un préstamo, recurrimos a entidades públicas para contrastar que la información proporcionada por el cliente es verdadera y no está adulterada". (Jhoan Ballón, comunicación personal, 10 de junio de 2018).

Así también, en el caso de Recursos Humanos, el experto nos comentó que el fin principal de la obtención de los documentos que muestran la información de identificación, es casi únicamente para cumplir con los procesos de selección y a requerimiento de la empresa empleadora, la cual contrata sus servicios para buscar el perfil adecuado. De esta manera, a complejidad o cantidad de documentos requeridos a los ciudadanos dependerá de la complejidad del cargo a cubrir solicitado.

El especialista en tecnología de RENIEC nos comentó, por ejemplo, que el trámite del DNI tiene mayor demanda en épocas de elecciones, esto debido al 
cambio de domicilio de las personas. Dicho trámite se genera en forma presencial y virtual. Sobre este punto, el entrevistado indicó lo siguiente:

"En época de elecciones los trámites web y los cambios de domicilio crecen en un 50\%”. (Gala Briceño, comunicación personal, 20 de junio de 2018).

El que nos indique que los trámites se realizan también en plataforma web es una buena señal, ya que el ciudadano se estaría orientando al uso de este canal, al menos en este trámite, lo que podría significar un buen augurio el hecho de que cada vez más los usuarios se orientarán al uso de herramientas digitales, descongestionando así el servicio de manera presencial.

Objetivo Nro. 2: Conocer qué tanto conoce el ciudadano mayor de edad sobre los organismos gubernamentales y privados que ofrecen los servicios $\mathrm{y}$ documentos de información de identificación personal.

Sobre este objetivo, ninguno de los especialistas ha podido brindar información debido a que no cuentan con esta información, sin embargo, se explayarán en los focus group.

Objetivo Nro. 3: Conocer el nivel de interoperabilidad de los organismos estatales y privados que brindan servicios de información de identificación personal al ciudadano mayor de edad.

Lo expresado por la experta legal en cuanto al tema de interoperabilidad, indicó que, en efecto, existe colaboración entre entidades del Estado para compartir información. Sobre el punto, la entrevistada indicó lo siguiente:

"Existe una agenda $2.0 \mathrm{y}$ el tema de la interoperabilidad que lo maneja el ONGEI y hay varios convenios de colaboración interinstitucional que ya se han firmado con RENIEC, con SUNAT, con el Poder Judicial y el Ministerio Público para el cruce de información”. (Rossmary Rivera, comunicación personal, 23 de junio de 2018). 
Otra de las especialistas comentó que la información de identificación que RENIEC brinda, por ejemplo, a las demás instituciones a través de la plataforma PIDE, se brinda solo a un nivel básico. La especialista afirmó:

"RENIEC brinda información básica del ciudadano a través de la Plataforma de Interoperabilidad del Estado - PIDE a las instituciones del estado". (G. Briceño, comunicación personal, 20 de junio de 2018).

Las opiniones en cuanto a las brechas que existen para lograr una mejor interoperabilidad tienen diferentes enfoques: una es el acceso a la tecnología, y otro aspecto, el poco compromiso y capacitación del personal de entidades públicas sobre las herramientas más eficiente para brindar a las personas la información adecuada (herramientas TIC). Sobre lo señalado, la entrevistada indica lo siguiente:

"Considero que faltan sectores públicos preparados para que puedan reducirse las brechas, mucho parte del servidor público que se comprometa con la institución y con el país". (Rossmary Rivera, comunicación personal, 23 de junio de 2018).

Un aspecto preocupante, es que el tema de interoperabilidad para el logro de un Gobierno Electrónico eficiente, aún no logra abarcar organismos que brinden servicios cruciales para los ciudadanos de toda edad, como es el sector Salud. Sobre el punto, se indica:

"En una entidad pública aún se encuentra en proceso de implementación de la historia clínica electrónica, por lo cual la información pública no se comparte". (Renzo López, comunicación personal, 03 de junio de 2018).

Y para finalizar con respecto a la información de ratios o estadística acerca de las necesidades, perfiles o comportamientos de los usuarios o ciudadanos, los 
especialistas de estas instituciones elegidas no cuentan con dicha información o no tienen una necesidad o urgencia de obtenerla.

\subsubsection{Análisis de los focus group.}

Objetivo Nro. 1: Conocer cuál es el fin de la obtención de la información de identificación personal.

Hemos encontrado que la obtención de la información de identificación que solicita el ciudadano, depende de la necesidad que se tenga en el momento. Así, por ejemplo, al empezar a trabajar en una empresa, los postulantes requerirán certificados de estudios realizados en entidades escolares o universitarias que acrediten su nivel de educación, en caso de que el postulante sea contratado por la empresa, el empleador podría exigirle para su ingreso que presente certificados de antecedentes penales o policiales. El caso más solicitado de documentos de información de identificación es el DNI, el que se suele solicitar por motivo de caducidad o pérdida o cambio de domicilio.

Los participantes del focus group en esta investigación, nos dejaron importantes apreciaciones que han aportado enormemente al análisis en los puntos mencionados. Así, para el grupo N.S.E C2, D, de edad entre 18 y 29 años, una persona señaló:

"He sacado mi DNI como 3 veces porque siempre lo ando perdiendo". (Olenka Guerra, comunicación personal, 17 de abril de 2018).

Otra integrante (focus group, N.S.E A, B, C1, 30 a 49 años de edad) informó:

"El DNI, lo hice por la web de RENIEC, hice el trámite de pago por la web y de allí me lo llevaron". (Silvia Vignolo, comunicación personal 18 abril).

Respecto a los motivos para tramitar los antecedentes policiales, un participante (integrante del focus group N.S.E A, B, C1, 18 a 29 años de edad) dijo: 
"Antecedentes policiales los he sacado en la comisaría de Magdalena, [...] siempre que me presento a algún trabajo, lo tengo que sacar". (Juan Pablo Linares, comunicación personal, 19 de abril de 2018).

Sobre este punto, además, otro joven (focus group N.S.E. C2, D, 18 a 29 años de edad) indicó:

"A mí los antecedentes policiales me los pidieron cuando ingresé a la universidad [...] y lo tramité en el Banco de la Nación”. (María José Albán, comunicación personal, 17 de abril de 2018).

Objetivo Nro. 2: Conocer qué tanto conoce el ciudadano mayor de edad sobre los organismos gubernamentales y privados que ofrecen los servicios y documentos de información de identificación personal.

Hemos encontrado diferentes respuestas de acuerdo a las edades y N.S.E. Por ejemplo, en los grupos de 18 a 29 del N.S.E A, B y C1, se pudo constatar que tienen una buena orientación y conocimiento de dónde encontrar información de identificación personal. Sobre este punto, los entrevistados refieren algunos aspectos a tomar en cuenta, como el caso de un integrante del focus group (N. S.E A, B, C1 de 18 a 29 años) quien manifestó:

"Sé que si uno entra a la página de INFOCORP sale tu historial crediticio". (Juan Pablo Linares, comunicación personal, 19 de abril de 2018).

Además, otro integrante (focus group N. S.E A, B, C1 de 18 a 29 años) indicó:

"Creo que esa información crediticia no es tan pública, sé que entran bancos o abogados para revisarlo". (Gonzalo Navarro, comunicación personal, 19 de abril de 2018).

Finalmente, sobre este punto, otro integrante del mismo grupo de edad refirió que: 
"Es que si necesito antecedentes policiales me voy a la comisaría de Magdalena". (Juan Pablo Linares, comunicación personal, 01 de mayo de 2018).

Mientras tanto, en los niveles del N.S.E C2, D1 de la misma edad, hemos descubierto que las personas entrevistadas tienen poco conocimiento sobre los organismos y canales donde pueden tramitar documentos de información de identificación personal.

En esta misma línea, subrayamos algunas preguntas y respuestas resaltantes que ayuden al análisis. A la pregunta: "Sobre el trámite de antecedentes policiales, ¿saben dónde tramitarlos aparte del Banco de la Nación?, un joven (focus group N.S.E. C2, D1, 18 a 29 años) indicó:

"En las comisarías". (Ricky Martínez, comunicación personal, 17 de abril de 2018).

Además, el entrevistador preguntó: “¿Saben de otro canal?” a lo que todos los integrantes del grupo N.S.E C2, D de 18 a 29 años respondieron que no (comunicación personal, 17 de abril de 2018).

Sobre el trámite de antecedentes penales, el entrevistador preguntó: “¿saben dónde tramitarlo?" a lo que todos los integrantes del N.S.E C2, D de 18 a 29 años respondieron que no (17 de abril de 2018)). Esta misma respuesta se produjo de forma unánime por el mismo grupo ante la pregunta "¿Si necesitan alguna copia de historial clínico, o de algún hospital, saben cómo realizar el trámite?" (Comunicación personal, 17 de abril de 2018).

Por su parte, los grupos del N.S.E A, B, C1 y C2, D1 de 50 a más, refirieron conocer algunos de los organismos y canales para realizar trámites sobre el punto mencionado.

Sobre el trámite de licencia de conducir, una persona indicó lo siguiente: 
"Se hace el trámite por internet, pero de todas maneras hay que acercarse al Touring para lo que es el examen médico [...] pero realmente el trámite es rapidísimo, porque hasta el examen médico fue menos de una mañana”. (Renee Alva, comunicación personal, 19 de abril).

Seguidamente, se realizó la siguiente pregunta: “¿Han tenido la necesidad para participar en un proceso de selección para algún trabajo de antecedentes policiales o penales?" y la respuesta de una joven del mismo grupo (N.S.E. C2, D1, 50 años a más) dijo que:

"Sí, hace años para un trabajo (adicional) de universidad [...] el trámite demoró como un mes". (Miriam Tamayo, Comunicación personal, 12 de abril de 2018).

El grupo que parecía estar más informado y tener noción de quioscos virtuales, trámites virtuales y centros MAC era el grupo de N.S.E. A, B, C1 de 30 a 49 años. Así, una joven de este grupo indicó:

"Hay unas maquinitas en el Jockey, donde yo saqué mi partida de nacimiento". (Fátima Miranda, conversación personal, 18 de abril de 2018).

Asimismo, otra entrevistada (focus group, N.S.E A, B, C1, 30 a 49 años de edad) dijo:

"Yo lo que sí he sacado es el duplicado de DNI, lo puedes tramitar por web, me parece que en 24 o 48 horas te lo dan". (Giannina Alvarado, comunicación personal, 18 de abril de 2018).

Al respecto de la pregunta “¿Conocen de algún lugar donde puedan tramitar la mayor cantidad de documentos posibles?", una persona participante en el focus group, (N.S.E A, B 30 a 49 años de edad) señaló: 
"Yo me he enterado de que existen unos MAC". (Heddyta Salazar, comunicación personal, 18 de abril de 2018).

Sin embargo, otra persona del mismo grupo preciso:

"Yo no sabía de su existencia hasta que una amiga me dijo, lo busqué en internet y me quedé sorprendida porque es grande”. (Fátima Miranda, comunicación personal, 18 de abril de 2018).

Mientras que en el grupo de N.S.E C1, D2, el conocimiento de estos organismos y diversos canales era irregular, pudiendo conocer solo 1 o 2 personas dentro del grupo de los canales que tienen disponibles como quioscos multimedia en centros comerciales o agencias en los MAC.

A medida que fuimos completando la ejecución de los focus group, encontramos que la percepción de la difusión de los servicios de identificación es baja en general, lo que genera una baja satisfacción de parte de los ciudadanos. Apropósito de esta situación, señalamos preguntas y respuestas centrales para el análisis. Ante la pregunta: “¿Uds. se sienten satisfechos de la forma en que encuentran información de estos servicios?" encontramos la siguiente respuesta en una persona participante del focus group, (N.S.E A, B, C1, 18 a 29 años de edad):

"Esa información no es que te la hayan llegar así de la nada, no es que abrí mi Facebook y encontré la información”. (Gonzalo Navarro, comunicación personal, 19 de abril de 2018).

A lo que otra persona del mismo grupo reforzó la idea anterior con un comentario:

“ni siquiera en televisión”. (Karla Mackie, comunicación personal, 19 de abril de 2018).

Y una mujer del focus group N.S.E A, B, C1, 30 a 49 años de edad, señaló: 
"Yo por ejemplo pregunto mucho en internet, [...] si no sé dónde queda, o como puedo hacer algún trámite, pregunta a veces de forma literal”. (Fátima Miranda, comunicación personal, 18 de abril de 2018).

Ante las respuestas señaladas, una mujer (focus group, N.S.E A, B, C1, 30 a 49 años de edad) subrayó lo siguiente:

"Lo que pasa es que encuentras la información cuando la necesitas, sería bueno no sé qué en algunas páginas [web] en la parte superior aparezca entérate de cómo realizar ciertos trámites". (Giannina Alvarado, conversación personal, 18 de abril de 2018).

Finalmente, un integrante del focus group, N.S.E A, B, C1, 50 años a más, respondió:

"Hay poca difusión, una manera asertiva de hacerlo podría ser mediante encartes, de las municipalidades, de los recibos telefónicos" (Carlos Navarro, comunicación personal, 19 de abril de 2018.

Objetivo Nro. 3: Conocer el nivel de interoperabilidad de los organismos estatales y privados que brindan servicios de información de identificación personal al ciudadano mayor de edad.

Cuando hicimos preguntas sobre interoperabilidad, el sector que más falencias mostró para todos los grupos, fue el del sector salud. Al respecto, algunos testimonios fueron los siguientes:

Mujer integrante del grupo N.S.E. A, B, de 50 años a más:

"He tenido que hacer el trámite de la epicrisis y otra documentación de la operación de mi esposo en el Hospital Rebagliati y lo tuve que hacer de manera presencial y esa información la llevé a otra entidad de salud para pedir una segunda opinión y todo el trámite demoró cerca de un mes”. (Zulema Maycock, comunicación personal, 19 de abril de 2018). 
La falta de integración de información en los sistemas de identificación, se hacen más evidente en el rubro de salud, ya que todos los grupos consideraron que es necesario que las entidades (privadas o del gobierno) deberían estar interconectadas para compartir la información básica de salud para que el ciudadano se sienta protegido en el caso de una emergencia o cambio de lugar de atención por motivos indistintos.

Otro de los grupos comentó que, para ellos, tener la información en un solo lugar con la seguridad correspondiente, podría ser de mucha ayuda al momento de realizar trámites sin tener que hacerlo de forma presencial. Sin embargo, este mismo grupo opinó que el acceso a esa información debería estar restringido y que el usuario pueda llevar un control sobre aquellos que intenten realizar estas consultas. Asimismo, varios integrantes de los grupos dijeron que alguna de la información extra en los chips de los DNI electrónicos debería considerarse como información básica y personal, tales como por ejemplo el tipo de sangre y alergias a medicamentos.

Así, una persona integrante del grupo de 31 años hasta 50 años, NSE A y B, entrevistada indicó lo siguiente:

"Lo que sería ideal es tener una plataforma donde uno ingrese con usuario y clave y ahí tengas todos los accesos a todos los trámites que requieras hacer, además que haya alertas que te avisen por ejemplo que tu brevete o el DNI están por vencer". (Stjepan Hiza, comunicación personal, 18 de abril de 2018).

Por último, hemos descubierto un aspecto importante que no habíamos considerado en el planteamiento de la hipótesis. Este se trata de la seguridad. Al plantearse los beneficios de la interoperabilidad, y de la posibilidad al acceso de información de identificación (datos personales) vía digital, los entrevistados en su mayoría- mostraron interés, sin embargo, también mostraron preocupación por la forma como restringir el acceso a este lugar virtual, y lo peligroso que podría ser el hecho de que información sensible y personal sea accesible en un 
solo lugar, pues en el país vivimos una inseguridad ciudadana que va en crecimiento. Sobre este punto, una persona, integrante del grupo N.S.E. C2 y D, de 18 hasta 30 años, resaltó lo siguiente:

"Pueda ser que me dé un poco de temor que toda mi información personal se encuentre en la web por lo que existen tantos peligros de robo de identificación o que puedan utilizar tu información para cometer delitos" (María José Albán, comunicación personal, 17 de abril de 2018).

\subsection{Discusión de resultados}

A partir de los hallazgos identificados en las entrevistas a profundidad dirigidas a especialistas y de los focus group realizados, obtuvimos algunos respaldos a nuestra hipótesis general planteada.

Objetivo Nro. 1: Conocer cuál es el fin de la obtención de la información de identificación personal.

Recuperando lo mencionado en la sección del marco teórico respecto a una parte de la historia del documento de identidad, remarcamos que este documento fue creado por un factor netamente electoral. Así, recalcamos que la identificación de las personas estuvo siempre vinculada al acto de sufragio, por tal motivo la normativa registral se dictó con la exclusiva finalidad de organizar los procesos electorales siendo la unidad de registro el ciudadano no la persona. Sobre esta base se estableció un título de sufragio (libreta electoral).

Así también, de acuerdo a nuestro análisis, hemos identificado que, uno de los fines más frecuentes de la renovación del DNI suele ser el cambio de domicilio por motivos de elecciones. Con esto, podemos rescatar que el motivo por el cual fue creado por primera vez el documento de identidad (estar habilitado para votar en las lecciones) es un factor prioritario pero cuyo trámite se realiza muchas veces a última hora. 
Objetivo Nro. 2: Conocer qué tanto conoce el ciudadano mayor de edad sobre los organismos gubernamentales y privados que ofrecen los servicios y documentos de información de identificación personal.

Sobre este objetivo, el actual jefe del RENIEC, Jorge Yrivarren mencionó lo siguiente:

"En la sociedad existen 4 procesos importantes en los que la sociedad participa, que son; el comercio electrónico, los negocios electrónicos, el aprendizaje electrónico y el Gobierno Electrónico”. (Andina, 2013).

Partiendo del proceso del Gobierno Electrónico, hemos hallado que las instituciones no están comunicando algunos de los beneficios del gobierno electrónico, como por ejemplo los beneficios del DNI electrónico vs el DNI tradicional, así como las facilidades que brinda la SBS para entregar informes del estado crediticio de las personas naturales en forma gratuita. A través de la realización de los focus group, identificamos que algunos grupos de los entrevistados desconocían los beneficios de este documento de identidad y de los servicios de la SBS. Así, vemos que estas instituciones deben mejorar su comunicación para proporcionar una enseñanza clara y didáctica de estos beneficios.

Objetivo Nro. 3: Conocer el nivel de interoperabilidad de los organismos estatales y privados que brindan servicios de información de identificación personal al ciudadano mayor de edad.

Según el portal web de la PCM gobiernodigital.gob.pe, es "la habilidad de los sistemas TIC, y de los procesos de negocios que ellas soportan, de intercambiar datos y posibilitar compartir información y conocimiento" [Consulta: 14 de junio de 2018].

Si vemos que el camino a la interoperabilidad va de la mano con el desarrollo de un Gobierno electrónico, podemos ver que este problema no es reciente, ha estado vigente tanto en el anterior como en el actual gobierno. La percepción que tiene el ciudadano respecto de los actores (instituciones), es que realizan esfuerzos aislados ahondando más en lo referente a trámites de documentos de identificación, y es que piensan que hay otros 
aspectos que también son importantes y que requieren de inmediatez, como lograr la interoperabilidad entre instituciones del sector salud.

La falta de integración (interoperabilidad) entre entidades relacionadas a la gestión de la información de identificación fueron percibidos en los focus group como un problema para los ciudadanos mayores de edad, aun cuando no hayan sido tan conscientes de esta falta como tal en primera instancia, se mostraron de acuerdo en que debería existir mejores formas de operar e integrar información básica relevante que actualmente se obtiene de diferentes instituciones privadas, instituciones del Estado, por diferentes canales y con diferentes niveles de eficiencia (como en el caso del trámite de duplicado del DNI que se puede obtener por 2 servicios diferentes, con canales de atención y niveles de eficiencia diferentes). Esta falta de integración lleva al desconocimiento del servicio que ofrecen dichas instituciones, logrando la confusión y desinformación de los ciudadanos. 


\section{Capítulo IV}

\section{Conclusiones y recomendaciones}

\subsection{Conclusiones}

Esta investigación fue realizada con la finalidad de responder las siguientes preguntas:

Pregunta general: ¿Cuán satisfecho está el ciudadano mayor de edad con los servicios que ofrecen las instituciones que gestionan documentos y servicios de información de identificación personal en Lima Metropolitana?

Los ciudadanos mayores de edad se encuentran insatisfechos con los servicios de información de identificación personal que brindan las organizaciones, tanto estatales como privadas, ello debido al desconocimiento de éstas. Además, existe la percepción de falta de difusión, deficiencias y complicaciones en algunos de los trámites que realizan para la obtención de la documentación solicitada.

Pregunta específica Nro. 1: ¿Qué servicios de información de identificación personal son más solicitados por un ciudadano mayor de edad y con qué fines?

De acuerdo a lo encontrado en las entrevistas y focus group, pudimos observar que, en líneas generales, el servicio de información de identificación personal más solicitado es el trámite de renovación o duplicado del DNI. Existen otros documentos que fueron mencionados en las entrevistas como antecedentes policiales y antecedentes penales.

Así, por ejemplo, mientras que algunos cambian el DNI por vencimiento, otros lo harán porque han cambiado de domicilio o por la cercanía de elecciones. Mientras una persona de 18 a 25 años del N.S.E. C y D que cambia constantemente de trabajo, tendrá que solicitar antecedentes policiales y penales para cada vez que ingrese a una nueva empresa, para una persona del N.S.E. A y B de 50 años que tenga un negocio propio, realizar este trámite ya no será necesario (ver análisis de focus group p. 52). 
Pregunta específica Nro. 2: ¿El ciudadano mayor de edad sabe dónde acudir si tiene que tramitar algún documento o servicio de información de identificación personal?

Lo que encontramos en esta investigación es que el ciudadano mayor de edad conoce dónde puede tramitar su DNI, sin embargo, no conoce todas las posibilidades o todos los canales donde solicitar otros servicios de información de identificación.

- En los grupos de los más jóvenes encontramos qué, en el N.S.E. A, B, C1 tienen algo de noción sobre dónde ubicar la información si es que no la conocen o no la han necesitado aún, (ver análisis focus group p. 53), mientras que en el grupo C2, D1, el conocimiento de estas instituciones es baja (ver análisis focus group p. 53).

- En los grupos de 50 años a más, tienen un conocimiento mayor de los canales e instituciones donde pueden gestionar los documentos de información de identificación (ver análisis focus group p. 54).

- El grupo más informado sobre las instituciones y canales de atención de los mismos fue el grupo de 30 a 49 años del N.S.E. A, B, C1 (ver análisis focus group p. 54).

- La mayoría de los grupos percibe que la comunicación de estos organismos es poca y en algunos grupos se presentaron ideas interesantes, siendo el internet uno de los medios más sugeridos (ver anexo focus group p. 55).

Pregunta específica Nro. 3: ¿Las entidades estatales y privadas están interconectadas para brindar una buena experiencia de atención a los ciudadanos mayores de edad de Lima Metropolitana en cuanto a los servicios de información de identificación personal?

En este último punto, confirmamos que el nivel de interoperabilidad para compartir información entre instituciones ya sean públicas o privadas, así como su nivel de sistematización es baja. Mientras que en otros países se habla de historias clínicas y recetas, ambos en formato digital y que puede enviarse vía email, en Lima, un paciente debe de esperar en el peor de los casos hasta 30 días (en el caso de hospitales) para obtener 
dicha información. Es importante para los ciudadanos contar con información de aspectos de salud que en situaciones de emergencia les pueda ayudar a tomar una decisión acertada.

Un aspecto importante mencionado por los especialistas en este punto, es el referente a la tecnología, sobre todo en los sectores públicos, pues apuntar a la interoperabilidad entre instituciones requerirá que se haga una inversión importante en tecnología hardware y software, así como la capacitación del personal en TIC.

Si bien es cierto, la interoperabilidad ayudará mucho a cubrir ciertos aspectos en eficiencia y rapidez para efectuar los trámites de documentos de información de identificación personal, los ciudadanos mayores de edad también son conscientes de que se debe brindar la seguridad del caso para no tener que lidiar con robo de información que pueda perjudicarlos. Vale señalar que la desconfianza en este tema se ha evidenciado en todas las edades de las personas colaboradoras con la investigación, pero es más fuerte en los grupos de mayor edad (ver análisis de focus group, p. 56-57).

\subsection{Hallazgos}

Otros aspectos importantes que no se habían considerado en este estudio, apunta a la seguridad y al poco o nulo conocimiento de las TIC tanto en los usuarios como en el personal de instituciones del Estado.

Si bien es cierto, el planteamiento de la posibilidad de centralizar la mayor cantidad de información de identificación posible en un DNI o en una plataforma por la cual los usuarios puedan encontrar, de manera sencilla, y efectiva, información personal que necesitan es positiva y deseada, también se observó en todos los grupos, la inseguridad de tener estos datos "online" sin medidas de niveles de seguridad. Al respecto, si bien el temor sobre los niveles de uso de las tecnologías existía en los más jóvenes, estos lo percibieron como una forma más eficaz y rápida de obtener lo que necesitaban, mientras que los más adultos, menos acostumbrados al uso de internet en su día a día, sí se mostraron más preocupados por este tema. 
Considerando la perspectiva de los organismos ofertantes de estos servicios de información de identificación personal; y -como lo mencionó uno de los especialistas de RENIEC- para lograr la digitalización de información, y con ello su compartición y ayuda al ciudadano, se necesita entrenamiento y capacitación constante sobre las TIC para el personal de estas instituciones (ver análisis de entrevistas a profundidad, Rossmary Rivera p. 51). 


\subsection{Recomendaciones}

A continuación, presentamos algunas recomendaciones generales y específicas por cada objetivo planteado en esta investigación:

Objetivo Nro. 1: Conocer cuál es el fin de la obtención de la información de identificación personal.

Los trámites de certificados de antecedentes penales y policiales también son muy solicitados y pueden ser tramitados en distintos lugares tales como comisarías y algunas agencias bancarias. En esa media, recomendamos realizar encuestas de satisfacción con el fin de medir el nivel de aceptación que el ciudadano respecto al servidor, así como también del lugar donde se atendió con el fin de realizar propuestas de mejora a futuro.

Un ejemplo que nos brindó uno de los entrevistados de focus group en el grupo de N.S.E A, B, C1 fue que en algunos distritos ya usan sistema de delivery o de envío del DNI a domicilio, el cual podría pensamos evaluarse para otros distritos de Lima Metropolitana.

Objetivo Nro. 2: Conocer qué tanto conoce el ciudadano mayor de edad sobre los organismos gubernamentales y privados que ofrecen los servicios y documentos de información de identificación personal.

Que las instituciones privadas y gubernamentales hagan un reconocimiento y una segmentación adecuada para crear estrategias de comunicación acorde a las características de los ciudadanos.

Por mencionar algunos casos ilustrativos de la problemática, muchas personas entrevistadas en el focus group indicaron no conocer los centros MAC, y en el caso que tener conocimiento al respecto, manifestaron haber llegado a ellos porque alguien se los recomendó o porque se los "encontró" de manera accidental. Para realizar una comunicación efectiva es necesario realizar una segmentación adecuada y con un presupuesto básico, lo que permitiría una mayor difusión de estos centros. Para esta segmentación, podría tomarse dos grupos de referencia: aquellos que estén habituados al uso de la tecnología (jóvenes entre 18 a 30 años), y aquellos que estén más acostumbrados 
a otros medios (radio, televisión, volantes impresos o avisos en recibos de la municipalidad o de agua).

Objetivo Nro. 3: Conocer el nivel de interoperabilidad de los organismos estatales y privados que brindan servicios de información de identificación personal al ciudadano mayor de edad.

Asimismo, para minorizar el efecto burocrático, las instituciones que brindan servicios de información de identificación, podrían realizar auditorías internas para automatizar sus procesos y en conjunto con las encuestas de satisfacción, obtener la información necesaria para acortar los tiempos y hacer que los procesos de obtención de información de identificación sean más eficientes.

Por último, recomendamos que, para la realización de futuros estudios sobre este tema, puedan aplicarse metodologías cuantitativas, a fin de complementar el aporte aquí presentado. 


\section{Referencias Bibliográficas}

Andina (2012). Construyendo nuestra identidad digital 13 setiembre. [Entrevista] Recuperado de https://bit.ly/2KEWExO [Consulta: 08 de marzo de 2018].

Skatteverket (2017). Documento de identidad para empadronados en Suecia Recuperado de https://bit.ly/2OY41T9 [Consulta: 20 de marzo de 2018].

Ministerio del Interior. (2015) DNI electrónico. España: Dirección General de la Policía. Recuperado de https://bit.ly/2MBZDIY [Consulta: 12 de febrero de 2018].

Avaro, D. (2017). Trazabilidad ciudadana y democracia: una aproximación desde la experiencia argentina. En Revista Mexicana de Ciencias Políticas y Sociales. Vol. 62. 255 pp. - 276 pp. México. Recuperado de https://bit.ly/2MfYRV3 [Consulta: 08 de marzo de 2018].

Azevedo, V., Bouillon, \& C., Irarrazavel, I. (2011) La efectividad de las redes de protección social: El rol de los sistemas integrados de información social en seis países de América Latina. Banco Interamericano de Desarrollo: Departamento de Investigación y Economista Jefe. [Consulta: 04 de abril de 2018].

Dirección General de Comunicación (2014) Comprender las políticas de la Unión Europea: Agenda Digital para Europa. Bélgica: Comisión Europea. [Consulta: 17 de abril de 2018].

Chung, E., García, V., Rupailla, \& C., Seminario, M. (2017) Factores claves para mejorar la calidad del servicio al cliente en las municipalidades de Lima Metropolitana. (Tesis de Licenciatura, Universidad Peruana de Ciencias, Lima, Perú).

Comisión Económica para América Latina y El Caribe (2007) Libro blanco de interoperabilidad de gobierno electrónico para América Latina y el Caribe. Versión 3.0. Naciones Unidas.

Consultora EY. (2016) Los retos que traen las nuevas tecnologías en el sector financiero. [Libro electrónico de la consultora Ernst \& Young] Recuperado de https://go.ey.com/2MF5AEY 
Diario El Peruano (27 de agosto de 2017) Interoperabilidad del Estado, una batalla digital. [Publicación de Diario El Peruano]. Recuperado de https://bit.ly/2M6QagT

Giones, A., \& Serrat, M., (2010) La gestión de la identidad digital: una nueva habilidad informacional y digital. Facultad de Biblioteconomia i Documentació Universitat de Barcelona, España. Recuperado de http://bid.ub.edu/24/giones2.htm

Mesa, C., (2014) La interoperabilidad como parte del desarrollo del gobierno electrónico en el Perú. (Tesis de Maestría, Pontificia Universidad Católica del Perú, Lima, Perú).

Nuñez, J., (2016) Derecho de identidad digital en internet. (Tesis de Doctorado, Universidad Nacional Mayor de San Marcos, Lima, Perú).

Nuñez, W., (2015) Solución e-government para la gestión de solicitudes de acceso a la información en los registros públicos. Caso: Perú. (Tesis de Maestría, Universidad de Piura, Lima, Perú).

Ortega, A., (2010) Modelo de un proceso integrado para el Registro de Identificación de Personas en Latinoamérica. (Tesis de Maestría, Universidad Nacional de Ingeniería, Lima, Perú).

Organización de los Estados Americanos (OAS). Sobre e-gobierno. Recuperado de http://portal.oas.org/Portal/Sector/SAP/DptodeModernizaci\%C3\%B3ndelEstadoyGober nabilidad/NPA/SobreProgramadeeGobierno/tabid/811/Default.aspx [Consulta: 14 de mayo de 2018].

Peña, C., (2016) Gobierno electrónico y seguridad de la información en el Registro Nacional de Identificación y Estado Civil. (Tesis de Maestría, Universidad César Vallejo, Lima, Perú).

Visurraga, J., (2016). Certificado Digital, Documento Nacional de Identidad Electrónico y Gobernabilidad Electrónica en Instituciones Públicas Peruanas. (Tesis de Doctorado, Universidad César Vallejo, Lima, Perú).

Presidencia del Consejo de Ministros (PCM). (2011). Plan de Desarrollo de la Sociedad de la Información en el Perú, La Agenda Digital Peruana 2.0. Recuperado de https://bit.ly/2KIW69Z [Consulta: 14 de junio de 2018]. 
Presidencia del Consejo de Ministros (PCM). Interoperabilidad. Recuperado de http://www.gobiernodigital.gob.pe/interoperabilidad/. [Consulta: 14 de mayo de 2018].

Revista Semana Económica (2017) Gobierno digital en el Perú: la identidad va primero. Recuperado de https://bit.ly/2OZZ3X5 [Consulta: 10 de mayo de 2018].

Reyes, D., (s.f.) Gob.pe, y el reto de un estado simple, digital y humano. Gerencia de Estrategia Digital e Innovación, La hora de la Transformación. Recuperado de https://bit.ly/2M5Efj8 [Consulta: 16 de mayo de 2018].

Rouse, M., (2014). Información de identificación personal (PII.) [La información de identificación personal (PII) es cualquier dato que podría identificar potencialmente a un individuo específico]. Recuperado de https://bit.ly/2vxpKug [Consulta: 01 de julio de 2018].

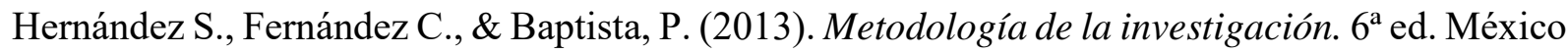
D.F.: Mc Graw Hill. 


\section{Anexos}

Anexo $\mathrm{N}^{\circ} 1$ Guía de indagación para Entrevista a profundidad con expertos

\begin{tabular}{|c|c|c|}
\hline Concepto & Dimensiones & Preguntas \\
\hline \multirow{8}{*}{$\begin{array}{l}\text { 1. Conocer cuál es el fin } \\
\text { de la obtención de la } \\
\text { información de } \\
\text { identificación personal }\end{array}$} & \multirow{4}{*}{$\begin{array}{l}\text { Gubernamental y } \\
\text { tecnológica } \\
\text { (RENIEC) }\end{array}$} & $\begin{array}{l}\text { ¿Cuál es la información con más demanda que desea } \\
\text { obtener el ciudadano común de ustedes? }\end{array}$ \\
\hline & & $\begin{array}{l}\text { ¿El ciudadano suele indicar para qué es dicha información? } \\
\text { ¿Existen estadísticas de los motivos de la solicitud de esta } \\
\text { información? }\end{array}$ \\
\hline & & $\begin{array}{l}\text { ¿Sabe cuánto tiempo en promedio emplea el ciudadano } \\
\text { desde que ingresa a la institución para ser atendido hasta } \\
\text { que se retira por cada servicio de información de } \\
\text { identificación que realiza? }\end{array}$ \\
\hline & & $\begin{array}{l}\text { ¿Conoce la opinión que tienen los ciudadanos sobre el } \\
\text { servicio que reciben de su institución? }\end{array}$ \\
\hline & \multirow[b]{2}{*}{ Salud } & $\begin{array}{l}\text { ¿Cuál es la información con más demanda que desea } \\
\text { obtener el ciudadano común de ustedes? }\end{array}$ \\
\hline & & $\begin{array}{l}\text { ¿El ciudadano suele indicar para qué es dicha información? } \\
\text { ¿Existen estadísticas de los motivos de la solicitud de esta } \\
\text { información? }\end{array}$ \\
\hline & \multirow[b]{2}{*}{ Financiera } & $\begin{array}{l}\text { ¿Cuál es la información con más demanda que desea } \\
\text { obtener el ciudadano común de ustedes? }\end{array}$ \\
\hline & & $\begin{array}{l}\text { ¿El ciudadano suele indicar para qué es dicha información? } \\
\text { ¿Existen estadísticas de los motivos de la solicitud de esta } \\
\text { información? }\end{array}$ \\
\hline
\end{tabular}




\begin{tabular}{|c|c|c|}
\hline \multirow{12}{*}{$\begin{array}{l}\text { 2. Conocer que tanto } \\
\text { conoce el ciudadano } \\
\text { mayor de edad sobre los } \\
\text { organismos } \\
\text { gubernamentales y } \\
\text { privados que ofrecen } \\
\text { los servicios y } \\
\text { documentos de } \\
\text { información identificación personal } \\
\text { ide }\end{array}$} & \multirow{3}{*}{ Salud } & $\begin{array}{l}\text { ¿Cuál es el estatus actual de la intormacion que el Estado } \\
\text { puede compartir con organismos dedicados a la salud } \\
\text { referente a un ciudadano mayor de edad? }\end{array}$ \\
\hline & & $\begin{array}{l}\text { ¿Esta información puede ser compartida desde el gobierno } \\
\text { hacia otras empresas privadas dedicadas a la salud? }\end{array}$ \\
\hline & & $\begin{array}{l}\text { Sí es así, ¿qué nivel de información brinda, y en qué casos } \\
\text { la brinda? }\end{array}$ \\
\hline & \multirow{4}{*}{ Legal } & $\begin{array}{l}\text { ¿Cuál es el nivel de información de identificación de un } \\
\text { individuo que está abierta a las empresas privadas } \\
\text { actualmente? }\end{array}$ \\
\hline & & $\begin{array}{l}\text { ¿Cuántas entidades existen donde deben de buscar esta } \\
\text { información las empresas? }\end{array}$ \\
\hline & & $\begin{array}{l}\text { ¿Cuál es la información de identificación de las personas } \\
\text { que puede ser pública? }\end{array}$ \\
\hline & & $\begin{array}{l}\text { ¿Qué canales utilizan actualmente para poder compartir la } \\
\text { información solicitada? }\end{array}$ \\
\hline & \multirow{2}{*}{$\begin{array}{l}\text { Gubernamental y } \\
\text { tecnológico } \\
\text { (RENIEC) }\end{array}$} & $\begin{array}{l}\text { ¿Cuál es la información con más demanda que desea } \\
\text { obtener el ciudadano común de ustedes? }\end{array}$ \\
\hline & & $\begin{array}{l}\text { ¿Qué canales utilizan actualmente para poder responder la } \\
\text { demanda/ consultas sobre información de identificación? }\end{array}$ \\
\hline & \multirow{3}{*}{ Financiera } & $\begin{array}{l}\text { ¿Hay alguna entidad que centraliza la información digital } \\
\text { de identificación de los ciudadanos respecto a su estado } \\
\text { financiero?, ¿Cuál es? }\end{array}$ \\
\hline & & $\begin{array}{l}\text { ¿Con qué otras entidades se comunican o comparte } \\
\text { información si se quiere validar algún dato de } \\
\text { identificación o récord de una persona natural mayor de } \\
\text { edad? }\end{array}$ \\
\hline & & $\begin{array}{l}\text { ¿Qué canales utilizan actualmente para poder responder la } \\
\text { demanda/ consultas sobre la información solicitada? }\end{array}$ \\
\hline
\end{tabular}




\begin{tabular}{|c|c|c|}
\hline & & $\begin{array}{l}\text { ¿Qué tan interconectados se encuentra los bancos con } \\
\text { entidades gubernamentales que brindan información de } \\
\text { identificación? }\end{array}$ \\
\hline & & $\begin{array}{l}\text { ¿Cada cuánto tiempo un banco necesita actualizar } \\
\text { información de identificación de sus clientes? }\end{array}$ \\
\hline \multirow{8}{*}{$\begin{array}{l}\text { 3. Conocer el nivel de } \\
\text { interoperabilidad de los } \\
\text { organismos estatales y } \\
\text { privados que brindan } \\
\text { servicios } \\
\text { información } \\
\text { identificación personal } \\
\text { al ciudadano mayor de } \\
\text { edad }\end{array}$} & \multirow{4}{*}{$\begin{array}{l}\text { Gubernamental y } \\
\text { tecnológica } \\
\text { (RENIEC) }\end{array}$} & $\begin{array}{l}\text { ¿Cuál es el estatus actual de la información de } \\
\text { identificación que su empresa o entidad puede compartir } \\
\text { con organismos privados o gubernamentales dedicados } \\
\text { sobre un ciudadano mayor de edad? }\end{array}$ \\
\hline & & $\begin{array}{l}\text { ¿A qué nivel estamos en la región en cuanto a } \\
\text { interoperabilidad? }\end{array}$ \\
\hline & & $\begin{array}{l}\text { ¿Cuál cree usted que son las brechas que impiden que las } \\
\text { interconexiones entre entidades privadas y del Estado sean } \\
\text { más utilizadas y mejor difundidas en la actualidad? }\end{array}$ \\
\hline & & $\begin{array}{l}\text { ¿Hasta qué nivel la información de identificación de un } \\
\text { ciudadano puede ser consultadas por las empresas ya sean } \\
\text { privadas o del gobierno? }\end{array}$ \\
\hline & \multirow{4}{*}{ Financiera } & $\begin{array}{l}\text { ¿Cuál es el estatus actual de la información de } \\
\text { identificación que su empresa o entidad puede compartir } \\
\text { con organismos privados o gubernamentales respecto al } \\
\text { historial financiero de un ciudadano mayor de edad? }\end{array}$ \\
\hline & & $\begin{array}{l}\text { ¿Qué organismos regulan esta compartición de } \\
\text { información? }\end{array}$ \\
\hline & & $\begin{array}{l}\text { ¿A qué nivel estamos en la región en cuanto a } \\
\text { interoperabilidad respecto a la información financiera que } \\
\text { se puede compartir de un ciudadano? }\end{array}$ \\
\hline & & $\begin{array}{l}\text { ¿Hasta qué nivel la información de identificación de un } \\
\text { ciudadano puede ser consultada por las empresas ya sean } \\
\text { privadas o del Estado? }\end{array}$ \\
\hline
\end{tabular}




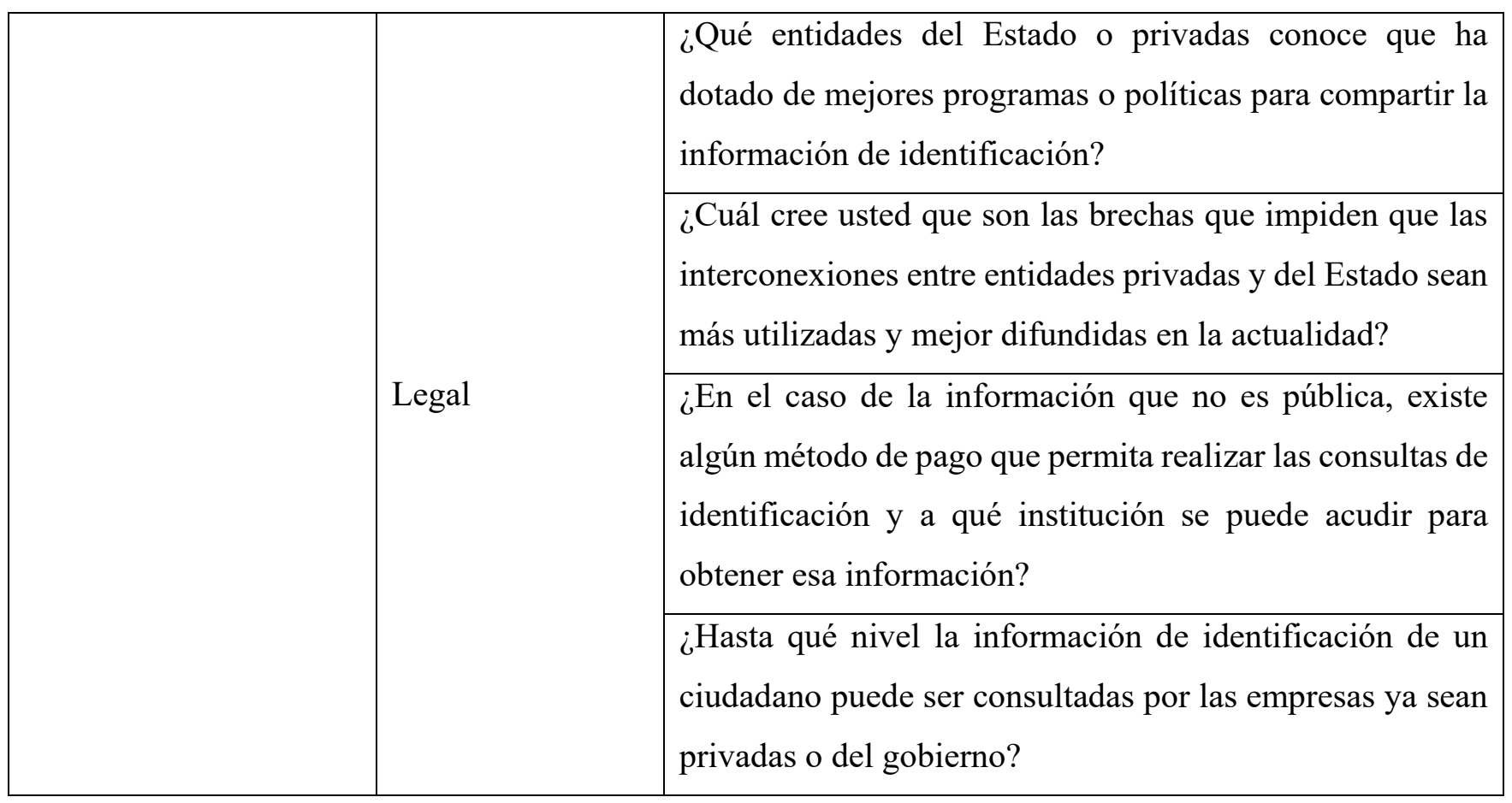




\section{Anexo $N^{\circ} 2$ Ficha técnica Entrevista a profundidad Nro. 1}

\section{I.- Datos generales}

\subsection{Objetivo del estudio}

1. Conocer cuál es el fin de la obtención de la información de identificación personal.

2. Conocer que tanto conoce el ciudadano mayor de edad sobre los organismos gubernamentales y privados que ofrecen los servicios y documentos de información de identificación personal.

3. Conocer el nivel de interoperabilidad de los organismos estatales y privados que brindan servicios de información de identificación personal al ciudadano mayor de edad.

\subsection{Metodología y muestra}

\subsubsection{Tipo de Investigación:}

Este es un tipo de investigación de fuente primaria, que consiste en el levantamiento de información directamente de diferentes especialistas que tengan que ver con el manejo de información de identidad del ciudadano mayor de edad. Se utilizó la metodología de la investigación cualitativa.

\subsubsection{Técnica e instrumento a utilizar:}

En este caso hemos utilizado la entrevista a profundidad, la cual fue llevada a cabo por el grupo del grupo de Tesis UPC.

Se utilizó como instrumento una guía de indagación, elaborada por el Grupo de Tesis y estuvo sujeto a la aprobación del asesor. 


\subsubsection{Muestra:}

La muestra estuvo compuesta por un grupo, con las siguientes características:

\begin{tabular}{|l|ll|}
\hline Nombre & Género & $\mathrm{N}^{\circ}$ entrevista \\
\hline Joan Ballón & Mujer & 01 \\
\hline
\end{tabular}

1.2.4 Fecha de Campo:

La entrevista se realizó el 11 de marzo del 2018 a las 17:00 horas en Avenida César Vallejo 1429 - Lince.

\subsection{Perfil del especialista}

Ejecutiva de 40 años, actualmente desempeñándose como Gestor de gestión efectiva de Servicios financieros, cuenta con más de 7 años de experiencia en la empresa MIBANCO.

\section{II.- Hallazgos de la entrevista}

\subsection{Conocer cuál es el fin de la obtención de la información de identificación personal.}

Al ser una institución privada, la información se obtiene de forma voluntaria de parte del ciudadano cada vez que éste desee adquirir un producto o servicio determinado del Banco.

Tipo de información solicitada por el ciudadano a la institución y fin: Activos y pasivos que tiene éste en el banco, el fin por lo general es mantener un registro de sus productos u obtener un producto o servicio nuevo.

Tipo de información solicitada por la institución y fin: Datos básicos como: DNI, lugar de residencia, historial crediticio ya sea persona natural o jurídica. El fin es conocer el perfil y su factibilidad para poder adquirir un producto o servicio del banco. 
2.2 Conocer que tanto conoce el ciudadano mayor de edad sobre los organismos gubernamentales y privados que ofrecen los servicios y documentos de información de identificación personal.

De acuerdo con las respuestas de la entrevista esta es la información que recaba la institución: datos básicos de los clientes: datos personales, DNI, teléfono, lugar de residencia, email, RUC,

La información sobre el historial financiero del cliente lo obtiene el banco a través de centrales de riesgo y en algunos casos con verificadores de campo (en caso haya que verificar propiedades o negocios, por ejemplo).

Parte de la información que recoge el banco proviene de instituciones del Estado, el banco puede solicitar datos de activos, propiedades, confirmación de residencia o multas a organismos como SUNARP, SUNAT entre otros. Para la obtención de esta información el banco paga un derecho a algunas de estas instituciones. El banco también se puede obtener información de otros organismos que suministren servicios (empresas de agua y energía eléctrica).

Dependiendo del producto que el cliente desee obtener el banco podría requerir entre 1 a 3 días y solicitar información entre 3 a 4 instituciones en promedio para obtener toda la información que se necesita del cliente

La información que se obtiene, no se actualiza a no ser que sea necesario, que es cuando el cliente desea obtener otro producto adicional.

2.3Conocer el nivel de interoperabilidad de los organismos estatales y privados que brindan servicios de información de identificación personal al ciudadano mayor de edad.

En cuanto a interoperabilidad, la información del ciudadano que es compartida y obtenida antes que se le otorgue un producto del banco (préstamos) se da desde organismos gubernamentales como son la SBS (estatal) y privadas como EQUIFAX.

La información del ciudadano (cliente) que el banco dirige a la SBS se da de manera mensual al enviar los reportes de sus operaciones

La información del usuario no puede ser usada para otros fines o compartida con cualquier institución o persona que lo solicite, y en esto se basa la ley de protección al consumidor, sin 
embargo, no se requiere de una autorización expresa del ciudadano para la obtención de información financiera (deudas) que en este caso el banco sí solicita a la SBS.

En caso de otros países, como Costa Rica, por ejemplo, los bancos no pueden solicitar información financiera del usuario a no ser que haya sido autorizada previamente por el ciudadano mayor de edad.

Las fuentes de información para determinada información del cliente (posesión de inmuebles o autos, por ejemplo) que se obtiene de otras instituciones como la SUNAT, se obtienen en algunos casos pagando por dicha información, en muchos casos esta información no está digitalizada.

\section{III.- $\quad$ Validación de variables}

Hipótesis

La falta de integración de sistemas entre entidades relacionadas a la gestión de la información de identificación personal y la falta de conocimiento de la población de estas instituciones, son la causa de insatisfacción del ciudadano mayor de edad que requieren estos documentos y servicios.

En este caso, la obtención de la información que solicita el banco del ciudadano es para un fin comercial y específico (adquisición de un producto o servicio del banco), sin embargo, la forma de obtención de información puede ser de diversas fuentes ya sea de instituciones públicas como privadas, siendo el tiempo y el costo de esta información un problema para brindar con mayor efectividad un determinado producto. No existe una forma única y sencilla de obtener la información necesaria, y en algunos casos la información no se encuentra digitalizada o tiene un costo.

La insatisfacción o complejidad para la obtención de información es tanto para la institución financiera además de la del ciudadano que ve estas faltas o demoras plasmadas en el tiempo de atención del banco.

\section{IV.- Conclusiones}

El flujo de información en temas financieros aún carece de vías de obtención que sean más efectivas y rápidas y de un ente estatal que la concentre. 
El dinamismo de este flujo de información o la interoperabilidad entre instituciones podría favorecer los tiempos de las operaciones de los usuarios.

La falta de documentos digitalizados en algunos casos es una barrera pues alarga los tiempos de obtención de la información. 


\section{Anexo $\mathrm{N}^{\circ} 3$ Ficha técnica Entrevista a profundidad Nro. 2}

\section{Datos generales}

\subsection{Objetivo del estudio}

1. Conocer cuál es el fin de la obtención de la información de identificación personal.

2. Conocer que tanto conoce el ciudadano mayor de edad sobre los organismos gubernamentales y privados que ofrecen los servicios y documentos de información de identificación personal.

3. Conocer el nivel de interoperabilidad de los organismos estatales y privados que brindan servicios de información de identificación personal al ciudadano mayor de edad.

\subsection{Metodología y muestra}

\subsubsection{Tipo de Investigación}

Investigación de fuente primaria, que consiste en el levantamiento de información directamente de diferentes especialistas que tengan que ver con el manejo de información de identidad, del ciudadano mayor de edad. Se utilizó la metodología de la investigación cualitativa.

\subsubsection{Técnica e instrumento a utilizar}

En este caso hemos utilizado la entrevista a profundidad, las cuales fueron llevadas a cabo por el grupo del grupo de Tesis UPC.

Se utilizó como instrumento una guía de indagación, elaborada por el Grupo de Tesis y estuvo sujeto a la aprobación del asesor. 


\subsubsection{Muestra}

La muestra estuvo compuesta por un grupo, con las siguientes características:

\begin{tabular}{|l|l|l|}
\hline Nombre & Género & $\mathrm{N}^{\circ}$ entrevista \\
\hline Gala Briceño & Mujer & 02 \\
\hline
\end{tabular}

1.2.4. Fecha de Campo

La entrevista se realizó el 21 de marzo del 2018 a las 17:00 horas en las oficinas de RENIEC

\subsection{Perfil del especialista}

Ejecutiva de 38 años, actualmente desempeñándose como Subgerente de Ingeniería de software de la RENIEC, cuenta con más de 7 años de experiencia en la empresa.

\section{II.- Hallazgos de la entrevista}

\subsection{Conocer cuál es el fin de la obtención de la información de identificación personal.}

Tipo de información más solicitada por parte del ciudadano hacia la institución y fin:

Constancia de inscripción (C4), formato donde contiene datos de: nombres, apellidos, foto, estado civil, dirección, se usan cuando el ciudadano necesita una forma de identificación y no tiene el DNI en físico.

Portal del ciudadano: los usuarios pueden sacar información digitalmente de constancias de inscripción, certificado de nacimiento, matrimonio, constancia de defunción, sin embargo, la información acerca de menores de edad es restringida. 
2.2 Conocer que tanto conoce el ciudadano mayor de edad sobre los organismos gubernamentales y privados que ofrecen los servicios y documentos de información de identificación personal.

Información recabada por la institución:

Datos básicos: datos personales, DNI, teléfono, lugar de residencia, email, RUC, entre otros.

\subsection{Conocer el nivel de interoperabilidad de los organismos estatales y privados que brindan servicios de información de identificación personal al ciudadano mayor de edad.}

En cuanto a interoperabilidad, la institución trabaja tanto con instituciones del Estado como privadas.

Para la compartición de información ya sea con el Estado o instituciones privadas, éstas deben de haber firmado un Convenio con la RENIEC (convenios pagados), la información que se otorga a través de Consultas en línea por ejemplo tiene 3 niveles de seguridad que se otorgarán de acuerdo con lo permitido.

Otras vías de comunicación para la compartición de información, es a través de una línea dedicada con la institución o por internet a través de medios seguros con certificados de seguridad.

El tipo de información que se brinda a empresas privadas, por ejemplo, es del servicio de verificación biométrica, que es usado por la banca, notarios, y TELCO.

Para organismos del Estado, tienen el sistema de Biometría que es usada por la PNP, sistema de IDENTIFICA (que trabajan con Patrulleros Inteligentes), Certificado Nacido vivo del MINSA, certificado de defunción en línea y de la madre gestante entre otros.

A nivel mundial, el RENIEC es el único que ha ganado un premio de identificación al menor. 
A nivel Latinoamérica, el Perú es el que tiene el mejor servicio de identificación biométrica.

A nivel de Interoperabilidad regional, está encaminado un proyecto con Bolivia y Colombia para integrar un sistema de verificación biométrica (ABIS).

Las brechas son tecnológicas y presupuestal, a nivel de instituciones del Estado.

Dentro de las instituciones que aprovechan mejor el servicio de información son la Banca y las TELCO.

\section{III.- Validación de variables}

Hipótesis

La falta de integración de sistemas entre entidades relacionadas a la gestión de la información de identificación personal y la falta de conocimiento de la población de estas instituciones, son la causa de insatisfacción del ciudadano mayor de edad que requieren estos documentos y servicios.

La solicitud que realiza el ciudadano común a la RENIEC es básica, (constancias de inscripción, certificado de nacimiento, matrimonio, constancia de defunción) y se puede obtener a través de su portal o en forma física en sus locales. En el caso del nivel de interoperabilidad, de acuerdo con las declaraciones de la especialista, el nivel de compartición de información es alta con instituciones privadas y estatales es alta y en la mayoría de los casos digitalizada, lo cual facilita las gestiones para la obtención de esta información entre personas jurídicas y requiere de una transacción de por medio (Convenios). Por otro lado, el nivel de interoperabilidad a nivel de región parece prometedor.

\section{IV.- Conclusiones}

El dinamismo de este flujo de información o la interoperabilidad para la obtención de información del ciudadano está enfocado en cuanto a temas de seguridad, como la identificación biométrica aplicada a sistemas de la PNP, Banca para evitar fraudes y telecomunicaciones, y en temas de registros de nacimientos y defunciones con el MINSA. 
No se ha visto una inclinación en cuanto a las necesidades que puede tener el ciudadano común sobre la información de identificación. La institución cubre las necesidades básicas, pero no parece estar preocupado en otorgar mayores facilidades o no indica hasta qué punto esta pueda darse al ciudadano común. 


\section{Anexo $\mathrm{N}^{\circ} 4$ Ficha técnica Entrevista a profundidad Nro. 3}

\section{Datos generales}

\subsection{Objetivo del estudio}

1. Conocer cuál es el fin de la obtención de la información de identificación personal.

2. Conocer que tanto conoce el ciudadano mayor de edad sobre los organismos gubernamentales y privados que ofrecen los servicios y documentos de información de identificación personal.

3. Conocer el nivel de interoperabilidad de los organismos estatales y privados que brindan servicios de información de identificación personal al ciudadano mayor de edad.

\subsection{Metodología y muestra}

\subsubsection{Tipo de Investigación}

Investigación de fuente primaria, que consiste en el levantamiento de información directamente de diferentes especialistas que tengan que ver con el manejo de información de identidad, del ciudadano mayor de edad. Se utilizó la metodología de la investigación cualitativa.

\subsubsection{Técnica e instrumento a utilizar:}

En este caso hemos utilizado la entrevista a profundidad, las cuales fueron llevadas a cabo por el grupo del grupo de Tesis UPC.

Se utilizó como instrumento una guía de indagación, elaborada por el Grupo de Tesis y estuvo sujeto a la aprobación del asesor. 


\subsubsection{Muestra:}

La muestra estuvo compuesta por un grupo, con las siguientes características:

\begin{tabular}{|l|l|l|}
\hline Nombre & Género & N. $^{\circ}$ de Entrevista \\
\hline Iván Lizarzaburu & Hombre & 03 \\
\hline
\end{tabular}

1.2.4. Fecha de Campo

La entrevista se realizó el 04 de abril del 2018 a las 11:00 horas, entrevista telefónica.

\subsection{Perfil del especialista}

Ejecutivo de 36 años, actualmente desempeñándose como Gerente de operaciones en 10HEAD HUNTERS, cuenta con más de 10 años de experiencia en procesos de selección y administración de personal.

\section{II.- Hallazgos de la entrevista}

2.1 Conocer cuál es el fin de la obtención de la información de identificación personal.

En este caso la información solicitada por la empresa de Head Hunting o selección de personal, obtiene la información de identificación básica de algunas instituciones gubernamentales o privadas para poder validar los perfiles (personas) que forman parte de un proceso de selección para que finalmente puedan ser contratados por alguna determinada empresa.

2.2 Conocer que tanto conoce el ciudadano mayor de edad sobre los organismos gubernamentales y privados que ofrecen los servicios y documentos de información de identificación personal. 
Información recabada por la institución que solicita los perfiles para un proceso de selección:

Datos básicos: datos personales, DNI, lugar de residencia, antecedentes policiales, penales, grado académico y perfil crediticio.

\subsection{Conocer el nivel de interoperabilidad de los organismos estatales y privados que brindan servicios de información de identificación personal al ciudadano mayor de edad.}

La información que mencionó el entrevistado, la información que se requiere para los procesos se consigue de las siguientes fuentes:

Los *MAC (Mejor atención al Ciudadano) son centro de atención que agrupan un conjunto de entidades para que los ciudadanos puedan realizar trámites como la obtención de antecedentes penales y policiales entre otros. Esta información no es gratuita, tiene un costo que en el caso de las empresas de selección lo puede cubrir la empresa que solicita cubrir la vacante o también puede costearlo el postulante.

Para verificación de grados académicos mencionó a la SUNEDU, la información se brinda en forma gratuita.

Para la verificación de estado financiero, recurren a INFOCORP o Equifax.

Sobre la rapidez de la obtención de esta información mencionó que no debería demorar más de 2 días.

El entrevistado mencionó no conocer alguna institución o portal donde se pueda encontrar toda la información necesaria en un mismo lugar, pero sí mencionó a los MAC.

A nivel de Interoperabilidad en la región, mencionó no estar familiarizado, pero supone que es el mismo caso que en Perú donde la información se consigue de varias fuentes. 
*Centro de Atención en el que el Estado a través de un conjunto de Entidades ofrece servicios públicos en una misma plataforma integrada para brindar al ciudadano, rapidez, confianza, transparencia y comodidad en un solo lugar.

\section{III.- Validación de variables}

Hipótesis

La falta de integración de sistemas entre entidades relacionadas a la gestión de la información de identificación personal y la falta de conocimiento de la población de estas instituciones, son la causa de insatisfacción del ciudadano mayor de edad que requieren estos documentos y servicios.

La información que se recaba en este caso es bastante dirigida y enfocada a la obtención de empleo, y si bien a nivel gubernamental existe un Centro de Atención dirigido a los ciudadanos y que puedan facilitar su proceso de trámites necesarios para la obtención de trabajo, aún falta la integración de otras instituciones privadas a las cuáles debe de acceder de forma independiente. Por otro lado, el nivel de compartición de información en estos centros de atención (MAC) es alta, sin embargo, de acuerdo con su página web el número de estos centros de atención es muy limitado para Lima Metropolitana (existen sólo 3) y a nivel nacional existe en 2 regiones más, Piura y en el Callao. Así mismo no todos los centros de atención cuentan con la misma variedad de servicios. Por lo que podemos ver que en realidad que el nivel de satisfacción se da nuevamente a nivel personas jurídicas, si bien es cierto los MAC cubren gran parte de la información necesaria, no tienen la cobertura necesaria.

\section{IV.- Conclusiones}

El flujo o manejo de información básica para procesos de contratación, se maneja de una manera sencilla y sin mucha dificultad (al parecer) sin embargo, hace falta más acceso del ciudadano común a este tipo de información, sobre todo en provincias. 


\section{Anexo $\mathrm{N}^{\circ} 5$ Ficha técnica Entrevista a profundidad Nro. 4}

\section{Datos generales}

\subsection{Objetivo del estudio}

1. Conocer que tanto conoce el ciudadano mayor de edad sobre los organismos gubernamentales y privados que ofrecen los servicios y documentos de información de identificación personal.

2. Conocer el nivel de interoperabilidad de los organismos estatales y privados que brindan servicios de información de identificación personal al ciudadano mayor de edad.

\subsection{Metodología y muestra}

\subsubsection{Tipo de Investigación}

Investigación de fuente primaria, que consiste en el levantamiento de información directamente de diferentes especialistas que tengan que ver con el manejo de información de identidad, del ciudadano mayor de edad. Se utilizó la metodología de la investigación cualitativa.

\subsubsection{Técnica e instrumento a utilizar:}

En este caso hemos utilizado la entrevista a profundidad, las cuales fueron llevadas a cabo por el grupo del grupo de Tesis UPC.

Se utilizó como instrumento una guía de indagación, elaborada por el Grupo de Tesis y estuvo sujeto a la aprobación del asesor. 


\subsubsection{Muestra:}

La muestra estuvo compuesta por un grupo, con las siguientes características:

\begin{tabular}{|l|ll|}
\hline Nombre & Género & N. $^{\circ}$ de Entrevista \\
\hline Rossmary Rivera & Mujer & 04 \\
\hline
\end{tabular}

\subsubsection{Fecha de Campo}

La entrevista se realizó el 04 de abril del 2018 a las 12:00 horas vía telefónica.

\subsection{Perfil del especialista}

Ejecutiva de 40 años, abogada, actualmente desempeñándose como asesora legal en una empresa de transporte, con amplia experiencia en sector público (ADUANAS, RENIEC y BANCO DE LA NACIÓN).

\section{II.- Hallazgos de la entrevista}

\subsection{Conocer que tanto conoce el ciudadano mayor de edad sobre} los organismos gubernamentales y privados que ofrecen los servicios y documentos de información de identificación personal.

De acuerdo con la ley de transparencia la información que puede compartir un organismo público del ciudadano son los que se encuentran en el acervo documentario, y que no impliquen información sobre seguridad nacional, o tributaria. Ya sea en forma digital o física.

Se crean normativas internas estableciendo los parámetros para entregar información a los usuarios. 
Los canales para que el ciudadano pueda solicitar la información es por medio de internet y a través de un formato en internet, las empresas públicas están obligados a desarrollar este formato. Por lo general las personas prefieren solicitar esta información de manera presencial en vez de hacerlo de manera digital.

El tiempo para recibir la información solicitada una vez que se solicita en mesa de partes de la institución pública, es por lo general es de 7 días hábiles, según ley si el organismo no tiene la información en ese tiempo establecido, se puede extender el plazo hasta 5 días hábiles adicionales, pero por lo general no se llega a cumplir este tiempo por el lado de la institución (ejemplo caso de expedientes).

\subsection{Conocer el nivel de interoperabilidad de los organismos estatales y privados que brindan servicios de información de identificación personal al ciudadano mayor de edad.}

Existen convenios de colaboración institucional, entre organismos como RENIEC, SUNAT, Poder Judicial y Ministerio Público. La RENIEC gestiona todo el tema información de identificación y siempre se ha prestado para entregar información como se debe, sin embargo, en el poder judicial y ministerio público como Aduanas (consulta RUC) hay mucho que trabajar a nivel de interoperabilidad.

La brecha tecnológica para brindar la información de identificación se da por el manejo de la información de los servidores públicos, el personal no está debidamente preparado o capacitado, falta compromiso, hay más falla humana que tecnológica.

El manejo de información física en vez de digital es necesario ya que Lima no es el Perú, falta más conocimiento a nivel tecnológico, es básica la información en papel.

\section{III.- Validación de variables}

Hipótesis 
La falta de integración de sistemas entre entidades relacionadas a la gestión de la información de identificación personal y la falta de conocimiento de la población de estas instituciones, son la causa de insatisfacción del ciudadano mayor de edad que requieren estos documentos y servicios.

Para la especialista esta premisa se cumple, pero no es solo la falta de integración de sistemas en instituciones del Estado, sino que además se necesita mayor capacitación a los que trabajan y brindan dicha información en estas instituciones.

\section{IV.- Conclusiones}

Adicional a las carencias en interoperabilidad y la brecha tecnológica, podemos ver que el factor humano es también importante, se hace evidente una falta de capacitación y manejo de las TIC (tecnologías de la información) para lograr que el flujo de la información se pueda dar de manera eficiente.

El formato digital si bien es importante para acortar tiempos en entrega de información, tendría sus limitaciones en provincias, donde no se cuenta con internet y equipos tecnológicos, personal que pueda operarlos y personas que sepan cosas tan sencillas como la creación de un correo electrónico donde pueda recibir la información. 


\section{Anexo $\mathrm{N}^{\circ} 6$ Ficha técnica Entrevista a profundidad Nro. 5}

\section{Datos generales}

\subsection{Objetivo del estudio}

1. Conocer cuál es el fin de la obtención de la información de identificación personal.

3. Conocer el nivel de interoperabilidad de los organismos estatales y privados que brindan servicios de información de identificación personal al ciudadano mayor de edad.

\subsection{Metodología y muestra}

\subsubsection{Tipo de Investigación}

Investigación de fuente primaria, que consiste en el levantamiento de información directamente de diferentes especialistas que tengan que ver con el manejo de información de identidad, del ciudadano mayor de edad. Se utilizó la metodología de la investigación cualitativa.

\subsubsection{Técnica e instrumento a utilizar:}

En este caso hemos utilizado la entrevista a profundidad, las cuales fueron llevadas a cabo por el grupo del grupo de Tesis UPC.

Se utilizó como instrumento una guía de indagación, elaborada por el Grupo de Tesis y estuvo sujeto a la aprobación del asesor.

\subsubsection{Muestra:}

La muestra estuvo compuesta por un grupo, con las siguientes características: 


\begin{tabular}{|l|l|l|}
\hline Nombre & Género & N. ${ }^{\circ}$ de Entrevista \\
\hline Renzo López & Hombre & 05 \\
\hline
\end{tabular}

1.2.4. Fecha de Campo

La entrevista se realizó el 26 de marzo del 2018 a las 17:00 horas.

\subsection{Perfil del especialista}

Médico Administrativo en el Ministerio de Salud, de aproximadamente 40 años.

\section{II.- Hallazgos de la entrevista}

\subsection{Conocer cuál es el fin de la obtención de la información de identificación personal.}

Dentro de la información mayormente solicitada por los ciudadanos mayores de edad, se encuentra información correspondiente a horarios, doctores, cupos para citas, entre otros. Otro tipo de información relevante para el desarrollo de esta tesis es referente a la cobertura del SIS (Seguro Integral de Salud) y entrega de Certificados Médicos.

\subsection{Conocer el nivel de interoperabilidad de los organismos estatales y privados que brindan servicios de información de identificación personal al ciudadano mayor de edad.}

En instituciones de salud pública a diferencia de una EPS (que se compone de una Red de hospitales particulares), la información no se encuentra digitalizada en hospitales del Estado, por lo cual la información de un paciente no puede compartirse entre hospitales del Estado y tampoco con instituciones privadas. La única forma sería solicitando la copia de la historia médica en físico para que el paciente pueda llevar está a una institución privada. 
En cuanto a interoperabilidad, el Ministerio de Salud trabaja en el desarrollo tecnológico para digitalizar información de los pacientes. Por el momento la información no puede ser compartida con ninguna institución pública

El Ministerio de Salud actualmente busca lograr la transferencia tecnológica, por la cual se elevaría el nivel de interoperabilidad de las plataformas de salud que ya existen en Perú. Esto implicaría implementar un software co-creado.

A nivel regional se viene trabajando en el proyecto Red Americana de Cooperación para el Desarrollo de la Salud Electrónica (RACSEL) http://www.tynmagazine.com/racsel-un-proyectolatinoamericano-de-salud-electronica-en-red/, proyecto apoyado por la iniciativa de Bienes Públicos Regionales del Banco Interamericano de Desarrollo (BID). El objetivo de esta red sería interconectar una red de colaboración en los países que la integren y poder tener la posibilidad de compartir Historias Clínicas Electrónicas (HCE) y busca además la heterogeneidad en el proceso de salud electrónica no solo a nivel países sino a nivel provincias también.

\section{III.- Validación de variables}

Hipótesis

La falta de integración de sistemas entre entidades relacionadas a la gestión de la información de identificación personal y la falta de conocimiento de la población de estas instituciones, son la causa de insatisfacción del ciudadano mayor de edad que requieren estos documentos y servicios.

En este caso observamos que ya se ha considerado la interoperabilidad entre países de la región, sin embargo, poco o nada se menciona la integración de sistemas de salud con otras redes de información en beneficio de los pacientes a nivel nacional.

\section{IV.- Conclusiones}

Consideramos que el nivel de interoperabilidad en este sector es importante, y el hecho que organismos como el BID están promoviendo el desarrollo de ésta en la región y que hayan incluido al Perú es bastante auspicioso. De acuerdo con información encontrada del proyecto RACSEL, es un proyecto que involucra a países como Costa Rica, Colombia, Chile y Uruguay además del Perú. 
Sin embargo, solo se ha encontrado información en los medios sobre este proyecto que data del 2017 pero no hay más información de los avances después de esta fecha. 


\section{Anexo N $N^{\circ} 7$ Preguntas filtro para Focus Group}

JEFE DE HOGAR: Aquella persona, hombre o mujer, de 15 a más, que aporta más económicamente en casa o toma las decisiones financieras de la familia, y vive en el hogar. HOGAR: conjunto de personas que, habitando en la misma vivienda, preparan y consumen sus alimentos en común.

¿Quién es la persona que aporta MÁS al sostenimiento económico de su hogar? (E: 1. Si identifica a dos personas o más, preguntar por la de mayor edad. 2. Si la persona que más aporta no vive en el hogar, preguntar por la que administra los ingresos que recibe de la persona ausente.)

Las siguientes preguntas se refieren a........ que es la persona que aporta MÁS al sostenimiento de su hogar (E: según pregunta 1)

N1. ¿Cuál es el último año o grado de estudios y nivel que aprobó el jefe de hogar (E: mencione el nombre según pregunta 1$)$ ?

\begin{tabular}{|l|l|l|l|l|l|}
\hline $\begin{array}{l}\text { Sin educación/ Educación } \\
\text { Inicial }\end{array}$ & 0 & $\begin{array}{l}\text { Superior Técnico } \\
\text { Completa }\end{array}$ & 3 & $\begin{array}{l}\text { Superior Univ. } \\
\text { Completa }\end{array}$ & 5 \\
\hline $\begin{array}{l}\text { Primaria incompleta o } \\
\text { completa/ Secundaria } \\
\text { incompleta }\end{array}$ & 1 & $\begin{array}{l}\text { Superior Univ. } \\
\text { Incompleta }\end{array}$ & 4 & $\begin{array}{l}\text { Postgrado } \\
\text { Universitario }\end{array}$ & 7 \\
\hline $\begin{array}{l}\text { Secundaria completa/ } \\
\text { Superior Técnico } \\
\text { Incompleta }\end{array}$ & 2 & & & & \\
\hline
\end{tabular}


N2. ¿Cuál de estos bienes tiene en su hogar que esté funcionando?

\begin{tabular}{|l|l|l|}
\cline { 2 - 3 } \multicolumn{1}{c|}{} & NO & SI \\
\hline Computadora, laptop, Tablet en funcionamiento & 0 & 2 \\
\hline Lavadora en funcionamiento & 0 & 2 \\
\hline Horno microondas en funcionamiento & 0 & 2 \\
\hline Refrigeradora/ Congeladora en funcionamiento & 0 & 2 \\
\hline SUMAR PUNTAJE & & \multicolumn{2}{|l}{} \\
\cline { 1 - 2 } &
\end{tabular}

N3. ¿Cuál de los siguientes bienes o servicios tiene en su hogar que esté funcionando?

\begin{tabular}{|l|l|l|}
\cline { 2 - 3 } \multicolumn{1}{l|}{$\begin{array}{l}\text { Auto o camioneta solo para uso particular (NO TAXI NI AUTO DE LA } \\
\text { EMPRESA) }\end{array}$} & 0 & 5 \\
\hline $\begin{array}{l}\text { Servicio doméstico en el hogar pagado (MINIMO QUE VAYA AL } \\
\text { HOGAR UNA VEZ POR SEMANA) }\end{array}$ & 0 & 5 \\
\hline SUMAR PUNTAJES & & \\
\hline
\end{tabular}

\begin{tabular}{|l|l|l|l|}
\hline $\begin{array}{l}\text { Tierra / Otro material (arena y } \\
\text { tablones sin pulir) }\end{array}$ & 0 & $\begin{array}{l}\text { Laminado tipo madera, láminas } \\
\text { asfálticas o similares }\end{array}$ & 7 \\
\hline $\begin{array}{l}\text { Cemento sin pulir o pulido / Madera } \\
\text { (entablados)/ tapizón }\end{array}$ & 3 & $\begin{array}{l}\text { Parquet o madera pulida y similares; } \\
\text { porcelanato, alfombra, mármol }\end{array}$ & \\
\hline $\begin{array}{l}\text { Losetas / terrazos, mayólicas, } \\
\text { cerámicos, vinílicos, mosaico o } \\
\text { similares }\end{array}$ & 5 & & \\
\hline
\end{tabular}

N4. ¿Cuál es el material predominante en los pisos de su vivienda? (CONSIDERAR ÁREA CONSTRUIDA. RESPUESTA ÚNICA) 
N5. ¿A qué sistema de prestaciones de salud está afiliado el jefe de hogar? (SI TIENE MÁS DE UNO CONSIDERAR EL DE MAYOR PUNTAJE. RESPUESTA ÚNICA)

\begin{tabular}{|l|l|l|l|}
\hline $\begin{array}{l}\text { No está afiliado a ningún seguro/ } \\
\text { Seguro Integral de Salud (SIS) }\end{array}$ & 0 & Seguro Salud FFAA/ Policiales & 4 \\
\hline ESSALUD & 2 & $\begin{array}{l}\text { Entidad prestadora de salud } \\
(\text { EPS)/ Seguro privado de salud }\end{array}$ & 6 \\
\hline
\end{tabular}

N6. ¿Cuál es el material predominante en las paredes exteriores de su vivienda? (NO REVESTIMIENTO, ES EL MATERIAL. RESPUESTA ÚNICA)

\begin{tabular}{|l|l|l|l|}
\hline Estera & 0 & $\begin{array}{l}\text { Piedra o sillar con cal } \\
\text { o cemento }\end{array}$ & 4 \\
\hline $\begin{array}{l}\text { Madera/ Piedra con barro/ Quincha (caña con barro) } \\
\text { / Tapia/ Adobe }\end{array}$ & 2 & $\begin{array}{l}\text { Ladrillo o bloque de } \\
\text { cemento }\end{array}$ & 6 \\
\hline
\end{tabular}

N7. El baño o servicio higiénico que tiene en su hogar está CONECTADO a:

\begin{tabular}{|l|l|l|l|l|}
\hline $\begin{array}{l}\text { NO TIENE O NO ESTÁ CONECTADO A } \\
\text { UN DESAGUE }\end{array}$ & $\begin{array}{l}\text { SÍ ESTÁ CONECTADO AL } \\
\text { DESAGUE } \\
\text { (SIN RED PÚBLICA) }\end{array}$ \\
\hline $\begin{array}{l}\text { (CON RED PÚBLICA) } \\
\text { No tiene baño }\end{array}$ & 0 & $\begin{array}{l}\text { Baño compartido fuera de la } \\
\text { vivienda. (Ejem: quintas, } \\
\text { corralones, cuartos con baño } \\
\text { compartido, etc.) }\end{array}$ & 3 \\
\hline $\begin{array}{l}\text { Baño que da a un pozo ciego, silo, } \\
\text { letrina, pozo séptico, río, acequia o } \\
\text { canal dentro o fuera del hogar }\end{array}$ & 1 & Baño dentro de la vivienda & 5 \\
\hline
\end{tabular}




\section{Anexo N ${ }^{\circ} 8$ Guía de Indagación Focus Group}

\begin{tabular}{|c|c|c|}
\hline Concepto & Dimensiones & Preguntas \\
\hline \multirow{2}{*}{\multicolumn{2}{|c|}{ Preguntas de apertura }} & $\begin{array}{l}\text { ¿Qué tan familiarizado con el uso de } \\
\text { correos electrónicos e información } \\
\text { digitalizada? }\end{array}$ \\
\hline & & ¿Tiene correo electrónico? \\
\hline \multirow{6}{*}{$\begin{array}{l}\text { 1. Conocer cuál es el fin de la } \\
\text { obtención de la información de } \\
\text { identificación }\end{array}$} & \multirow{2}{*}{$\begin{array}{l}\text { Gubernamental } \\
\text { (RENIEC) }\end{array}$} & $\begin{array}{l}\text { ¿Cuándo ha sido la última vez que } \\
\text { realizó algún trámite para la } \\
\text { obtención de información de } \\
\text { identificación? }\end{array}$ \\
\hline & & $\begin{array}{l}\text { En el último año, ¿ha necesitado } \\
\text { realizar algún trámite de } \\
\text { información de identificación? ¿Con } \\
\text { qué fin realizo este trámite? }\end{array}$ \\
\hline & \multirow{2}{*}{ Salud } & $\begin{array}{l}\text { ¿Ha solicitado alguna vez informes } \\
\text { de su historia clínica a un centro de } \\
\text { salud del estado, ya sea ESSALUD, } \\
\text { Hospital o SIS? ¿Con qué fin? }\end{array}$ \\
\hline & & $\begin{array}{l}\text { ¿Ha solicitado alguna vez informes } \\
\text { de su historia clínica a un centro de } \\
\text { salud particular? }\end{array}$ \\
\hline & Financiera & $\begin{array}{l}\text { En lo que va del año, ¿alguna } \\
\text { institución financiera le ha } \\
\text { solicitado alguna documentación de } \\
\text { identificación? ¿Con que fin?, ¿qué } \\
\text { servicio del banco? }\end{array}$ \\
\hline & Legal & $\begin{array}{l}\text { ¿Ha tenido la necesidad de realizar } \\
\text { alguna acción judicial o de índole } \\
\text { legal en lo que va del año? ¿Con qué } \\
\text { fin? }\end{array}$ \\
\hline
\end{tabular}




\begin{tabular}{|c|c|c|}
\hline & Laboral & $\begin{array}{l}\text { ¿En el proceso de selección de algún } \\
\text { trabajo le han solicitado presentar } \\
\text { algún tipo de documentación de } \\
\text { identificación?, ¿cuáles y cuál ha } \\
\text { sido el fin? }\end{array}$ \\
\hline \multirow{9}{*}{$\begin{array}{l}\text { 2. Conocer que tanto conoce el } \\
\text { ciudadano sobre los organismos } \\
\text { gubernamentales y privados que } \\
\text { ofrecen los servicios de información } \\
\text { de identificación }\end{array}$} & \multirow{3}{*}{$\begin{array}{l}\text { Gubernamental } \\
\text { (RENIEC) }\end{array}$} & $\begin{array}{l}\text { ¿Conoce los canales para solicitar } \\
\text { información de documento de } \\
\text { identidad, certificados de } \\
\text { matrimonio o defunción? }\end{array}$ \\
\hline & & $\begin{array}{l}\text { ¿Sabe si estos trámites pueden } \\
\text { hacerse de manera digital? }\end{array}$ \\
\hline & & $\begin{array}{l}\text { ¿Cuánto es el tiempo promedio que } \\
\text { usa para realizar estos trámites? }\end{array}$ \\
\hline & \multirow{3}{*}{ Salud } & $\begin{array}{l}\text { Si ha solicitado alguna vez copia de } \\
\text { su historia clínica en una entidad } \\
\text { privada o estatal, ¿cuánto tempo le } \\
\text { ha demorado? }\end{array}$ \\
\hline & & $\begin{array}{l}\text { ¿Ha tenido que hacerlo de manera } \\
\text { presencial o virtual? }\end{array}$ \\
\hline & & $\begin{array}{l}\text { ¿Cuál ha sido el trámite para ello? } \\
\text { ¿Ha tenido que pagar por el mismo? }\end{array}$ \\
\hline & \multirow{3}{*}{ Financiera } & $\begin{array}{l}\text { ¿Conoce cuáles son los medios para } \\
\text { obtener su historial creditico? ¿Sabe } \\
\text { si puede obtenerlo de manera } \\
\text { virtual? }\end{array}$ \\
\hline & & $\begin{array}{l}\text { ¿Sabe si tiene que realizar algún } \\
\text { pago de por medio? }\end{array}$ \\
\hline & & $\begin{array}{l}\text { ¿Estos trámites los ha realizado de } \\
\text { manera presencial o virtual? }\end{array}$ \\
\hline
\end{tabular}




\begin{tabular}{|c|c|c|}
\hline & & $\begin{array}{l}\text { ¿Ha realizado algún pago de por } \\
\text { medio?, ¿lo ha realizado de manera } \\
\text { presencial virtual o presencial? }\end{array}$ \\
\hline & & $\begin{array}{l}\text { ¿Sabe si puede realizar seguimiento } \\
\text { a estos procesos? }\end{array}$ \\
\hline & Laboral & $\begin{array}{l}\text { ¿Le han solicitado algún tipo de } \\
\text { documentación como antecedentes } \\
\text { policiales o penales?, ¿dónde ha } \\
\text { realizado el trámite? ¿Sabe si puede } \\
\text { hacerlo de manera virtual? }\end{array}$ \\
\hline & & ¿Ha pagado una tarifa por ellos? \\
\hline & & $\begin{array}{l}\text { ¿Conoce de algún lugar en donde } \\
\text { pueda realizar la mayor cantidad de } \\
\text { trámites de información de } \\
\text { identificación en Lima? }\end{array}$ \\
\hline & 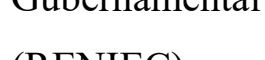 & ¿y en provincias? ¿cuáles son? \\
\hline & & ¿Qué trámites comprende? \\
\hline $\begin{array}{l}\text { 3. Conocer el nivel de } \\
\text { interoperabilidad de los organismos }\end{array}$ & & $\begin{array}{l}\text { ¿Sabe de alguna plataforma que } \\
\text { ofrezca estos mismos servicios? ¿La } \\
\text { ha usado? }\end{array}$ \\
\hline identificación al ciudadano mayor de & Co1nd & $\begin{array}{l}\text { ¿Ha podido utilizar su historial } \\
\text { médico de una institución particular } \\
\text { en una estatal o viceversa? }\end{array}$ \\
\hline & Naruu & $\begin{array}{l}\text { ¿Ha tenido la necesidad de atenderse } \\
\text { en provincia y tener a la mano su } \\
\text { historial clínico? }\end{array}$ \\
\hline & Financiera & $\begin{array}{l}\text { ¿Tiene información de si las } \\
\text { entidades financieras } \\
\text { información de su } \\
\text { crediticio? }\end{array}$ \\
\hline
\end{tabular}




\begin{tabular}{|c|c|}
\hline \multirow{3}{*}{ Preguntas de cierre } & $\begin{array}{l}\text { ¿Conoce si a nivel provincias existe } \\
\text { más facilidades para obtener } \\
\text { información de identificación de } \\
\text { diversa índole (legal, salud, } \\
\text { financiero)? }\end{array}$ \\
\hline & $\begin{array}{l}\text { ¿Qué considera que se pueda } \\
\text { mejorar en cuanto a manejo y } \\
\text { compartición de información de } \\
\text { identificación entre entidades } \\
\text { privadas o estatales? }\end{array}$ \\
\hline & $\begin{array}{l}\text { ¿Está satisfecho con los medios y la } \\
\text { forma en que puede obtener } \\
\text { información sobre identificación } \\
\text { actualmente? }\end{array}$ \\
\hline
\end{tabular}




\section{Anexo $\mathrm{N}^{\circ} 9$ Ficha técnica Focus Group}

Grupo 1 - Jóvenes adultos de 18 a 29 años, N.S.E. A, B, C1

\section{Datos generales}

\subsection{Objetivo del estudio}

1. Conocer cuál es el fin de la obtención de la información de identificación personal.

2. Conocer que tanto conoce el ciudadano mayor de edad sobre los organismos gubernamentales y privados que ofrecen los servicios y documentos de información de identificación personal.

3. Conocer el nivel de interoperabilidad de los organismos estatales y privados que brindan servicios de información de identificación personal al ciudadano mayor de edad.

\subsection{Metodología y muestra}

\subsubsection{Tipo de Investigación}

Investigación de fuente primaria, que consiste en el levantamiento de información directamente de diferentes grupos de focus.

Grupo de jóvenes adultos, adultos y adultos mayores, segmentados de la siguiente manera:

Grupo 1: Jóvenes adultos de 18 a 29 años, N.S.E. A, B, C1

Grupo 2: Jóvenes adultos de 18 a 29 años, N.S.E. C2, D

Grupo 3: Adultos de 30 a 49 años, N.S.E. A, B, C1

Grupo 4: Adultos de 30 a 49 años, N.S.E. C, D2

Grupo 5: Adultos mayores de $50 \mathrm{a}+$ años, N.S.E. A, B, C1 
Grupo 6: Adultos mayores de 50 a + años, N.S.E. C2, D

Cada focus group estuvo integrado por 6 personas.

1.2.2. Técnica e instrumento a utilizar:

Para el desarrollo de los focus group se usaron los siguientes instrumentos:

- Cuestionario filtro

- Guía de indagación, que estuvieron sujetos a la aprobación del asesor.

1.2.3. Muestra

La muestra del grupo 1, estuvo compuesta por las siguientes características:

\begin{tabular}{|l|l|l|}
\hline Nombre & Edad & N.S.E. \\
\hline Karla Mackie Bravo & 25 & \\
\hline Adrián Briceño Alva & 24 & \\
\hline Juan Pablo Linares & 25 & \\
\hline Gonzalo Navarro & 22 & A, B, C1 \\
\hline Patty Briceño Alva & 29 & \\
\hline Elizabeth Flores Arce & 26 & \\
\hline
\end{tabular}

1.2.4. Fecha de Campo

La entrevista se realizó el 19 de abril del 2018 a las 20:00 horas en Jr. Salaverry 375 Magdalena.

II.- Hallazgo de las entrevistas 


\subsection{Objetivo 1: Conocer cuál es el fin de la obtención de la información de identificación personal.}

En este grupo, la mayoría mencionó que el motivo principal en el último año ha sido tramitar duplicados de los documentos de identificación (DNI) por renovación o por pérdida.

En temas de salud ninguno de los encuestados había tenido la necesidad de solicitar trámites de copias de historia clínica u hospitales.

En temas financieros, el grupo no ha tenido oportunidad de solicitar o indagar sobre su historial crediticio, lo que conocen es que los bancos son los que realizan este trámite por ellos.

En el caso de antecedentes policiales y penales, conocían como realizar el trámite de manera presencial para cuestiones de trabajo y se enteraron por medio de un familiar.

\subsection{Objetivo 2: Conocer que tanto conoce el ciudadano mayor de edad sobre los organismos gubernamentales y privados que ofrecen los servicios $y$ documentos de información de identificación personal.}

Para el trámite de duplicados o renovación de DNI, algunos de ellos comentaron que realizan éste de forma presencial en las oficina del RENIEC, aunque algunos de ellos aseguraron que realizaron los trámites por vía virtual, inclusive indicaron que ahora también el pago para este trámite se puede realizar de modo virtual (pago a través de pasarela de pagos, tarjeta visa) y han recibido el documento en su domicilio, cabe agregar que no todos los participantes del grupo conocían de este proceso y de esta modalidad a domicilio.

Sobre la difusión de cómo realizar estos trámites indicaron que en realidad ellos buscaron la información en buscadores web y se mostraron conformes sobre cómo se enteraron de los procedimientos para realizar sus trámites, pues consideran que fácil y práctico buscar este tipo de información a través de Google. Si bien es cierto dieron referencias de no incomodarse por la realizar la búsqueda, comentaron que algunas plataformas como la del RENIEC no son amigables 
para navegar, pues la información no es fácil de encontrar en la misma página y a veces han tenido que solicitar la información por correo. Otro aspecto del que se quejaron es la lentitud de la página web.

Para este grupo en cambio, la SUNAT tuvo comentarios más favorables, indicaron que es más amigable para navegar y pueden obtener la información que se requiere de forma fácil.

Para los trámites presenciales por ejemplo de duplicado de DNI, partidas de nacimiento, antecedentes policiales comentaron tener conocimiento de los centros MAC, y mencionaron algunos de los servicios que ofrecen.

Alguno de los participantes mencionó haber realizado trámites para la obtención de pasaportes y haber encontrado diferencias en el trámite del Biométrico y el normal, para lo cual la información sobre las pautas para realizar el trámite la obtuvo a través de un familiar.

\subsection{Objetivo 3: Conocer el nivel de interoperabilidad de los organismos estatales y privados que brindan servicios de información de identificación personal al ciudadano mayor de edad.}

Uno de los entrevistados mencionó el haber conocido un poco como funciona los trámites de DNI por ejemplo en Colombia, al haber tenido experiencia de pérdida de un DNI, donde la persona tuvo que viajar de Medellín a la capital (Bogotá) para poder solicitar ayuda en el consulado peruano, experiencia que le tomó un par de días adicionales. Por otro lado, 2 personas del grupo tuvieron que realizar trámite de duplicado de DNI en Piura y Cusco, por lo cual tuvieron que indagar sobre cómo realizar el proceso, el cuál consideraron no fue complicado ni demoró tanto como pensaban.

El grupo hizo más referencia a la automatización de los trámites, para ellos las colas representan pérdida de tiempo y expresaron sentirse a gusto con trámites más rápidos y de forma virtual donde se haga la entrega por delivery de algunos documentos. Para ellos la pérdida de tiempo es un tema importante. 
Se les preguntó si tenía conocimiento de las diferencias del DNI electrónico con el normal, y uno de ellos sí tenían cierta idea de las diferencias y de la información que contiene el chip, la interconexión que tiene con otras instituciones y la información a la que se podría acceder.

\section{III.- Validación de variables}

\subsection{Hipótesis}

La falta de integración de sistemas entre entidades relacionadas a la gestión de la información de identificación personal y la falta de conocimiento de la población de estas instituciones, son la causa de insatisfacción del ciudadano mayor de edad que requieren estos documentos y servicios.

A pesar de que todos expresaron que en efecto habían tenido que buscar la información, y que en algunos desconocían los canales para realizar trámites para obtención de diversos documentos o desconocían la existencia de los MAC, no se mostraron tan inconformes puesto que se sienten cómodos realizando la búsqueda de información en internet. El aspecto en el que estuvieron de acuerdo es que el tiempo es importante e indicaron su molestia en el tiempo que se gasta en realizar trámites presenciales y en la poca facilidad de navegación que tienen algunas plataformas web cuando han tenido que buscar información específica en éstas.

\section{IV.- Conclusiones}

Siendo una generación joven, este grupo se mostró bastante dispuesto a buscar la información, mientras que las mejoras que podrían tener o solicitarían a las instituciones del Estado, es brindar inmediatez en los trámites presenciales, es decir, no les importa pasar mucho tiempo en la máquina para buscar los pasos de los trámites, pero sí están interesados en que estos procesos no les haga perder tiempo si las realizan en forma presencial. Evitar colas es importante. La seguridad también fue un punto importante, al comentar cómo se podría salvaguardar la información personal si esta se ofrece en forma digital a través del DNI electrónico y de una aplicación.

Asimismo, consideran que la información de salud como tipos de sangre o conocimiento de alergias son necesarias y deberían de estar presentes en la información del DNI. 


\section{Anexo N ${ }^{\circ} 10$ Ficha técnica Focus Group}

Grupo 2 - Jóvenes adultos de 18 a 29 años, N.S.E. C2, D

\section{Datos generales}

\subsection{Objetivo del estudio}

1. Conocer cuál es el fin de la obtención de la información de identificación personal.

2. Conocer que tanto conoce el ciudadano mayor de edad sobre los organismos gubernamentales y privados que ofrecen los servicios y documentos de información de identificación personal.

3. Conocer el nivel de interoperabilidad de los organismos estatales y privados que brindan servicios de información de identificación personal al ciudadano mayor de edad.

\subsection{Metodología y muestra}

\subsubsection{Tipo de Investigación}

Investigación de fuente primaria, que consiste en el levantamiento de información directamente de diferentes grupos de focus.

Grupo de jóvenes adultos, adultos y adultos mayores, segmentados de la siguiente manera:

Grupo 1: Jóvenes adultos de 18 a 29 años, N.S.E. A, B, C1

Grupo 2: Jóvenes adultos de 18 a 29 años, N.S.E. C2, D

Grupo 3: Adultos de 30 a 49 años, N.S.E. A, B, C1

Grupo 4: Adultos de 30 a 49 años, N.S.E. C, D2

Grupo 5: Adultos mayores de 50 a + años, N.S.E. A, B, C1 
Grupo 6: Adultos mayores de 50 a + años, N.S.E. C2, D

Cada focus group estuvo integrado por 6 personas.

\subsubsection{Técnica e instrumento a utilizar}

Para el desarrollo de los focus group se usaron los siguientes instrumentos:

Cuestionario filtro

Guía de indagación, que estuvieron sujetos a la aprobación del asesor.

\subsubsection{Muestra}

La muestra del grupo 2, estuvo compuesta por las siguientes características:

\begin{tabular}{|l|l|l|}
\hline Nombre & Edad & N.S.E. \\
\hline Pedro Rueda Cayllahua & 20 & \\
\hline David Leonardo Arrese & 21 & \\
\hline Olenka Guerra & 21 & \\
\hline Ricky Leo Martínez & 18 & C2, D \\
\hline María José Albán & 18 & \\
\hline Sergio Gonzales & 18 & \\
\hline
\end{tabular}

1.2.4. Fecha de Campo

La entrevista se realizó el 17 de abril del 2018 a las 20:00 horas en Jr. Salaverry 375 Magdalena.

\section{II.- Hallazgos de la entrevista}




\subsection{Objetivo 1: Conocer cuál es el fin de la obtención de la información de identificación personal.}

En RENIEC: En este grupo de entrevistados, la mayoría mencionó que el motivo principal en el último año había sido tramitar duplicados de los documentos de identificación por motivos de pérdida.

Desde el punto de vista financiero, no se encuentran muy familiarizados con el uso de servicios que los lleve a realizar trámites con documentación de identidad, salvo en los casos de apertura de cuenta para lo cual los bancos sólo les solicitan la copia de DNI.

En temas de salud y otros trámites legales con notarías, solo uno de los participantes mencionó haber realizado este tipo de trámites, uno como consecuencia del otro.

En el caso de antecedentes policiales y penales, algunos de ellos han tramitados estos documentos por motivo de ingreso a un trabajo o para trámites de la universidad.

\subsection{Objetivo 2: Conocer que tanto conoce el ciudadano mayor de edad sobre los organismos gubernamentales y privados que ofrecen los servicios $y$ documentos de información de identificación personal.}

Acerca del conocimiento de las instituciones que existen para tramitar algunos documentos de información e identificación básicos, mencionaron tener conocimiento solo del RENIEC como lugar para realizar el trámite para la obtención del DNI.

A medida que avanzó el focus, algunos de ellos mencionaron tener conocimiento de instituciones como los MAC, y otras oficinas de RENIEC ubicadas en hospitales, así también, mencionaron conocer algunas páginas web donde encontrar información necesaria para la obtención de algunos documentos. 
El conocimiento de estos canales lo obtuvieron por búsqueda de internet. es más, se mostró como el grupo más activo en búsqueda de información y más familiarizado y con más confianza en el uso de aplicaciones para realizar trámites y seguimientos en el trámite de duplicado de DNI, por ejemplo.

En cuanto a la información como obtención de copias de historial de salud, pudimos observar que solo uno persona del grupo había tenido la necesidad de realizar este trámite.

En el caso de entidades financieras, no estaban al tanto y tampoco parecían tener la necesidad de realizar estos trámites.

La información que tenían de los canales donde realizar los trámites de antecedentes penales y policiales, no era la más actualizada pues se refirieron sólo a las comisarías.

\subsection{Objetivo 3: Conocer el nivel de interoperabilidad de los organismos estatales y privados que brindan servicios de información de identificación personal al ciudadano mayor de edad.}

En cuanto a interoperabilidad, la mayoría del grupo considera que la utilidad se basa en la rapidez en la que puedan obtener la información o trámite necesario.

Algunos aspectos que podrían ser negativos van por el lado de la funcionalidad y rapidez por ejemplo de una plataforma donde se puedan ubicar estos servicios. asimismo, que el grupo más beneficiado con esto sería el público joven.

Aun así, mencionaron el temor del uso de información y la posibilidad que esté al alcance de extraños, una forma de combatir esto podría tener algún tipo de permisos, tener más opciones a través de códigos de seguridad para que extraños no obtengan información personal de otras personas. 


\section{III.- Validación de variables}

\subsection{Hipótesis}

La falta de integración de sistemas entre entidades relacionadas a la gestión de la información de identificación personal y la falta de conocimiento de la población de estas instituciones, son la causa de insatisfacción del ciudadano mayor de edad que requieren estos documentos y servicios.

El grupo, a pesar de tener poca experiencia en el manejo de trámites se mostró insatisfecho de las vías de comunicación que brindan información, y se mostraron más a favor de que la comunicación se pueda dar a través de redes sociales, ya que están más familiarizados con ellos.

\section{IV.- Conclusiones}

Existe un desconocimiento en su mayoría sobre los accesos a información y cierta despreocupación al respecto, al ser un grupo que justamente por ser jóvenes adultos, han tenido poca necesidad al haber ingresado apenas al mundo adulto y laboral.

La tendencia de canales digitales, el tener el acceso de información por esta vía es la más apreciada y valorada, sin embargo, el tema de la preocupación por la seguridad de información está presente. 


\section{Anexo $N^{\circ} 11$ Ficha técnica Focus Group}

Grupo 3 - Jóvenes adultos de 30 a 49 años, N.S.E. A, B, C1

\section{Datos generales}

\subsection{Objetivo del estudio}

1. Conocer cuál es el fin de la obtención de la información de identificación personal.

2. Conocer que tanto conoce el ciudadano mayor de edad sobre los organismos gubernamentales y privados que ofrecen los servicios y documentos de información de identificación personal.

3. Conocer el nivel de interoperabilidad de los organismos estatales y privados que brindan servicios de información de identificación personal al ciudadano mayor de edad.

\subsection{Metodología y muestra}

\subsubsection{Tipo de Investigación}

Investigación de fuente primaria, que consiste en el levantamiento de información directamente de diferentes grupos de focus.

Grupo de jóvenes adultos, adultos y adultos mayores, segmentados de la siguiente manera:

Grupo 1: Jóvenes adultos de 18 a 29 años, N.S.E. A, B, C1

Grupo 2: Jóvenes adultos de 18 a 29 años, N.S.E. C2, D

Grupo 3: Adultos de 30 a 49 años, N.S.E. A, B, C1

Grupo 4: Adultos de 30 a 49 años, N.S.E. C, D2

Grupo 5: Adultos mayores de $50 \mathrm{a}+$ años, N.S.E. A, B, C1 
Grupo 6: Adultos mayores de 50 a + años, N.S.E. C2, D

Cada focus group estuvo integrado por 6 personas.

\subsubsection{Técnica e instrumento a utilizar}

Para el desarrollo de los focus group se usaron los siguientes instrumentos:

- Cuestionario filtro

- Guía de indagación, que estuvieron sujetos a la aprobación del asesor.

\subsubsection{Muestra:}

La muestra del grupo 3, estuvo compuesta por las siguientes características:

\begin{tabular}{|l|l|l|}
\hline Nombre & Edad & N.S.E. \\
\hline Silvia Vignolo & 38 & \\
\hline Gianinna Alvarado & 37 & \\
\hline Fátima Miranda Yapur & 31 & \\
\hline Stjepan Hiza Bulic & 41 & \\
\hline Heddyta Salazar Tejada & 37 & \\
\hline Javier Espinoza & 33 \\
\hline
\end{tabular}

1.2.4. Fecha de Campo

La entrevista se realizó el 18 de abril del 2018 a las 20:00 horas en Jr. Salaverry 375 Magdalena. 


\section{II.- Hallazgos de la entrevista}

\subsection{Objetivo 1: Conocer cuál es el fin de la obtención de la información de identificación personal.}

En este grupo, la mayoría mencionó que el motivo principal en el último año ha sido tramitar duplicados de los documentos de identificación por renovación de ellos y de sus hijos.

Se conversó también acerca de trámite del duplicado del brevete.

En temas de salud parte del grupo sí han tenido la necesidad de solicitar trámites de copias de historia clínica o exámenes, en algunos casos fueron de un mes más/menos y otros lo realizaron de un día para otro o al instante, dependía de que era lo que solicitaban y el lugar.

En temas financieros, el grupo sí ha tenido oportunidad de solicitar o indagar sobre su historial crediticio, lo que conocen es que los bancos y las empresas de telefonía saben esa información.

En el caso de antecedentes policiales y penales, o trámites para constituir empresa, entre otros, todo el grupo conocía como realizar esos trámites.

\subsection{Objetivo 2: Conocer que tanto conoce el ciudadano mayor de edad sobre los organismos gubernamentales y privados que ofrecen los servicios y documentos de información de identificación personal.}

Para el trámite de duplicado de DNI en la RENIEC, algunos de ellos realizaron los trámites por vía virtual y en otros en forma presencial por estar cerca a la agencia y también utilizaron quioscos multimedia para impresión de partida de nacimiento, realizando el pago de algunos de estos trámites en modo virtual (visa) y algunos casos tuvieron entrega a domicilio.

Sobre la obtención de la información, se mostraron conformes sobre cómo se enteraron de los procesos de trámites, pues consideran que es útil buscarlo en Google y en foros. 
Mostraron algo de disconformidad por las páginas de las entidades gubernamentales por no tener una información clara y actualizada.

Tienen una apreciación de que las personas en general no tienen una buena comprensión de lectura para las indicaciones que encuentren en la red.

Comentaron tener conocimiento de los centros MAC y de los servicios que ofrecen y los lugares donde se encuentran.

Prefieren utilizar para los trámites en línea, una laptop o una PC, pero no confían mucho en el celular, más que nada por una sensación de seguridad y comodidad.

Piensan también que la información de las personas debería tener ciertas escalas de seguridad para cierto tipo de documentación que maneja cada persona.

\subsection{Objetivo 3: Conocer el nivel de interoperabilidad de los} organismos estatales y privados que brindan servicios de información de identificación personal al ciudadano mayor de edad.

No tienen conocimiento de experiencias en el extranjero, salvo una persona que comentó que tiene una amiga en los Estados Unidos que realiza sus pagos de multas en una sola plataforma o aplicación en su celular de manera eficaz.

\section{III.- Validación de variables}

\subsection{Hipótesis}

La falta de integración de sistemas entre entidades relacionadas a la gestión de la información de identificación personal y la falta de conocimiento de la población de estas instituciones, son la causa de insatisfacción del ciudadano mayor de edad que requieren estos documentos y servicios. 
Comentan que la información que encuentran de las entidades donde tienen que realizar trámites no son nada amigables, tienen la apreciación que solo colocan contenido por cumplir con las normas y no para facilitar la navegación al ciudadano, quien es quien accede a estas páginas.

Consideran que el nuevo documento de identidad que tiene chip no es útil en estos momentos, tienen la esperanza que eso cambie en un futuro cercano.

También presentaron su malestar por algunos sistemas que no son estables y se cuelgan a cada rato

\section{IV.- Conclusiones}

Este grupo se mostró algo receloso en que toda la información esté en un solo lugar, debido más que nada a un tema de inseguridad, por un lado, lo consideran una buena idea, pero por otro lo encuentran como una posible oportunidad para la gente que pueda aprovecharse de eso para mal utilizar esa información en su contra. 


\section{Anexo N 12 Ficha técnica Focus Group}

Grupo 4 - Adultos de 30 a 49 años, N.S.E. C2, D

\section{Datos generales}

\subsection{Objetivo del estudio}

1. Conocer cuál es el fin de la obtención de la información de identificación personal.

2. Conocer que tanto conoce el ciudadano mayor de edad sobre los organismos gubernamentales y privados que ofrecen los servicios y documentos de información de identificación personal.

3. Conocer el nivel de interoperabilidad de los organismos estatales y privados que brindan servicios de información de identificación personal al ciudadano mayor de edad.

\subsection{Metodología y muestra}

\subsubsection{Tipo de Investigación}

Investigación de fuente primaria, que consiste en el levantamiento de información directamente de diferentes grupos de focus.

Grupo de jóvenes adultos, adultos y adultos mayores, segmentados de la siguiente manera:

Grupo 1: Jóvenes adultos de 18 a 29 años, N.S.E. A, B, C1

Grupo 2: Jóvenes adultos de 18 a 29 años, N.S.E. C2, D

Grupo 3: Adultos de 30 a 49 años, N.S.E. A, B, C1

Grupo 4: Adultos de 30 a 49 años, N.S.E. C, D2

Grupo 5: Adultos mayores de 50 a + años, N.S.E. A, B, C1 
Grupo 6: Adultos mayores de 50 a + años, N.S.E. C2, D

Cada focus group estuvo integrado por 6 personas.

\subsubsection{Técnica e instrumento a utilizar}

Para el desarrollo de los focus group se usaron los siguientes instrumentos:

Cuestionario filtro

Guía de indagación, que estuvieron sujetos a la aprobación del asesor.

\subsubsection{Muestra:}

La muestra del grupo 4, estuvo compuesta por las siguientes características:

\begin{tabular}{|l|l|l|}
\hline Nombre & Edad & N.S.E. \\
\hline Maritza Rojas & 42 & \\
\hline Laura Torres & 42 & \\
\hline Leonardo Yupanqui & 41 & C2, D \\
\hline Graciela Tacza & 30 & \\
\hline Rómulo Gavilán & 45 & \\
\hline Wenceslao Loja & 45 & \\
\hline
\end{tabular}

1.2.5. Fecha de Campo

La entrevista se realizó el 12 de abril del 2018 a las 09:00 horas en Sala de Dirección de Hidrografía y Navegación, Callao. 


\section{II.- Hallazgos de la entrevista}

\subsection{Objetivo 1: Conocer cuál es el fin de la obtención de la información de identificación personal.}

La mayoría de los entrevistados realizaron por lo menos el trámite del DNI, duplicado o renovación, y en algunos casos han realizado el trámite de antecedentes policiales y penales por motivo de trabajo.

Uno de los entrevistados mencionó haber tenido la necesidad hace un par de años de solicitar el historial médico en la clínica Internacional, para lo cual realizó el trámite con una ficha, en tanto que otro de los asistentes realizó dicho trámite en el Hospital del Niño, para cambiar el seguro de su hija, al haber pasado a la mayoría de edad.

Uno de los entrevistados manifestó haber realizado el trámite de solicitud de historial financiero en San Isidro (que podría ser Equifax), a solicitud del Fondo de vivienda de la Marina (FOVIMAR), que compete al Estado.

Una de las personas del grupo mencionó que, como parte de los requisitos para solicitar un préstamo en el Banco de la Nación, tuvo que solicitar un certificado de No Adeudo a las instituciones financieras donde tenía una tarjeta de crédito.

\subsection{Objetivo 2: Conocer que tanto conoce el ciudadano mayor de edad sobre los organismos gubernamentales y privados que ofrecen los servicios y documentos de información de identificación personal.}

Los canales que se mencionaron como conocidos para realizar trámites de copias o duplicados de DNI, fueron el RENIEC y el MAC (conocido como mall) y los que lo conocen consideran que es lugar donde se pueden efectuar trámites de documentos de una manera rápida. Gran parte del grupo mencionó tener conocimiento de la forma de solicitar trámites online, pero sólo uno de ellos mencionó haber realizado el trámite. 
Asimismo, el trámite de antecedentes policiales y penales, los han realizado en forma presencial en el MAC. Del grupo, la mitad de las personas no conocían de la existencia de los MAC.

\subsection{Objetivo 3: Conocer el nivel de interoperabilidad de los} organismos estatales y privados que brindan servicios de información de identificación personal al ciudadano mayor de edad.

Sobre el tema de interoperabilidad, algunos consideran que las facilidades que se dan por ejemplo para solicitud de trámites en hospitales son mucho más burocráticas que en clínicas, además tienen la idea preconcebida de que en provincias la solicitud de trámites de identificación personal debe ser mucho más complicado y lento de lo que puede ser en Lima.

También consideraron que el tema de interoperabilidad sobre todo en la obtención de información médica podría ser de mucha ayuda, en caso de ofrecer información como alergias y tipos de sangre, y que esta información se ofrezca también de manera online.

Asimismo, consideran que el punto más frágil es la privacidad de la información que podría ser vulnerable en el medio en que vivimos.

\section{III.- Validación de las variables}

\subsection{Hipótesis}

La falta de integración de sistemas entre entidades relacionadas a la gestión de la información de identificación personal y la falta de conocimiento de la población de estas instituciones, son la causa de insatisfacción del ciudadano mayor de edad que requieren estos documentos y servicios.

La opinión del grupo es que al momento la forma en que se brinda la información de trámites y de los canales que se tienen actualmente son suficientes, pero que se está agilizando poco a poco, y que esperan que a través del DNI electrónico haya más posibilidades. 


\section{IV.- Conclusiones}

Las necesidades básicas de este grupo fueron básicamente en procesos de duplicados o renovación de DNI y de servicios de salud, en lo cual no mostraron tener muchas quejas de los trámites que deben de realizar, para la mayoría del grupo la creación de los MAC es un punto favorable, pero sin embargo no los conocían o no tenían idea de qué tipo de trámites brinda. Podríamos decir que al no tener necesidad de realizar muchos trámites no era un tema muy urgente o crítico. 


\section{Anexo $N^{\circ} 13$ Ficha técnica Focus Group}

Grupo 5 - Adultos mayores de 50 a + años, N.S.E. A, B, C1

\section{Datos generales}

\subsection{Objetivo del estudio}

1. Conocer cuál es el fin de la obtención de la información de identificación personal.

2. Conocer que tanto conoce el ciudadano mayor de edad sobre los organismos gubernamentales y privados que ofrecen los servicios y documentos de información de identificación personal.

3. Conocer el nivel de interoperabilidad de los organismos estatales y privados que brindan servicios de información de identificación personal al ciudadano mayor de edad.

\subsection{Metodología y muestra}

\subsubsection{Tipo de Investigación}

Investigación de fuente primaria, que consiste en el levantamiento de información directamente de diferentes grupos de focus.

Grupo de jóvenes adultos, adultos y adultos mayores, segmentados de la siguiente manera:

Grupo 1: Jóvenes adultos de 18 a 29 años, N.S.E. A, B, C1

Grupo 2: Jóvenes adultos de 18 a 29 años, N.S.E. C2, D

Grupo 3: Adultos de 30 a 49 años, N.S.E. A, B, C1

Grupo 4: Adultos de 30 a 49 años, N.S.E. C, D2

Grupo 5: Adultos mayores de 50 a + años, N.S.E. A, B, C1 
Grupo 6: Adultos mayores de $50 \mathrm{a}+$ años, N.S.E. C2, D

Cada focus group estuvo integrado por 6 personas.

\subsubsection{Técnica e instrumento a utilizar}

Para el desarrollo de los focus group se usaron los siguientes instrumentos:

Cuestionario filtro

Guía de indagación, que estuvieron sujetos a la aprobación del asesor.

\subsubsection{Muestra:}

La muestra del grupo 5, estuvo compuesta por las siguientes características:

\begin{tabular}{|l|l|l|}
\hline Nombre & Edad & N.S.E. \\
\hline Carlos Navarro & 57 & \\
\hline Blanca Tuesta & 50 & \\
\hline Zulema Maycock & 65 & A, B, C1 \\
\hline Renee Alva & 65 & \\
\hline Elsa Guevara & 60 & \\
\hline Salvador Linares & 68 &
\end{tabular}

1.2.4. Fecha de Campo

La entrevista se realizó el 19 de abril del 2018 a las 21:00 horas en Jr. Salaverry 375 Magdalena.

\section{II.- Hallazgos de la entrevista}




\subsection{Objetivo 1: Conocer cuál es el fin de la obtención de la información de identificación personal.}

Una de las personas realizó renovación de licencia de conducir en Lima y otra realizó su trámite en provincia.

Algunos de los integrantes realizaron el trámite del duplicado del DNI.

Un integrante del grupo realiza certificados médicos, judiciales, etc., por internet y luego recoge el documento tramitado personalmente.

En cuestión de salud uno de los integrantes si hizo un trámite para copia de una historia para presentarla de un hospital a una clínica.

En el caso de la persona que trabaja en seguros, las pólizas lo manejan por internet, en formatos digitales. (PDF)

En el caso de la persona que realiza consultoría comenta que ha realizado trámites para certificar educación en las universidades para poder presentarla a la embajada canadiense.

Uno de los participantes que era, realizó trámite de constancias médicas por internet.

Uno de los integrantes realizó un trámite judicial y el todo el grupo realizó un reclamo a la municipalidad.

En el caso de información crediticia si conocen donde pueden encontrarla.

2.2 Objetivo 2: Conocer que tanto conoce el ciudadano mayor de edad sobre los organismos gubernamentales y privados que ofrecen los servicios y documentos de información de identificación personal.

Uno de los entrevistados era consultor que trabaja diariamente orientando y facilitando algunos trámites para aplicaciones de Visa a países como Canadá, al tener una buena experiencia realizando 
este trabajo, comenta que los trámites relacionados con documentos de educación son los más tediosos, debido que hay muchos pasos para poder obtener la documentación válida y con valor oficial para presentarla a la embajada. Gran parte de este trámite debe de hacerse de forma presencial, y puede durar hasta dos meses y gran parte del tiempo que se emplea es por la demora de las respuestas de las universidades peruanas, luego de ello se llevarán los documentos a otras entidades y traductores oficiales.

Otra entrevistada nos contó un caso de un trámite que hizo para obtener la copia de una historia y examen médico de manera presencial, el cual duró un mes aproximadamente desde que inició hasta conseguir la documentación.

Quienes realizaron el trámite de duplicado del DNI lo realizaron por internet y fueron a recogerlo a la agencia del RENIEC no hay que olvidar que este grupo debido a tener más de 65 en su mayoría no hace el pago solo el trámite, por ley es gratuito.

La persona que realizó el trámite de la licencia de conducir lo realizó por internet, mientras que el pago lo hizo en el banco de la Nación y el recojo del mismo también de manera presencial.

Todo el grupo comentó que conocía o había escuchado de los centros MAC, pero no tienen muy claro en dónde se encuentran, pero si conocen que pueden realizar varios trámites como por ejemplo el de la obtención o renovación del pasaporte.

El trámite judicial mencionado por uno de los integrantes ya fue sentenciado y todo el proceso y seguimiento se hizo de manera presencial, en el caso del reclamo también todo el seguimiento se está realizando de manera presencial el cual aún no había sido atendido a la fecha del focus.

El grupo está muy consciente de que existen distintas formas de estafa por internet como el phishing por ello consideran que la información que se obtenga o guarde online debe de tener algún nivel de seguridad.

Sobre las experiencias fuera del país uno de los entrevistados comenta que por medio de un familiar tiene conocimiento de que en Japón no existe aún una facilidad para realizar trámites ya que uno lo debe hacer de forma presencial e incluso viajar grandes distancias de una ciudad a otra, por el contrario el que conoce sobre Canadá comenta que en este país los trámites los realizan vía web y 
las respuestas o certificados los reciben vía correo físico, agregó que el servicio de correos es bueno y confiable pero muy lento.

\subsection{Objetivo 3: Conocer el nivel de interoperabilidad de los} organismos estatales y privados que brindan servicios de información de identificación personal al ciudadano mayor de edad.

Uno de los integrantes comenta que la seguridad de la información entre instituciones ha avanzado y siente que es más segura y que los lugares que antes solían realizar documentación falsa ya no son exitosos debido a la seguridad de la información actual en los sistemas de las instituciones.

Se mencionó que los trámites de documentos de identificación que se realizan en Perú comparado con otros países son buenos e incluso hasta más eficientes.

Comentan también la eficiencia de Registro Públicos en comunicar y alertar al ciudadano y que sus procesos internos son buenos.

El centro de salud donde trabaja el doctor del grupo comenta que se ha contratado a una empresa privada para realizar un sistema que permita compartir información como historias clínicas, exámenes y análisis con otras entidades de salud como clínicas y hospitales. Proyecto que pertenece a esa entidad privada, y que también tiene conocimiento de que el Estado está por realizar un proyecto a gran escala para que esta interconexión de historias clínicas se realice a nivel nacional.

\section{III.- Validación de variables}

\subsection{Hipótesis}

La falta de integración de sistemas entre entidades relacionadas a la gestión de la información de identificación personal y la falta de conocimiento de la población de estas instituciones, son la causa de insatisfacción del ciudadano mayor de edad que requieren estos documentos y servicios. 
En cuestión de salud si hablaron de una disconformidad en la nula interoperabilidad entre los centros de salud privados y del gobierno para compartir información como historias, exámenes, resultados de análisis, etc.

Tienen comentarios y apreciaciones contradictorias ya que para algunos las instituciones del Estado si trabajan bien en cambio otros no presentan una buena experiencia, en algunos casos.

\section{IV.- Conclusiones}

Este grupo comenta que las personas mayores de edad se les dificulta un poco el uso de los sistemas de información disponible de forma digital, pero sí son conscientes que las generaciones venideras ya resuelven casi todo de forma virtual sin consultar de forma presencial.

Existe en el grupo la esperanza que las entidades de salud se interconecten en un plazo no muy lejano para el beneficio de ellos mismos.

El poco conocimiento del uso de la información disponible en la web se nota en algunos casos para que la realización de los trámites sea más eficaz y se puedan realizar en menos tiempo, ya que usualmente las señoras salen y buscan de manera presencial la búsqueda de información.

El grupo recomienda que podría ser efectivo una forma de publicitar o comunicar cómo hacer trámites en recibos por honorarios para informar mejor a la población.

Hay personas que aún buscan la información de trámites en periódicos en físico.

Tienen mucho temor a que la información personal se encuentre en un solo lugar ya que podría ser mal usado o manipulado incluso también piensan que debería haber una restricción a la información de salud y que no todos puedan acceder a ella, quizá solo funcionarios de salud. 


\section{Anexo $\mathrm{N}^{\circ} 14$ Ficha técnica Focus Group}

Grupo 6 - Adultos mayores de 50 a + años, N.S.E. C2, D

\section{Datos generales}

\subsection{Objetivo del estudio}

1. Conocer cuál es el fin de la obtención de la información de identificación personal.

2. Conocer que tanto conoce el ciudadano mayor de edad sobre los organismos gubernamentales y privados que ofrecen los servicios y documentos de información de identificación personal.

3. Conocer el nivel de interoperabilidad de los organismos estatales y privados que brindan servicios de información de identificación personal al ciudadano mayor de edad.

\subsection{Metodología y muestra}

\subsubsection{Tipo de Investigación}

Investigación de fuente primaria, que consiste en el levantamiento de información directamente de diferentes grupos de focus.

Grupo de jóvenes adultos, adultos y adultos mayores, segmentados de la siguiente manera:

Grupo 1: Jóvenes adultos de 18 a 29 años, N.S.E. A, B, C1

Grupo 2: Jóvenes adultos de 18 a 29 años, N.S.E. C2, D

Grupo 3: Adultos de 30 a 49 años, N.S.E. A, B, C1

Grupo 4: Adultos de 30 a 49 años, N.S.E. C, D2

Grupo 5: Adultos mayores de 50 a + años, N.S.E. A, B, C1 
Grupo 6: Adultos mayores de 50 a + años, N.S.E. C2, D

Cada focus group estuvo integrado por 6 personas.

1.2.2. Técnica e instrumento a utilizar

Para el desarrollo de los focus group se usaron los siguientes instrumentos:

- Cuestionario filtro

- Guía de indagación, que estuvieron sujetos a la aprobación del asesor.

\subsubsection{Muestra:}

La muestra del grupo 6, estuvo compuesta por las siguientes características:

\begin{tabular}{|l|l|l|}
\hline Nombre & Edad & N.S.E. \\
\hline Teresa Campos & 58 & \\
\hline Nora Obregú & 59 & \\
\hline Mario Calderón & 51 & \\
\hline Miriam Tamayo & 59 & \\
\hline Sara Huallanca & 53 & \\
\hline Pedro Hinojo & 52 & \\
\hline
\end{tabular}

1.2.4. Fecha de Campo

La entrevista se realizó el 12 de abril del 2018 a las 10:00 horas en Sala de Dirección de Hidrografía y Navegación, Callao. 


\section{II.- Hallazgos de la entrevista}

\subsection{Objetivo 1: Conocer cuál es el fin de la obtención de la información de identificación personal.}

Los trámites a los que recurrió la mayoría del grupo fue la renovación o duplicado de DNI

Una de las participantes mencionó que tuvo que realizar trámites de legalización de una carta poder, en cuyo caso los requisitos para el trámite debían hacerse de manera digitalizada, por ser una nueva modalidad, el proceso demoró más de lo habitual.

Uno de ellos tuvo la oportunidad de solicitar un préstamo donde tuvo un problema para certificar que se había cancelado una deuda de hace más de 15 años, por lo cual tuvo que realizar trámites en varias instituciones y reparar el error que un banco había cometido.

\subsection{Objetivo 2: Conocer que tanto conoce el ciudadano mayor de} edad sobre los organismos gubernamentales y privados que ofrecen los servicios y documentos de información de identificación personal.

El grupo desconocía de los trámites que podían realizarse en los MAC y de los lugares donde podían realizarse la mayoría de los trámites de identificación personal (salvo el trámite de duplicados o renovación de DNI) tanto en forma presencial como virtual.

Uno de los entrevistados mencionó tener conocimiento de un canal que ha sido habilitado para poder llegar a pueblos alejados en la selva, donde se unen instituciones como el Banco de la Nación, la Marina de Guerra y el RENIEC.

\subsection{Objetivo 3: Conocer el nivel de interoperabilidad de los} organismos estatales y privados que brindan servicios de 


\section{información de identificación personal al ciudadano mayor de edad.}

Parte del grupo mostró su disconformidad por casos de presentación de documentos en forma reiterativa, por ejemplo, para una viuda que tuvo que acreditar con más documentos su estado civil a pesar de encontrarse este en su DNI.

Otra entrevistada mencionó haber tenido problemas por razones de homonimia, para lo cual debe de estar pendiente de los estatus que muestra el sistema financiero sobre su historial.

\section{III.- Validación de las variables}

\subsection{Hipótesis}

La falta de integración de sistemas entre entidades relacionadas a la gestión de la información de identificación personal y la falta de conocimiento de la población de estas instituciones, son la causa de insatisfacción del ciudadano mayor de edad que requieren estos documentos y servicios.

Debido a la poca necesidad que el grupo ha tenido de realizar trámites de documentos de identificación, no se han encontrado mucha inconformidad. Por ejemplo, para el grupo soluciones como el MAC (después de ahondar en qué consiste y qué servicios brinda), representa para ellos un servicio ágil y suficiente, pero sí se mostraron muy disconformes con la poca o nula información que tienen de los canales que existen para realizar trámites.

Por otro lado, sí se mostraron a favor de que las instituciones tengan un mejor manejo de la información y que ésta esté compilada en el DNI electrónico, para poder evitar trámites burocráticos que puede ser reiterativos, así como que se brinde en este documento, información básica de salud.

\section{IV.- Conclusiones}

Concluimos que debido a la baja necesidad de realizar trámites que ha experimentado este grupo debido a algunas características que presenta (personas en planilla de la Marina de Guerra, mayores de edad, acostumbradas a la burocracia del Estado) no hay mucha conciencia acerca de las facilidades que podría tener los servicios de identificación, pues si bien en un momento no 
mostraron mucha disconformidad sobre los canales por los cuales podrían acceder a documentos de identificación, a medida que se ahondaba más en el tema, iban poniéndose a favor en llegar a una forma de acceder a estos de una manera más ágil y con servicios interconectados y menos burocráticos. 